\title{
PROPOSTA DE PARÂMETROS DE TRANSFORMAÇÃO ENTRE OS SISTEMAS WGS-84 E O SAD-69 PARA A REGIÃO DE SÃO CARLOS-SP
}

\author{
Maurício Roberto Veronez
}

Dissertação apresentada à Escola de Engenharia de São Carlos da Universidade de São Paulo, como parte dos requisitos para obtenção do título de Mestre em Transportes

ORIENTADOR: Prof. Dr. Paulo César Lima Segantine

São Carlos

1998 


\section{DEDICATÓRIA}

Dedico esta Dissertação a minha família $e$ a minha namorada Cleidi. 


\section{AGRADECIMENTOS}

Em primeiro lugar agradeço a $D E U S$ por mostrar o caminho correto na condução do meu programa de Mestrado.

Agradeço a minha família e, principalmente, ao meu irmão Marcelo por proporcionarem tal êxito.

Meus sinceros agradecimentos ao meu Orientador Prof. Segantine por aceitarme a trabalhar sob sua orientação, pelo constante apoio, pelas críticas e sugestões, que só vieram a enriquecer o trabalho.

Não poderia deixar de agradecer aos colegas de batente, do Laboratório de Mensuração, responsáveis pelo clima de entusiasmo que tanto nos estimulou.

Ao colega Attus, pela grande ajuda na coleta dos dados de campo.

E, finalmente, agradeço à minha namorada Cleidi pelo amor, compreensão, paciência, dedicação e amizade que proporcionou nos momentos mais difíceis. 


\section{SUMÁRIO}

LISTA DE FIGURAS......................................................................................................

LISTA DE TABELAS..............................................................................................ii

LISTA DE ABREVIATURAS E SIGLAS...............................................................iv

LISTA DE SÍMBOLOS...............................................................................................vi

RESUMO............................................................................................................................

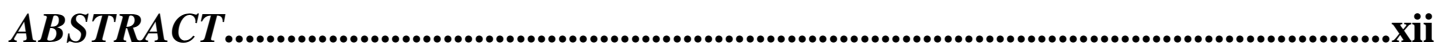

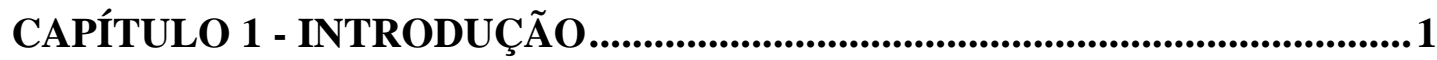

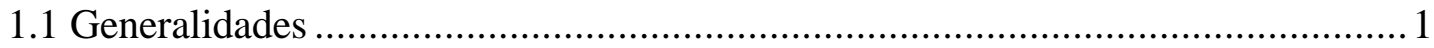

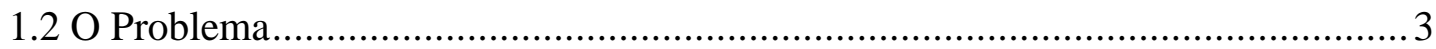

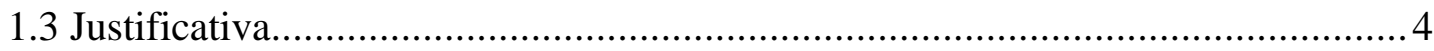

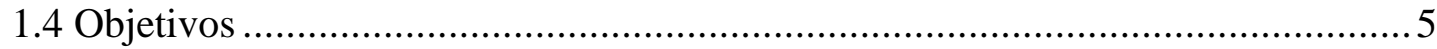

CAPÍTULO 2 - SISTEMAS GEODÉSICOS DE REFERÊNCIA ..........................6

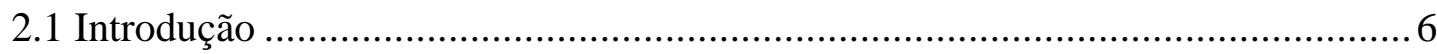

2.2 Posicionamento e orientação de um datum geodésico horizontal ...........................

2.2.1 Condições de paralelismo - a equação de Laplace .......................................... 8

2.3 Principais sistemas geodésicos de referência ..................................................... 12

2.3.1 Sistema Terrestre Médio (ou Sistema Cartesiano Global).......................... 12

2.3.2 Sistema Geodésico Mundial.................................................................... 14

2.3.3 Sistema Cartesiano Geodésico …………………….................................. 18

CAPÍTULO 3 - REDES GEODÉSICAS .........................................................21

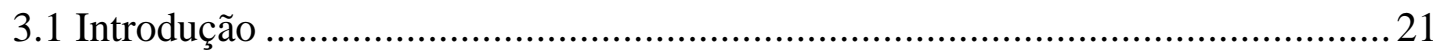

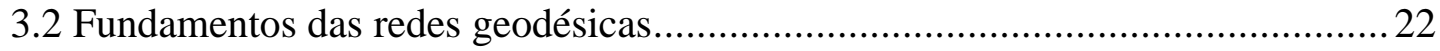

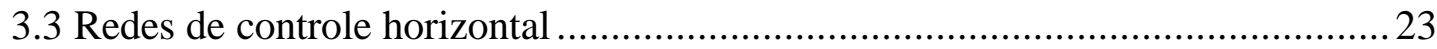


3.3.1 Determinação de pontos de controle horizontais através de triangulação.. 24

3.3.1.1 Ajustamento de uma triangulação geodésica................................... 26

3.3.1.1.1 Número de equações de condição ............................................ 28

3.3.2 Determinação de pontos de controle horizontais através da trilateração ... 33

3.3.3 Determinação de pontos de controle horizontais através da poligonação.. 33

3.3.4 Cálculos das posições horizontais de uma rede geodésica ....................... 34

3.3.4.1 Seções normais recíprocas ....................................................... 34

3.3.4.2 Ângulo entre a linha geodésica e a seção normal.............................. 38

3.3.5 Determinação de pontos de controle utilizando o sistema GPS............... 42

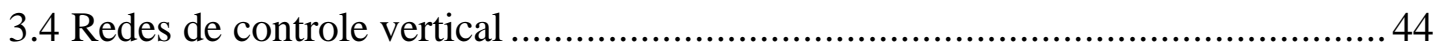

3.4.1 Nivelamento de precisão utilizando o GPS ....................................... 47

3.4.1.1 Definição do processo de nivelamento utilizando o GPS ...................48

CAPÍTULO 4 - MODELOS MATEMÁTICOS DE TRANSFORMAÇÃO DE COORDENADAS UTILIZADOS NA COMBINAÇÃO DE REDES GEODÉSICAS.......................................................52

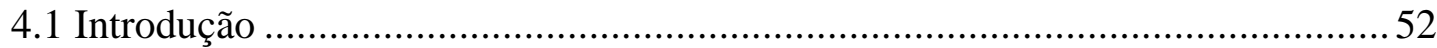

4.2 Transformação tridimensional de Helmert ............................................... 53

4.2.1 Formulação do problema pelo Método dos Mínimos Quadrados (MMQ). 55

4.2.1.1 Definiç̧ão da matriz peso ......................................................... 61

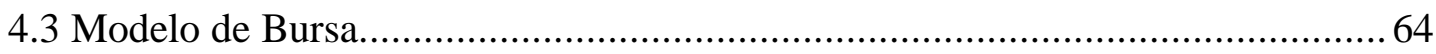

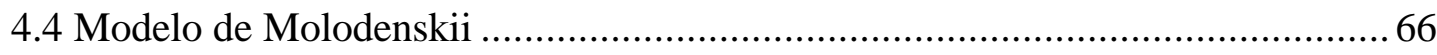

4.4.1 Modelo de Molodenskii - primeira versão........................................... 67

4.4.2 Modelo de Molodenskii - segunda versão ...........................................6 69

CAPÍTULO 5 - PROCEDIMENTO METODOLÓGICO .............................. 71

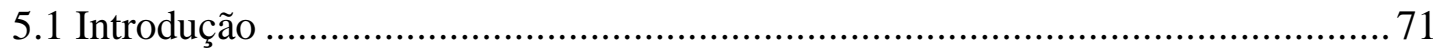

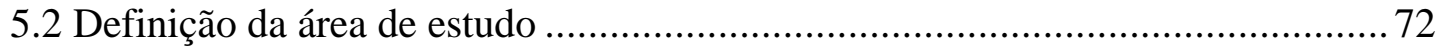

5.3 Determinação das ondulações geoidais dos vértices ................................... 76

5.4 Rastreio com o sistema GPS nos quatro vértices da rede do SGB localizados na região de São Carlos-SP.................................................................... 77

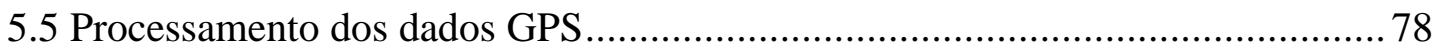


5.6 Determinação dos sete parâmetros de transformação entre os sistemas WGS-84 e SAD-69

5.7 Determinação dos três parâmetros de transformação entre os sistemas WGS-84 e SAD-69

5.8 Aplicação dos parâmetros de transformação oficiais divulgados pelo IBGE nos

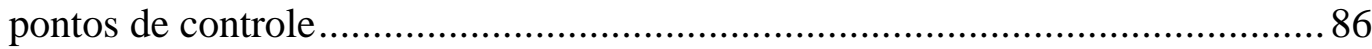

5.9 Análise do efeito da ondulação geoidal na determinação dos parâmetros de

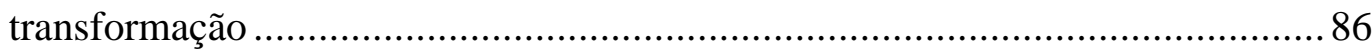

CAPÍTULO 6 - RESULTADOS E DISCUSSÕES ............................................. 87

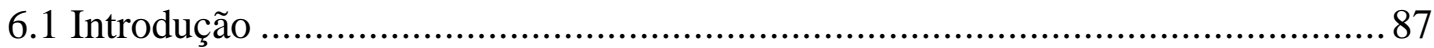

6.2 Valores encontrados para os parâmetros de transformação ajustados considerando a ondulação geoidal ......................................................... 88

6.3 Discrepâncias encontradas nos vértices de controle...................................... 91

6.4 Valores encontrados para os parâmetros de transformação desconsiderando a ondulação geoidal 95

6.5 Discrepâncias encontradas nos vértices de controle em função dos parâmetros de transformação obtidos a partir da desconsideração da ondulação geoidal...........98

CAPÍTULO 7 - CONCLUSÕES E RECOMENDAÇÕES.

ANEXO - Monografia dos quatro vértices pertencentes à rede do SGB localizados.... na região de São Carlos-SP .104

REFERÊNCIAS BIBLIOGRÁFICAS. .109 


\section{LISTA DE FIGURAS}

FIGURA 2.1 - Ilustração do Sistema Terrestre Médio e coordenadas cartesianas de

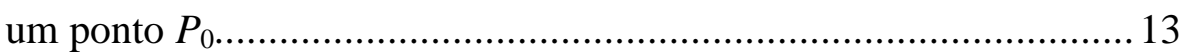

FIGURA 2.2 - Ilustração do sistema de referência do Sistema Geodésico Mundial (1984)

FIGURA 2.3 - Ilustração do Sistema Cartesiano Geodésico 19

FIGURA 3.1 - Ilustração de um quadrilátero completo de uma triangulação ........... 25

FIGURA 3.2 - Ilustração do excesso esférico em um triângulo geodésico...............26

FIGURA 3.3 - Normais ao elipsóide em pontos de mesmo meridiano..................... 35

FIGURA 3.4 - Normais ao elipsóide em pontos de mesmo paralelo ........................ 35

FIGURA 3.5 - Normais ao elipsóide em pontos localizados em paralelos e

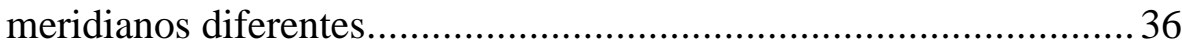

FIGURA 3.6 - Linha geodésica entre dois pontos. ........................................... 38

FIGURA 3.7 - Ilustração de um nivelamento geométrico................................... 46

FIGURA 3.8 - Relação entre altura geométrica e altitude ortométrica .................... 49

FIGURA 4.1 - Ilustração da transformação tridimensional de Helmert.................... 54

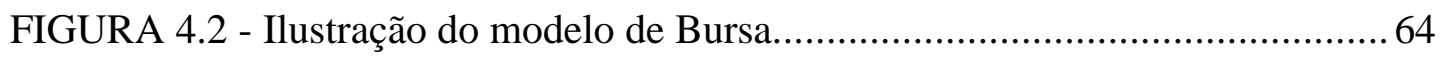

FIGURA 4.3 - Ilustração do modelo de Molodenskii - primeira versão...................67 67

FIGURA 4.4 - Ilustração do modelo de Molodenskii - segunda versão ...................69

FIGURA 5.1 - Ilustração dos vértices utilizados na determinação dos parâmetros de transformação e os utilizados no controle............................... 73

FIGURA 5.2 - Ilustração do vetor translação entre um sistema geodésico geocêntrico e um geodésico local.................................................. 84 


\section{LISTA DE TABELAS}

TABELA 2.1 - Parâmetros do elipsóide WGS-84....................................................15

TABELA 5.1 - Coordenadas geodésicas no sistema SAD-69 dos vértices utilizados na determinação dos parâmetros de transformação considerando a ondulação geoidal. ............................................................. 74

TABELA 5.2 - Coordenadas geodésicas no sistema WGS-84 dos vértices utilizados na determinação dos parâmetros de transformação........................ 74

TABELA 5.3 - Coordenadas geodésicas no sistema SAD-69 dos vértices utilizados no Controle. 75

TABELA 5.4 - Coordenadas geodésicas no sistema WGS-84 dos vértices utilizados no Controle.

TABELA 5.5 - Valores das ondulações geoidais dos vértices utilizados na elaboração do trabalho 77

TABELA 5.6 - Comprimento das linhas bases rastreadas com o sistema GPS na Região de São Carlos-SP 78

TABELA 5.7 - Quadro resumo das soluções encontradas em $\mathrm{L}_{1}$ e $\mathrm{L}_{3}$ das linhas bases rastreadas

TABELA 5.8 - Valores de RMS em função da distância da linha base e do tempo de observação, SEGANTINE (1997). 80

TABELA 5.9 - Coordenadas geodésicas cartesianas no sistema SAD-69 dos vértices utilizados na determinação dos parâmetros de transformação desconsiderando a ondulação geoidal. 86

TABELA 6.1 - Resultado do ajustamento dos sete parâmetros de transformação considerando a ondulação geoidal

TABELA 6.2 - Resultado do ajustamento dos três parâmetros de transformação considerando a ondulação geoidal 
TABELA 6.3 - Discrepâncias encontradas nos vértices de controle em função dos sete parâmetros de transformação, considerando a ondulação

geoidal 93

TABELA 6.4 - Discrepâncias encontradas nos vértices de controle em função dos três parâmetros de transformação, considerando a ondulação geoidal.

TABELA 6.5 - Discrepâncias encontradas nos vértices de controle considerando os parâmetros de transformação divulgados oficialmente pelo IBGE. . 94

TABELA 6.6 - Resultado do ajustamento dos sete parâmetros de transformação desconsiderando a ondulação geoidal. .......................................96

TABELA 6.7 - Resultado do ajustamento dos três parâmetros de transformação desconsiderando a ondulação geoidal.

TABELA 6.8 - Discrepâncias encontradas nos vértices de controle em função dos três parâmetros de transformação, desconsiderando a ondulação geoidal. .98

TABELA 6.9 - Discrepâncias encontradas nos vértices de controle em função dos sete parâmetros de transformação, desconsiderando a ondulação geoidal. 


\section{LISTA DE ABREVIATURAS E SIGLAS}

\begin{tabular}{|c|c|}
\hline SA & - Selective Availability \\
\hline $\mathrm{BIH}$ & - Bureau International de L'Heure \\
\hline BTS & - BIH Terrestrial System \\
\hline CIGNET & - Cooperative International GPS Network \\
\hline $\mathrm{CIO}$ & - Conventional International Origin \\
\hline CIS & - Conventional Inertial System \\
\hline CTP & - Conventional Terrestrial Pole \\
\hline CTRS & - Conventional Terrestrial Reference Frame \\
\hline CTS & - Conventional Terrestrial System \\
\hline DMA & - Defense Mapping Agency \\
\hline EPUSP/PTR & - Escola Politécnica da Universidade de São Paulo \\
\hline GPS & - Global Positioning System \\
\hline IAG & - International Association of Geodesy \\
\hline IAU & - International Astronomical Union \\
\hline IBGE & - Instituto Brasileiro de Geografia e Estatística \\
\hline IERS & - International Earth Rotation Service \\
\hline IPMS & - International Polar Motion Service \\
\hline ITRF & - International Earth Rotation Service - Terrestrial Reference Frame \\
\hline LLR & - Lunar Laser Ranging \\
\hline MGB-92 & - Mapa Geoidal do Brasil-1992 \\
\hline MMQ & - Método dos Mínimos Quadrados \\
\hline MVC & - Matriz Variância Covariância \\
\hline NAD-27 & - North American Datum of 1927 \\
\hline NAVSTAR & - Navigation System with Time and Ranging \\
\hline
\end{tabular}


NGS - National Geodetic Survey

NNR - No - Net - Rotation

NNSS - Navy Navigation Satellite System

PT's - Pontos Trigonométricos

RMS - Root Mean Square

RN's - Referências de Níveis

SAD-69 - South Americam Datum 1969

SAL - Sistema Astronômico Local

SCG - Sistema Cartesiano Geodésico

SGB - Sistema Geodésico Brasileiro

SLR - Satellite Laser Ranging

STM - Sistema Terrestre Médio

UNESP - Universidade Estadual Paulista

VLBI - Very Long Baseline Interferometry

WGS-84 - World Geodetic System - 1984 


\section{LISTA DE SÍMBOLOS}

\begin{tabular}{|c|c|}
\hline$a$ & - semi-eixo maior do elipsóide \\
\hline$A$ & - matriz do sistema de equações normais do método paramétrico \\
\hline$A z^{\prime}$ & - azimute da seção normal direta \\
\hline$A z$ & - azimute da linha geodésica \\
\hline$b$ & - semi-eixo menor do elipsóide \\
\hline$B$ & - matriz dos coeficientes no ajustamento pelo método dos correlatos \\
\hline$B_{0}$ & - distância zenital observada em $P_{0}$ \\
\hline$C$ & - número de equações de condição \\
\hline $\mathrm{c}$ & - número total de equações \\
\hline$c_{a}$ & - número de equações de ângulos \\
\hline$c_{L}$ & - número de equações de lado \\
\hline$D$ & - número de novas direções observadas nos dois sentidos \\
\hline$d T$ & - correção do vetor translação \\
\hline$d R$ & - matriz rotação diferencial \\
\hline$d \alpha_{1}$ & - rotação diferencial em torno do eixo $X$ do sistema geodésico local \\
\hline$d \alpha_{2}$ & - rotação diferencial em torno do eixo $Y$ do sistema geodésico local \\
\hline$d \alpha_{3}$ & - rotação diferencial em torno do eixo $Z$ do sistema geodésico local \\
\hline$d \mu$ & - correção para o fator de escala \\
\hline$E$ & - coordenada UTM Este \\
\hline$e^{2}$ & - quadrado da primeira excentricidade do elipsóide \\
\hline$e^{\prime 2}$ & - quadrado da segunda excentricidade do elipsóide \\
\hline$f$ & - achatamento do elipsóide de revolução \\
\hline$G$ & - matriz dos coeficientes \\
\hline
\end{tabular}




\begin{tabular}{|c|c|}
\hline$H$ & - altitude ortométrica de um ponto qualquer \\
\hline$h$ & - altura geométrica de um ponto qualquer \\
\hline$H_{O A}$ & - altitude ortométrica do ponto origem da rede do Sistema \\
\hline \multirow{3}{*}{$h_{0}$} & Geodésico Brasileiro \\
\hline & - altura geométrica do ponto origem da rede do Sistema Geodésico \\
\hline & Brasileiro \\
\hline$I$ & - matriz identidade \\
\hline$I$ & - número total de linhas visadas \\
\hline$I_{2}$ & - número de linhas visadas em ambas as direções \\
\hline$K$ & - multiplicador de Lagrange \\
\hline$L$ & - número total de lados do quadrilátero completo \\
\hline$L_{0}$ & - matriz que é função dos parâmetros aproximados \\
\hline$L^{\prime}$ & - número de lados observados em ambas as direções \\
\hline$L_{b}$ & - vetor dos valores observados \\
\hline$L_{a}$ & - vetor dos valores observados ajustados \\
\hline$M$ & - raio de curvatura da seção meridiana \\
\hline$n$ & - número de ângulos medidos e independentes \\
\hline$N$ & - grande normal \\
\hline$N$ & - coordenada UTM Norte \\
\hline$P$ & - matriz peso \\
\hline$p$ & $\begin{array}{l}\text { - número total de vértices no estabelecimento do coeficiente de } \\
\text { rigidez }\end{array}$ \\
\hline$p^{\prime}$ & - número de vértices ocupados \\
\hline$P_{0}$ & - ponto origem da rede do Sistema Geodésico Brasileiro \\
\hline$R$ & $\begin{array}{l}\text { - matriz resultante de um produto de três matrizes ortogonais de } \\
\text { rotação em torno dos eixos } X, Y \text { e } Z \text {, respectivamente }\end{array}$ \\
\hline$r_{k}$ & $\begin{array}{l}\text { - vetor de posição do ponto inicial da rede terrestre estabelecido no } \\
\text { sistema geodésico local }\end{array}$ \\
\hline$r_{k i}$ & $\begin{array}{l}\text { - vetor de posição de um ponto qualquer } i \text { estabelecido no sistema } \\
\text { topocêntrico com origem no datum }\end{array}$ \\
\hline$R_{X}\left(\alpha_{1}\right)$ & - matriz ortogonal de rotação em relação ao eixo $X$ \\
\hline
\end{tabular}




\begin{tabular}{|c|c|}
\hline$R_{Y}\left(\alpha_{2}\right)$ & - matriz ortogonal de rotação em relação ao eixo $Y$ \\
\hline$R_{Z}\left(\alpha_{3}\right)$ & - matriz ortogonal de rotação em relação ao eixo $Z$ \\
\hline$R_{0}$ & - matriz de rotação aproximada \\
\hline$R$ & $\begin{array}{l}\text { - coeficiente de rigidez e em algumas equações foi definido como } \\
\text { raio médio de curvatura da esfera local }\end{array}$ \\
\hline$R_{i}$ & - leitura na mira à ré da posição " $i "$ \\
\hline$S^{\prime}$ & - distância da seção normal direta \\
\hline$S$ & - distância da linha geodésica \\
\hline$S$ & - área do triângulo esférico \\
\hline$T$ & - vetor de translação \\
\hline$T_{0}$ & $\begin{array}{l}\text { - vetor de translação aproximado cuja as componentes são as } \\
\text { translação aproximadas em relação a } X, Y \mathrm{e} Z\end{array}$ \\
\hline$T_{X}$ & - Translação em relação ao eixo $X$ \\
\hline$T_{Y}$ & - Translação em relação ao eixo $Y$ \\
\hline$T_{Z}$ & - Translação em relação ao eixo $Z$ \\
\hline $\boldsymbol{V}$ & - vetor dos resíduos \\
\hline$V_{i}$ & _ leitura na mira à vante da posição " $i "$ \\
\hline$v$ & $\begin{array}{l}\text { - número total de vértice no ajustamento de uma triangulação } \\
\text { geodésica pelo método dos correlatos }\end{array}$ \\
\hline$v_{2}$ & numero de vértices ocupados \\
\hline $\boldsymbol{W}$ & - vetor do erro de fechamento \\
\hline$W^{\prime \prime}$ & - convergência meridiana em segundos \\
\hline$X$ & $\begin{array}{l}\text { - vetor com origem no sistema de coordenadas geodésico local, que } \\
\text { une um ponto na superfície da Terra }\end{array}$ \\
\hline$X_{T}$ & $\begin{array}{l}\text { - vetor com origem no sistema de coordenadas geocêntrico, que une } \\
\text { um ponto na superfície da Terra; }\end{array}$ \\
\hline$X_{0}$ & $\begin{array}{l}\text { - vetor cujas componentes são os valores aproximados dos } \\
\text { parâmetros }\end{array}$ \\
\hline $\boldsymbol{X}$ & - vetor correção do ajustamento de observações \\
\hline$X_{a}$ & - vetor dos parâmetros ajustados \\
\hline$x_{\mathrm{p}}$ & - componente $x$ do movimento polar \\
\hline
\end{tabular}




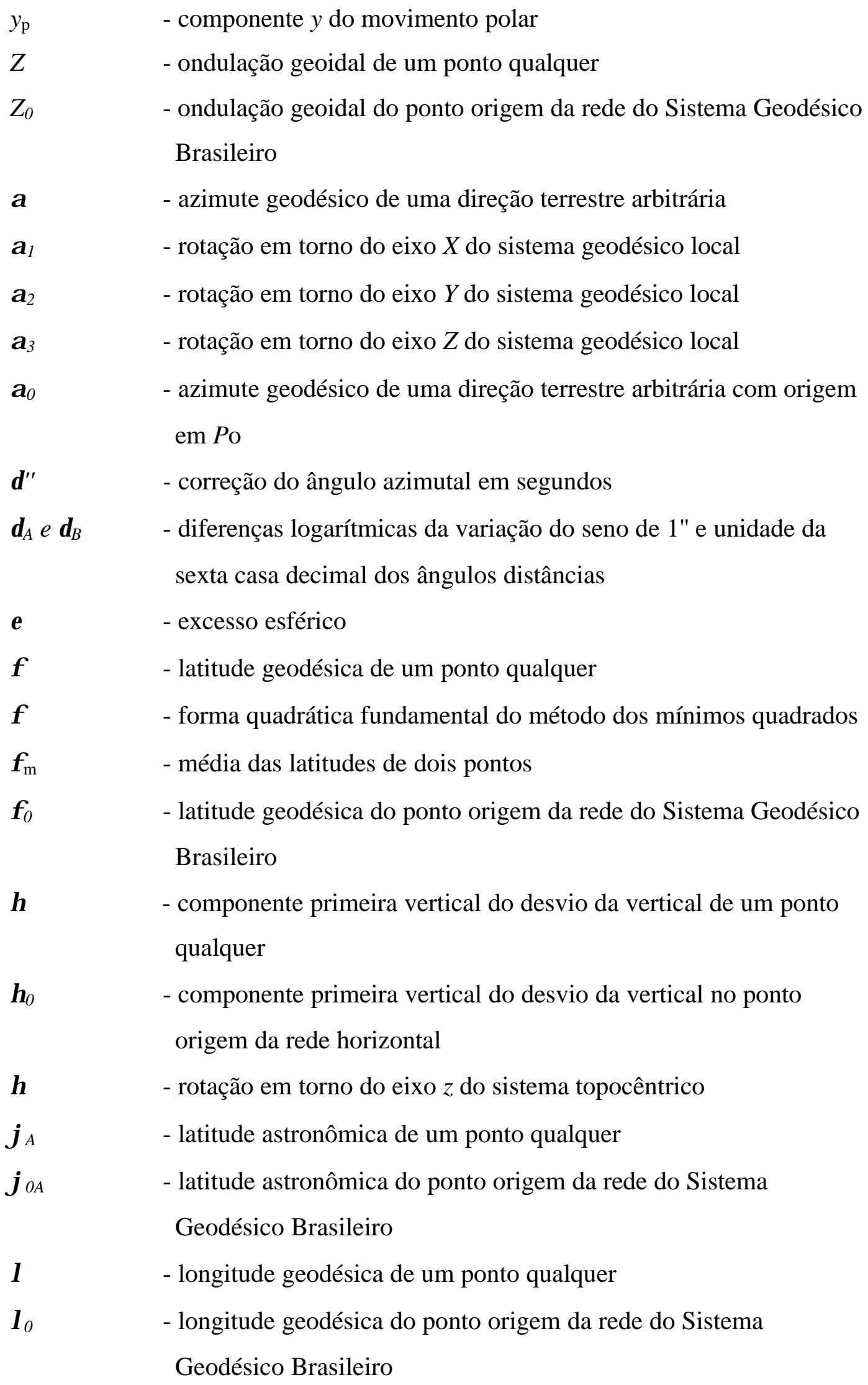




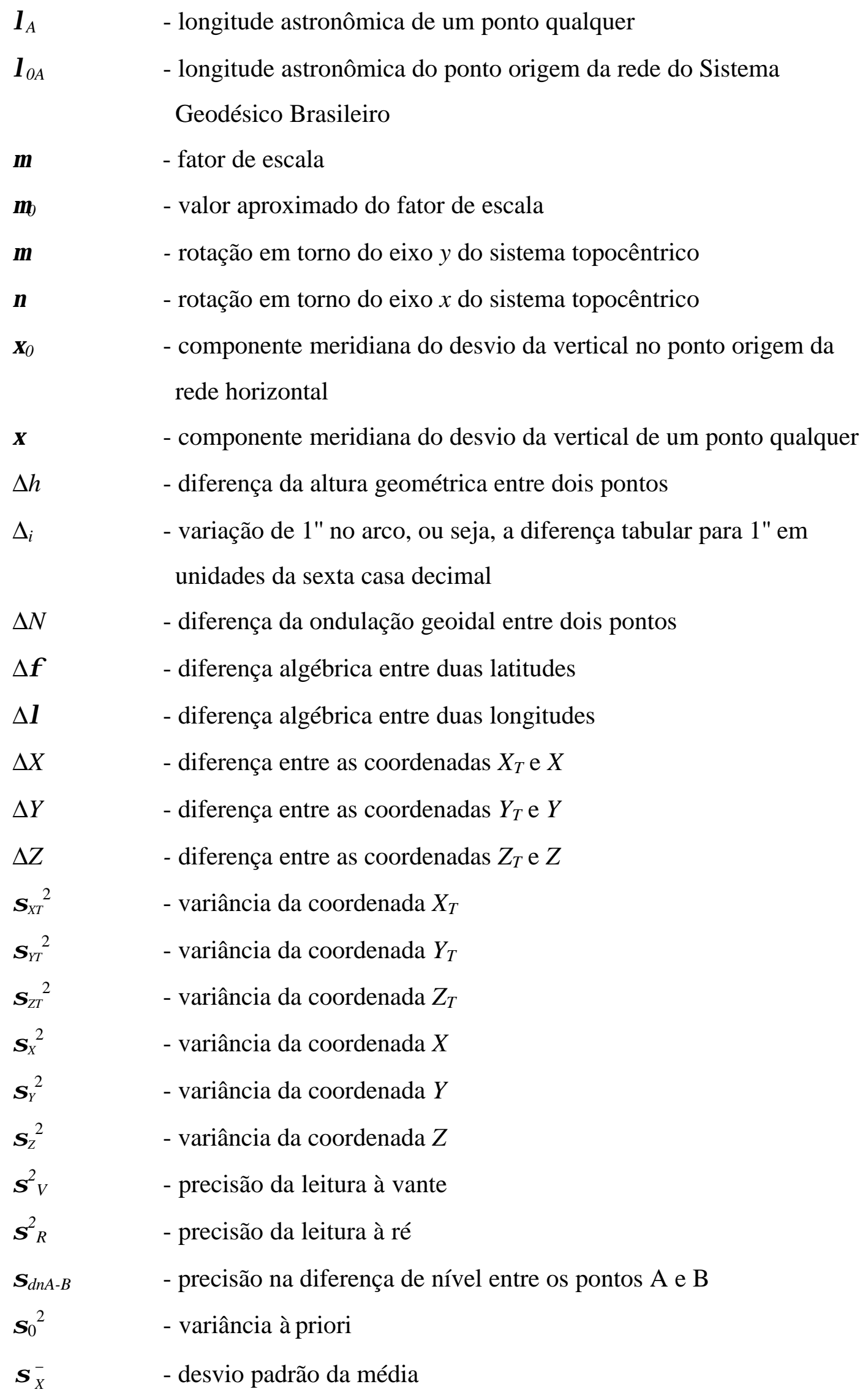




\section{RESUMO}

VERONEZ, M. R. (1998). Proposta de parâmetros de transformação entre os sistemas WGS-84 e o SAD-69 para região de São Carlos-SP. São Carlos, 1998. 113p. Dissertação (Mestrado) - Escola de Engenharia de São Carlos, Universidade de São Paulo.

O sistema de referência da rede de satélites GPS (Global Positioning System) é o sistema geocêntrico World Geodetic System 1984 (WGS-84). As coordenadas de pontos obtidos usando o GPS são definidas para este sistema de referência. Entretanto, o engenheiro ao utilizar as coordenadas destes pontos geodésicos, requer que estejam referenciados no sistema local. O sistema local está associado a um elipsóide que melhor se adapta à área de trabalho. No Brasil, é adotado o sistema não geocêntrico South American Datum SAD-69. Uma vez que o WGS-84 é um sistema geocêntrico e o local não é, algumas transformações de coordenadas são necessárias. Os parâmetros de transformação das coordenadas entre os dois sistemas, publicados pelo IBGE para todo o Brasil, apresentam divergências se comparados a parâmetros obtidos para uma determinada região. Assim este trabalho tem por finalidade discutir alguns métodos possíveis de serem empregados para determinar os parâmetros de transformação entre os sistemas WGS-84 e o SAD-69, para a região de São CarlosSP.

Palavras-chave: transformação; sistemas de referência; coordenadas. 


\begin{abstract}
VERONEZ, M. R. (1998). Proposal of transformation parameters between the WGS-84 and SAD-69 systems for the region of São Carlos-SP. São Carlos, 1998. 113p. Dissertação (Mestrado) - Escola de Engenharia de São Carlos, Universidade de São Paulo.
\end{abstract}

The reference system of the satellites network GPS (Global Positioning System) is the geocentric system WGS-84. When the coordinates of a point in the Earth's surface are computed by using a GPS receiver, they are computed for this reference system. However, for practical purposes is desirable that the computed point be in the local coordinate system of the user, which is associated to an ellipsoid that best fits the region of work. In the Brazil, is accepted the system geocentric not South American Datum 1969 (SAD-69). Considering that the WGS-84 system is a geocentric system and that the local system is not, it is necessary to perform some transformation of coordinates. The transformation parameters of the coordinates between two system, published by IBGE all over Brazil, present regional divergency. From this point of view, this paper discus some methods that can be applied to determine the transformation parameters between WGS-84 and SAD-69 systems, for the region of São Carlos-SP.

Keywords: transformation; reference systems; coordinates. 


\section{CAPÍTULO 1 - INTRODUÇÃO}

\subsection{Generalidades}

Os sistemas de referência são definidos rigorosamente apenas em situações ideais. Geralmente, quando se procura estabelecer um referencial para um processamento de dados práticos, ligados à realidade física da Terra, se admite alguma forma de simplificação. A simplificação é obviamente função de alguns fatores, tais como: qualidade exigida dos valores processados, complexidade da definição do sistema e dos modelos matemáticos envolvidos, etc.

A forma real da Terra é aproximada por um Geóide, definido como a superfície equipotencial, que em qualquer lugar é perpendicular à vertical dada por um fio de prumo e que coincide com o nível médio não perturbado dos mares, TORGE (1983). O Geóide é uma superfície irregular matematicamente indefinida.

Um Sistema Geodésico corresponde a uma superfície de referência onde se estabelece a base para o cálculo dos levantamentos de controle horizontal, por meio do qual é considerada a curvatura da Terra. Esta superfície de referência corresponde a um elipsóide de revolução.

Num sistema geodésico definem-se as normais elipsoidais e os meridianos geodésicos. As normais são retas perpendiculares ao elipsóide de revolução. Cada ponto do espaço pertence, portanto, a somente uma normal elipsoidal que, por sua vez, intercepta necessariamente o eixo de revolução do elipsóide. O plano definido por este eixo com a normal traçada por um ponto qualquer do espaço é o meridiano geodésico do ponto. Assim, o meridiano geodésico corresponde a linha do elipsóide de referência cujos pontos tem a mesma longitude geodésica. 
Um Sistema Geodésico Local (Sistema não Geocêntrico) é aquele que está associado a um elipsóide de referência que melhor se adapta à área de interesse. Surge o conceito de sistema local ou não geocêntrico decorrente da condição de uma boa adaptação localizada do elipsóide ao geóide.

Quando se define um Sistema Geodésico Local, geralmente se estabelece a condição de paralelismo entre os seus eixos coordenados e os eixos do Sistema Terrestre Médio. A definição do Sistema Terrestre Médio decorre da necessidade de se reduzir latitudes, longitudes e azimutes astronômicos a uma época comum de referência, devido à variação direcional do eixo de rotação da Terra. Esta variação é temporal e origina um fenômeno denominado de movimento do polo. Duas organizações internacionais, o IPMS (International Polar Motion Service) e o BIH (Bureau International de L'Heure) determinam rotineiramente o movimento do polo. Os resultados são publicados periodicamente na forma de pares coordenados $\left(x_{p}, y_{p}\right)$ em relação a um sistema cartesiano plano, e cuja origem é um ponto fixo da superfície terrestre definido no período de 1900 a 1906.0, CASTAÑEDA (1986). Este é um polo médio onde recebe a denominação de CIO (Conventional International Origin). Ele estabelece, com o centro de massa da Terra, um eixo médio convencional de rotação, invariável no tempo, ao contrário do eixo real de rotação das Terra.

É de se esperar que ao definir um Sistema Geodésico Local o mesmo não coincida com o modelo estabelecido matematicamente, uma vez que toda medição física realizada jamais está isenta de erros sistemáticos. Logo, é conveniente dizer que o Sistema Geodésico Local está bem próximo do que foi definido.

Uma melhor proximidade do sistema, entre sua materialização e sua definição, pode ser alcançado com equipamentos mais precisos, métodos de observações mais adequados, a realização de ajustamento de redes, etc.

O South Americam Datum 1969 (SAD-69), corresponde a um sistema de referência não geocêntrico oficialmente adotado para uniformização dos trabalhos geodésicos e cartográficos desenvolvidos no continente sul-americano. A sua utilização foi recomendada desde 1969 como datum único para a América do Sul, decorrência da aprovação do relatório final da equipe norte americana do DMA (Defense Mapping Agency), pelo Comitê de Geodésia reunido na XI Consultoria Panamericana sobre Cartografia, em Washington, E.U.A, CATAÑEDA (1986). O 
SAD-69 foi oficialmente adotado como sistema de referência para trabalhos geodésicos e cartográficos desenvolvidos em território brasileiro, apenas em 1979.

O WGS-84 (World Geodetic System - 1984), corresponde a um sistema terrestre de referência, usado para o posicionamento a partir de estações de observações e para a descrição de resultados da geodésia por satélites. O WGS-84, que embora com este nome, foi adotado apenas em 1987. Este sistema está associado a um elipsóide de revolução geocêntrico.

No que diz respeito à definição do WGS-84, o International Earth Rotation Service (IERS), comprovam a sua adequada materialização. O afastamento deste em relação à materialização do Sistema Terrestre Médio é submétrico, IERS (1993).

$\mathrm{Na}$ materialização do Sistema Geodésico Local Brasileiro SAD-69, foi estabelecido a condição de paralelismo entre os seus eixos coordenados em relação aos do Sistema Terrestre Médio. Em função disso a Fundação Instituto Brasileiro de Geografia e Estatística (IBGE) determinou e divulgou oficialmente os parâmetros de transformação entre os sistemas WGS-84 e SAD-69.

Os parâmetros divulgados foram obtidos apenas no Vértice Chuá - MG (origem da rede geodésica brasileira) e são, FORTES et al. (1989):

$$
\begin{aligned}
& \bullet T_{X}=+66,87 \mathrm{~m} \pm 0,43 \mathrm{~m} \\
& \bullet T_{Y}=-4,37 \mathrm{~m} \pm 0,44 \mathrm{~m} \\
& \bullet T_{Z}=+38,52 \mathrm{~m} \pm 0,40 \mathrm{~m}
\end{aligned}
$$

\subsection{O Problema}

O principal problema a ser discutido neste trabalho diz respeito às discrepâncias encontradas na transformação de coordenadas ao utilizar os parâmetros de transformação entre os sistemas de referências WGS-84 e SAD-69, divulgados pelo IBGE. 


\subsection{Justificativa}

A utilização do sistema GPS está cada vez mais acessível, e sem dúvida, já está muito popularizado nos meios científico e técnico brasileiro.

Esta revolução que o sistema GPS vem trazendo aos procedimentos de levantamentos geodésicos pode ser avaliada pela classificação dos levantamentos executados com a sua utilização. Conforme o Boletim de Serviço 1602 de 01 de agosto de 1984, que contempla as Especificações e Normas Gerais para Levantamentos Geodésicos, a categoria de alta precisão (âmbito nacional) subdivide-se em dois subgrupos, IBGE, (1993): científicos e fundamentais (ou de $1^{\mathrm{a}}$ ordem), com precisões associadas melhores que 1/500.000 e 1/100.000, respectivamente. Na ocasião que o boletim de serviço foi redigido, o IBGE era praticamente a única instituição capaz de executar levantamentos fundamentais, sendo que os científicos requeriam equipamentos e técnicas de alta complexidade e elevado custo, tais como SLR (Satellite Laser Ranging), LLR (Lunar Laser Ranging) e VLBI (Very Long Baseline Interferometry). No entanto, os posicionamentos geodésicos com o GPS são capazes de facilmente fornecer resultados com precisão da ordem de 1 a 2ppm, após ajustamento, passíveis de serem obtidos utilizando-se receptores que observam a fase da portadora.

Pelo exposto, verifica-se que o advento do sistema de posicionamento global é responsável por uma melhoria de qualidade da rede de alta precisão do SGB de pelo menos 100 vezes, IBGE (1993). Este fato reveste-se da maior importância no momento atual, quando inúmeras empresas usuárias do sistema se surpreendem ao obterem resíduos da ordem de 10ppm em ajustamentos realizados a partir de levantamentos GPS apoiados em mais de um ponto da rede clássica do SGB, IBGE (1993).

Quando as coordenadas adivindas do GPS são transformadas para SAD-69, parte desta exatidão acaba sendo degradada, em função dos parâmetros de transformação utilizados. Alguns estudos publicados confirmam que o erro cometido utilizando-se os parâmetros de transformação oficiais divulgados pelo IBGE é significativo, comprometendo toda exatidão das coordenadas advindas do GPS quando são transformadas para SAD-69. 
Outra justificativa diz respeito aos parâmetros fornecidos pelo IBGE, onde, os mesmos foram determinados apenas no vértice Chuá - MG que é a origem da rede do SGB.

Segundo FORTES et al. (1989), a vantagem desta determinação de parâmetros consiste na não influência das distorções da rede e do mapa geoidal nos valores calculados, uma vez que foram utilizadas coordenadas definidas no ponto origem.

Uma análise crítica desta citação, é que, se o objetivo era determinar os parâmetros de transformação, que cobrissem todo território nacional, a amostragem para tal determinação deveria constar de vértices localizados em todas as regiões brasileiras, com influência ou não de distorções da rede e do mapa geoidal.

\subsection{Objetivos}

Os principais objetivos deste trabalho são:

- apresentar alguns modelos matemáticos de transformação de coordenadas, utilizados em combinação de redes geodésicas, com o intuito de estimar parâmetros de transformação entre os sistemas WGS-84 e SAD-69, para a região de São Carlos (SP).

- verificar os resíduos do ajustamento dos parâmetros considerando (três translações) e (três translações, três rotações e um fator de escala), respectivamente.

- verificar a influência do geóide na estimativa dos parâmetros de transformação entre os dois sistemas, para a região de São Carlos (SP). 


\section{CAPÍTULO 2 - SISTEMAS GEODÉSICOS DE REFERÊNCIA}

\subsection{Introdução}

O principal problema da Geodésia pode ser entendido como: determinar as coordenadas espaciais de qualquer ponto $P$ na superfície física da Terra. Assim, no estabelecimento da posição de $P$, a definição de um sistema apropriado ao qual estas coordenadas espaciais se referem é de primordial importância.

Devido aos movimentos de rotação da Terra e de outros fenômenos geodinâmicos, um sistema de coordenadas "Terra Fixa", rigorosamente definido em função da precisão de nossas observações é, atualmente, uma das principais preocupações da comunidade científica em Geodésia e Geofísica.

Recentemente encontros, simpósios e workshops, organizados juntamente com a International Association of Geodesy (IAG) e a International Astronomical Union (IAU) vem debatendo a respeito de trabalhos de diferentes grupos da comunidade científica internacional com o propósito de estabelecer sistemas de referências confiáveis.

Um sistema coordenado (no espaço físico ou abstrato) é definido, segundo CASTAÑEDA (1986), como sendo uma relação de regras que especifica univocamente a posição de cada ponto do espaço através de um conjunto ordenado de números reais denominados coordenadas. A propriedade mais importante de qualquer espaço é sua dimensionalidade, que se mede pelo número de coordenadas necessárias à especificação do posicionamento de cada um de seus pontos. 
A grande vantagem de se usar um Sistema Cartesiano Tridimensional (3-D) é que ele é completamente definido pela origem, direção e sentido dos três eixos. No entanto, apresenta o inconveniente de não refletir, de forma direta, uma variação de altitude.

Tradicionalmente, a superfície terrestre tem sido representada pelas coordenadas geodésicas latitude, longitude e altitude ortométrica, enquanto que, uma porção limitada desta superfície pode, simplificadamente, ser definida pelas coordenadas topocêntricas, RODRIGUES (1993).

\subsection{Posicionamento e orientação de um datum geodésico horizontal}

Os pares coordenados $(\phi, \lambda)$ relativos às estações de uma rede horizontal clássica encontram-se associados a um determinado sistema elipsoidal geodésico, ao qual necessariamente corresponde um elipsóide de revolução denominado Datum Geodésico Horizontal, CASTAÑEDA (1986).

Para o estabelecimento de um Datum Geodésico Horizontal há a necessidade de definição de duas condições importantes:

- definir os parâmetros que caracterizam a geometria do elipsóide;

- definir o posicionamento e a orientação do elipsóide em relação ao Sistema Terrestre Médio.

O Sistema Geodésico Local oficialmente adotado no Brasil é o SAD-69, onde seu posicionamento e orientação se deu através do método clássico. Segundo CASTAÑEDA (1986), o conceito básico que permeia o método clássico de posicionamento e orientação de Datum Geodésico Horizontal é a possibilidade de se arbitrar livremente certos parâmetros definidores da situação espacial do datum relativamente à Terra. Quando se fala definir a situação de um datum geodésico horizontal equivale a fixar o posicionamento e a orientação do Sistema Cartesiano Geodésico (SCG) em relação ao Sistema Terrestre Médio (STM).

Isso é possível estabelecendo-se seis parâmetros a saber: 
- 3 rotações $(\varepsilon, \psi, \omega)$ : rotações fundamentais que aplicadas ao SCG, em uma ordem pré-estabelecida, proporciona o paralelismo entre o SCG e o STM. Estes três parâmetros correspondem aos parâmetros de orientação do datum;

- 3 translações $\left(x_{c}, y_{c}, z_{c}\right)$ : componentes do vetor translação, onde proporcionam a definição do posicionamento espacial do datum em relação ao STM.

Na prática, a abordagem geocêntrica de posicionamento espacial do datum, definição essa referida aos componentes do vetor translação, é substituída por uma outra técnica diferente, mas equivalente denominada de abordagem topocêntrica.

$\mathrm{O}$ ponto $\left(P_{0}\right)$ é denominado ponto origem da rede e a abordagem topocêntrica consiste no estabelecimento de seis parâmetros neste ponto. A explicação de cada parâmetro é dada a seguir:

$\phi_{0}, \lambda_{0}$ correspondem à latitude e longitude geodésicas de $P_{0}$. Essas coordenadas especificam uma normal ao ponto inicial. A direção dessa normal é definida em relação ao Sistema Astronômico Local (SAL) com origem em $P_{0}$. A definição da orientação da normal em relação a este sistema se dá através de dois parâmetros que são as componentes do desvio da vertical em $P_{0}$. Estas componentes são a componente primeira vertical $\eta_{0}$ e a componente meridiana $\xi_{0}$. O quinto parâmetro a ser definido é a ondulação geoidal $N_{0}$. O sexto e último parâmetro a ser definido é o azimute geodésico $\alpha_{0}$ de uma direção terrestre arbitrária, com origem em $P_{0}$.

\subsubsection{Condições de paralelismo - a equação de Laplace}

O objetivo deste item é alertar sobre possíveis erros sistemáticos existentes na definição do SAD-69 e quais as consequências destes erros na condição de paralelismo estabelecido entre o Sistema Cartesiano Geodésico e o Sistema Terrestre Médio.

Quando se impõem a condição de paralelismo entre o SCG e o STM na abordagem geocêntrica, fica bem claro que três, dos seis parâmetros de posicionamento e orientação do datum em relação à Terra são anulados, que são as três rotações $(\varepsilon, \psi, \omega)$, sobrando apenas as três translações $x_{c}, y_{c}, z_{c}$. 
Mas como é de interesse prático a abordagem topocêntrica, a imposição de paralelismo entre os Sistemas Cartesiano Geodésico e o Sistema Terrestre Médio não é tão evidente sobre os parâmetros a serem definidos no ponto inicial $P_{0}$. As relações matemáticas que ilustram os efeitos da suposição de paralelismo sobre os parâmetros no ponto inicial são chamados de expressões de condições de paralelismo. Para analisar estas expressões vamos introduzir algumas grandezas que são passíveis de serem medidas, que correspondem aos parâmetros de posicionamento e orientação do datum. Assim temos:

$-\varphi_{O A}, \lambda_{O A}, H_{O A}$ e $A_{O A}$ : correspondem, respectivamente, latitude astronômica, longitude astronômica, altitude ortométrica e azimute astronômico de partida;

- $\phi_{0}, \lambda_{0}, h_{0}$ e $\alpha_{0}$ : correspondem, respectivamente, latitude geodésica, longitude geodésica, altura geométrica e azimute geodésico de partida.

Segundo CASTAÑEDA (1986), para assegurar a condição de paralelismo, é necessário que os parâmetros de orientação da normal $\eta_{0}$, $\xi_{0}$ e $\alpha_{0}$ preencham as seguintes relações matemáticas:

$$
\begin{aligned}
& \xi_{0}=\varphi_{0 A}-\phi_{0} \\
& \eta_{0}=\left(\lambda_{0 A}-\lambda_{0}\right) \cdot \cos \phi_{0} \\
& \alpha_{0}=A_{0 A}-\left(\eta_{0} \cdot \operatorname{tg} \phi_{0}\right)
\end{aligned}
$$

onde:

- $\xi_{0}$ é a componente meridiana do desvio da vertical no ponto origem da rede horizontal;

- $\eta_{0}$ é a componente primeira vertical do desvio da vertical no ponto origem da rede horizontal;

- $\alpha_{0}$ é o azimute geodésico de uma direção terrestre arbitrária com origem em $P$ o; 
- $\varphi_{0 A}$ e $\phi_{0}$ correspondem à latitude astronômica e latitude geodésica do ponto origem da rede, respectivamente.

- $\lambda_{O A}$ e $\lambda_{O}$ correspondem à longitude astronômica e longitude geodésica do ponto origem da rede, respectivamente.

Estas equações constituem condições locais ou topocêntricas de paralelismo entre os sistemas SCG e STM. Sendo assim, são em função destas equações que são tiradas inferências particulares de maior interesse no que diz respeito à condição de paralelismo entre os sistemas em questão. Pode-se generalizar para demais pontos as equações (2.1), (2.2) e (2.3).

Quanto a eq.(2.3), a mesma trata-se da conhecida expressão de condição de Laplace de uma forma simplificada que proporciona a conversão de azimutes astronômicos em seus respectivos geodésicos. Assim tem-se:

$$
\begin{aligned}
& \xi=\varphi_{A}-\phi \\
& \eta=\left(\lambda_{A}-\lambda\right) \cdot \cos \phi \\
& \alpha=A_{A}-(\eta \cdot \operatorname{tg} \phi)
\end{aligned}
$$

Segundo CASTAÑEDA (1986), as equações (2.1) e (2.2) são pouco significativas no processo de orientação de um Datum Geodésico Horizontal. Na realidade, estas duas equações atuam basicamente como expressões às quais se recorrem para obtenção das coordenadas $\left(\phi_{0}, \lambda_{0}\right)$ do ponto inicial, uma vez estipulados os valores de $\eta_{0}$ e $\xi_{0}$.

É através da equação de Laplace que se estabelece a função de parâmetro topocêntrico orientador do datum estabelecido. Por sua importância, há a necessidade de se estabelecer considerações adicionais sobre a equação de Laplace. A eq.(2.3) é a equação simplificada de Laplace. A seguir é estabelecido a expressão rigorosa, CASTAÑEDA (1986):

$$
\begin{aligned}
& \alpha_{0}=A_{0 A}-\left(\eta_{0} \cdot \operatorname{tg} \phi_{0}\right)-\left(\xi_{0} \cdot \operatorname{sen} \alpha_{0}-\eta_{0} \cdot \cos \alpha_{0}\right) \cdot \cot g \beta_{0} \\
& \beta_{0}=B_{0}+\left(\xi_{0} \cdot \cos \alpha_{0}\right)-\left(\eta_{0} \cdot \operatorname{sen} \alpha_{0}\right)
\end{aligned}
$$


onde:

- $B_{0}$ é a distância zenital observada em $P_{0}$, segundo a linha de visada da direção de partida;

- $\beta_{0}$ é a grandeza geodésica correspondente.

Quando se trata de orientação de um datum geodésico horizontal é importante salientar que é possível minimizar erros acidentais em determinações astronômicas isoladas através de um grande número de repetições. Já no que diz respeito aos erros sistemáticos decorrentes da negligência de algumas reduções que devem ser aplicadas às observações astronômicas, o aumento do número de repetições de nada adianta.

Mesmo com a expressão rigorosa de Laplace, demonstram outros autores que outras reduções são necessárias quando se procedem a transformação de azimutes astronômicos em geodésicos.

Segundo TORGE (1983), essa transformação é expressa a seguir de uma forma genérica:

$$
\alpha=A_{A}-(\eta \cdot \operatorname{tg} \phi)-(\xi \cdot \operatorname{sen} \alpha-\eta \cdot \cos \alpha) \cdot \cot g \beta+\left(\frac{e^{2}}{2 \cdot b \cdot \operatorname{sen} 1 "} \cdot h_{v} \cdot \cos ^{2} \phi \cdot \operatorname{sen} 2 \alpha\right)(2.9
$$

onde:

- $b$ é semi-eixo menor do elipsóide;

$\checkmark e^{2}$ é o quadrado da primeira excentricidade;

- $h_{v}$ é a altura geométrica do ponto observado.

O termo adicional à expressão rigorosa de Laplace representa o efeito sobre as observações azimutais, da não coplanaridade das normais ao elipsóide relativas aos pontos de observação e observados.

Tomando-se como exemplo o vértice Chuá, CASTAÑEDA (1986), chegou que, o termo referido à expressão rigorosa da equação de Laplace é:

$$
-\left(\xi_{0} \cdot \operatorname{sen} \alpha_{0}-\eta_{0} \cdot \cos \alpha_{0}\right) \cdot \cot g \beta_{0} \cong-0,0004 "
$$

O termo referido à expressão de Torge é: 


$$
+\left(\frac{e^{2}}{2 \cdot b \cdot \operatorname{sen} 1^{\prime \prime}} \cdot h_{v} \cdot \cos ^{2} \phi_{0} \cdot \operatorname{sen} 2 \alpha_{0}\right) \cong-0,004^{\prime \prime}
$$

Estes valores encontrados são valores pequenos em relação ao erro padrão desejável em relação a uma determinação astronômica de primeira ordem que é de 0,2 segundos (Boletim de Serviço n ${ }^{0} 1602$ - Suplemento, agosto de 1983 - IBGE).

Mesmo em se tratando de pequenas magnitudes, não se pode negligenciar a possibilidade destas parcelas causarem um efeito significativo sobre a orientação do datum. Assim um questionamento mais objetivo da condição de orientação espacial de um sistema geodésico definido requer um levantamento cuidadoso de todas as possíveis tendenciosidades verificadas em cada aplicação da eq.(2.7) considerada no processo de definição de $\alpha_{0}$, CASTAÑEDA (1986).

\subsection{Principais sistemas geodésicos de referência}

\subsubsection{Sistema Terrestre Médio (ou Sistema Cartesiano Global)}

Este sistema é usado nas observações astronômicas, observações a partir de sistema de posicionamento global e na orientação e posicionamento dos sistemas geodésicos, RODRIGUES (1993). A figura 2.1 ilustra de maneira mais objetiva o problema. 


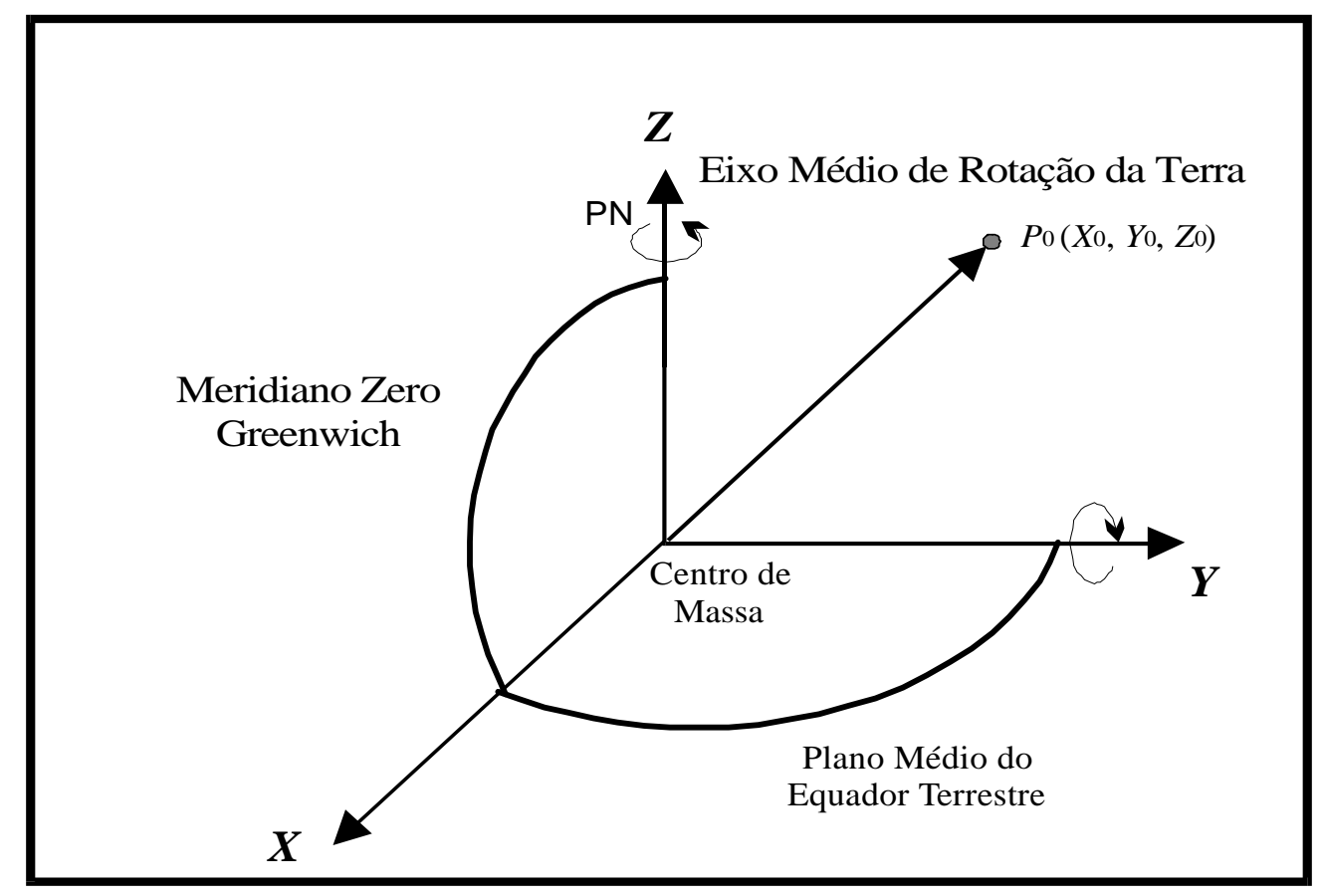

FIGURA 2.1 - Ilustração do Sistema Terrestre Médio e coordenadas cartesianas de um ponto $P_{0}$.

\section{a) Origem:}

No geocentro (centro de massa da Terra), incluindo a massa da atmosfera.

b) Eixo Z:

- Direção: coincide com o eixo médio de Rotação da Terra, indicado pelas cinco estações do "International Earth Rotation Service - IERS";

- Sentido Positivo: O sentido geocentro $\rightarrow$ CTP ("Conventional Terrestrial Pole), ou Polo Norte Médio.

\section{c) Eixo X:}

- Direção: aquela determinada pela intersecção do plano médio do equador terrestre com o plano que contém o Meridiano Médio de Greenwich (Meridiano Zero), definido pelo IERS;

- Sentido Positivo: sentido geocentro $\rightarrow$ semi - meridiano superior de Greenwich. 


\section{d) Eixo Y:}

- Direção: perpendicular aos eixos X e Z;

- Sentido Positivo: aquele que torna o sistema dextrógiro. Um sistema é considerado dextrógiro quando o produto vetorial $\boldsymbol{X} \cdot \boldsymbol{Y}=+\boldsymbol{Z}$.

\subsubsection{Sistema Geodésico Mundial}

Os sistemas de coordenadas mundial são materializados por estações cujas coordenadas derivam de observações de satélites artificiais e as soluções são acompanhadas por diferentes organizações às quais usam seus próprios programas e métodos. SOLER et al. (1988), exemplifica os sistemas mundiais mais usados em Geodésia:

- Sistema WGS-72: sistema derivado de observações Doppler e efemérides do NNSS (Navy Navigation Satellite System). Antes de 4 de janeiro de 1987, foram também realizadas observações de "pseudoranges" e utilizouse efemérides precisas de navegação.

- Sistema WGS-84: depois de 4 de janeiro de 1987, foram realizados através de observações de fase e utilizou-se efemérides precisas do sistema NAVSTAR (Navigation System with Time and Ranging) GPS.

- Sistema SLR: este sistema é definido pelas efemérides do satélite LAGEOS.

- Sistema VLBI: onde proporciona somente orientação e escala, mas nunca uma origem geocêntrica. Entretanto, determinam precisamente os parâmetros de rotação da Terra que são as componentes do movimento polar $\left(x_{p}, y_{p}\right)$, e o tempo universal necessário para uma rigorosa definição do Sistema de Referência Convencional Terrestre (CTRS). Um Sistema de Referência Convencional Terrestre (CTRS) é definido como MCCARTHY apud MONICO et al. (1996):

- o sistema é geocêntrico, com o centro de massa definido para a Terra, incluindo oceanos e atmosfera;

- a escala é aquela de um sistema terrestre local, dentro do significado da teoria gravitacional relativística; 
- a orientação obedece a do BIH (Bureal International de L'Heure) para a época de 1984.0;

- a evolução temporal da orientação não deve permitir rotação global residual com respeito à crosta, o que se convencionou denominar NNR (No - Net - Rotation).

$\mathrm{Na}$ geodésia por satélite, existem dois sistemas de referência, SEGANTINE (1995):

- "Space-Fixed": Sistema Inercial de Referência (CIS), usado na descrição do movimento dos satélites;

• "Earth-Fixed": Sistema Terrestre de Referência (CTS), usado para o posicionamento a partir de estações de observações e para a descrição de resultados da geodésia por satélite.

Desde 1987, o sistema GPS tem usado como sistema de referência o World Geodetic System WGS-84 que é um sistema do tipo CTS. Associa-se ao WGS-84 um elipsóide equipotencial geométrico de revolução que é definido como, MONICO e SEGANTINE (1996):

TABELA 2.1 - Parâmetros do elipsóide WGS-84

\begin{tabular}{cc}
\hline Parâmetros & Valores \\
\hline Semi-eixo maior do elipsóide & $a=6378137 \mathrm{~m}$ \\
Achatamento & $f=1 / 298,257223563$ \\
Velocidade angular da Terra & $\omega_{E}=7292115 \times 10^{-11}{\mathrm{rad} \times \mathrm{s}^{-1}}$ \\
Constante gravitacional terrestre & $\mu=3986005 \times 8 \mathrm{~m}^{3} / \mathrm{s}^{2}$ \\
\hline
\end{tabular}

De acordo com WHITE et al. (1989), a definição do sistema de referência do WGS-84 é: 


\section{a) Origem:}

Centro de massa da Terra, ou seja, sistema geocêntrico

\section{b) Eixo Z:}

Direção do Conventional Terretrial Pole (CTP) ou Polo Norte Médio, como definido pela Bureal International de L'Heure (BIH) sobre as bases das coordenadas estabelecidas pelas estações BIH.

\section{c) Eixo X:}

Definido pela intersecção do plano do Meridiano de Referência WGS-84 e o plano médio do Equador. O meridiano de Referência sendo paralelo ao meridiano Zero definido pelo BIH sobre as bases das coordenadas estabelecidas pelas estações BIH.

\section{d) Eixo Y:}

Possui a direção perpendicular aos eixos X e $\mathrm{Z}$ e o sentido positivo aquele que torna o sistema dextrógiro.

A figura 2.2 ilustra de maneira mais objetiva a definição do WGS-84.

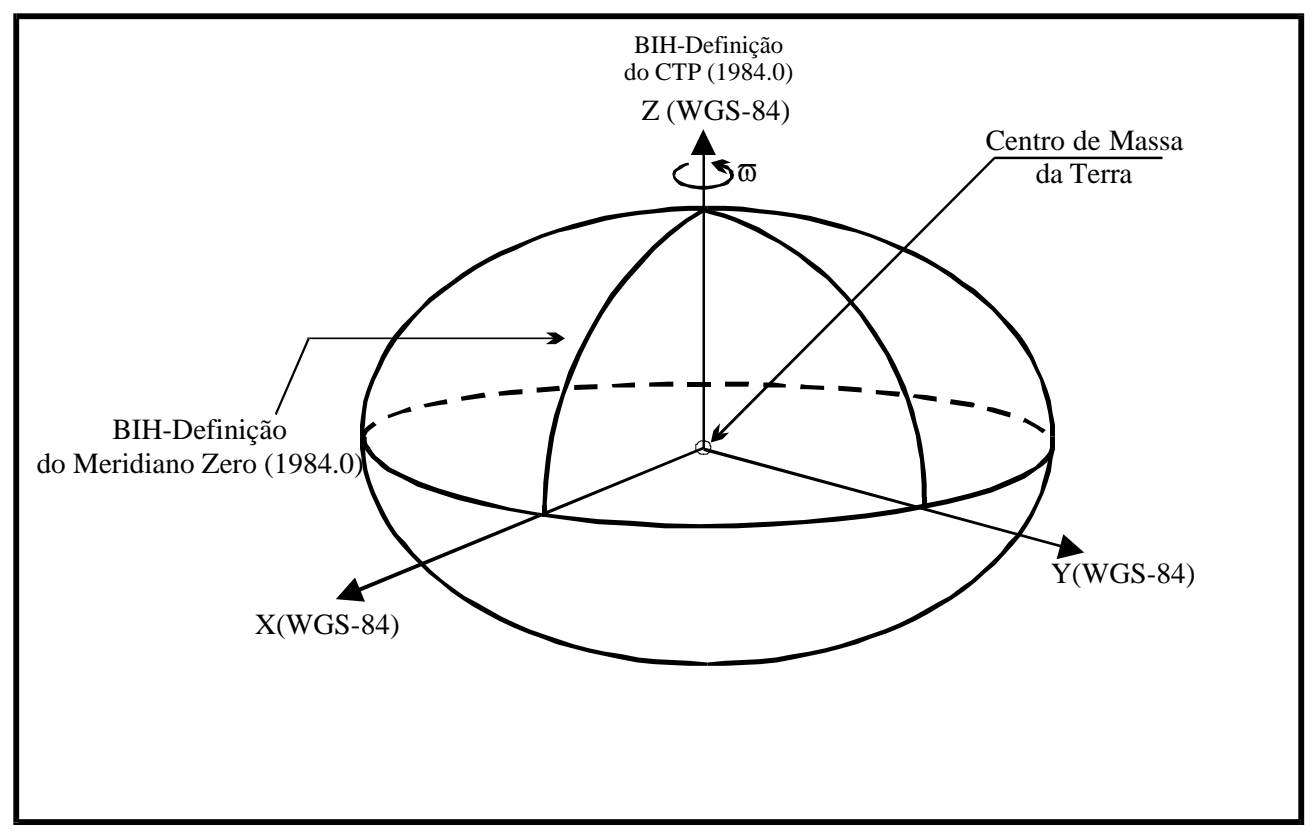

FIGURA 2.2 - Ilustração do sistema de referência do Sistema Geodésico Mundial (1984) 
Atualmente, o sistema GPS é de uso consagrado na comunidade técnica e quando se fala no seu sistema de referência verifica-se também que as suas características e definição é de domínio dos profissionais de Geodésia, Geofísica e Cartografia. O que não se sabe por parte de muitos destes profissionais é que o sistema de referência WGS-84 só é válido para processamento de dados efetuados a partir das efemérides transmitidas. Quando utiliza-se as efemérides precisas ou efemérides pós processadas o sistema de referência a ser utilizado é o ITRF (International Earth Rotation Service - Terrestrial Reference Frame). O WGS-84, após alguns refinamentos passou a ser compatível com o ITRF na ordem do decímetro, MALY \& SLATER apud MONICO et al. (1996).

As atividades do BIH iniciaram-se em 1985 com a realização do CTRS. As realizações do BTS (BIH Terrestrial System) foram denominadas BTS84, BTS85, BTS86 e BTS87. O BIH foi substituído em 1988 pelo Serviço Internacional de Rotação da Terra IERS.

Após 1988 as funções do BIH foram transferidas para o pelo Serviço Internacional de Rotação da Terra o qual passou a realizar o ITRF.

A primeira realização do ITRF ficou conhecida pelo nome de ITRF-0, onde adotou-se a origem, a orientação e a escala do BTS87. Várias realizações do ITRF se concretizaram após a inicial e foram estabelecidas as realizações ITRF88, ITRF89, ...., ITRF94.

O sistema ITRF diferencia-se do sistema WGS-84 por duas grandezas que são o tempo e a velocidade. Assim, uma estação ITRF, além de suas coordenadas geocêntricas $X, Y, Z$ é caracterizada pelas velocidades de suas coordenadas, numa determinada época $t(1988,0)$.

A análise de velocidades das coordenadas até o estabelecimento do ITRF91, eram obtidas por modelos de velocidades das placas tectônicas. A partir de 1991 a análise das velocidades já estavam embutidas no próprio sistema, sendo que o modelo de movimentação das placas tectônicas passaram a ser utilizados como informações adicionais.

Até a publicação do ITRF92, todas as realizações do ITRS seguiram praticamente o mesmo padrão. No ITRF93 houve uma mudança em relação às outras no que diz respeito à orientação da rede. Até esta realização adotava-se como 
injunção uma orientação com relação a uma rede sem rotação (NNR), relativa ao ano de 1988. No ITRF93, a orientação e sua variação com o tempo passou a ser consistente com os parâmetros de rotação da Terra produzidos pelo IERS, MONICO et al. (1996).

$\mathrm{Na}$ realização do ITRF94 as estações foram classificadas de acordo com a qualidade de suas coordenadas e respectivas velocidades. Assim as estações foram divididas em quatro classes: A, B, C e D. O ITRF apresenta algumas vantagens em relação ao WGS-84 principalmente no que diz respeito ao erro de posicionamento. Segundo SEEBER (1993), quando se adota o WGS-84 como sistema de referência, este sistema proporciona um erro de posicionamento da ordem de \pm 1 a $2 \mathrm{~m}$. Já o ITRF leva a uma precisão no posicionamento inferior a $10 \mathrm{~cm}$.

Nos padrões IERS recomenda-se adotar o ITRF para redes geodésicas e o WGS-84 para fins de mapeamento.

\subsubsection{Sistema Cartesiano Geodésico}

Extremamente importante no contexto deste trabalho, sua definição se dá segundo CASTAÑEDA (1986):

• origem coincidente com o centro geométrico do elipsóide;

- eixo terciário coincidente com o eixo de revolução do elipsóide. Sua orientação positiva é para o norte. O plano primário corresponde portanto ao equatorial geodésico;

- plano secundário é o que contém o semi-plano meridiano de referência de longitudes geodésicas. O semi eixo primário positivo está contido naquele semi-plano;

- polaridade dextrógira.

A figura 2.3 ilustra melhor a definição: 


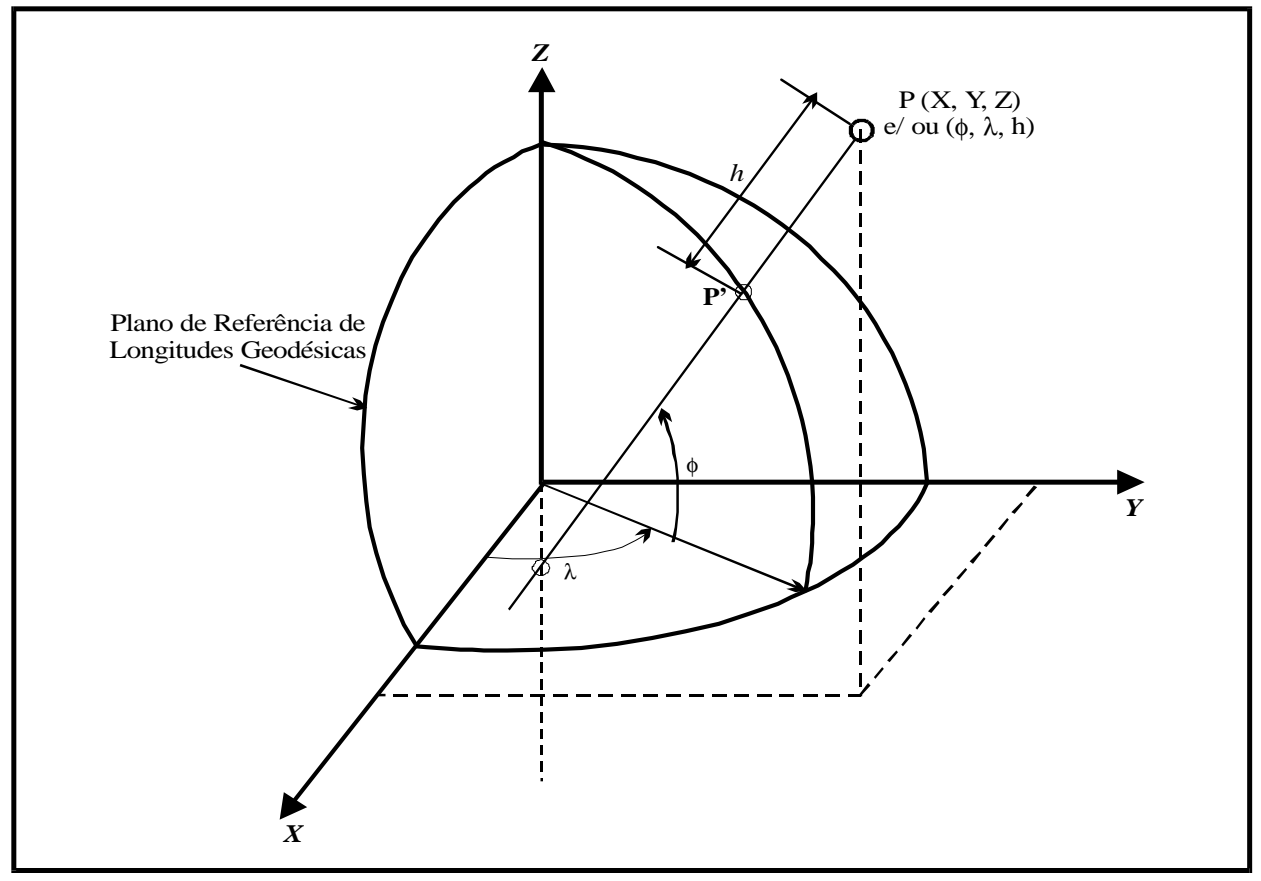

FIGURA 2.3 - Ilustração do Sistema Cartesiano Geodésico

Verifica-se pela figura 2.3 que é possível estabelecer uma relação entre as coordenadas geodésicas $(\phi, \lambda, h)$ e as coordenadas cartesianas de um ponto $P$ localizado na superfície física da Terra. Esta relação é:

$$
\begin{aligned}
& X_{P}=(N+h) \cdot \cos \phi \cdot \cos \lambda \\
& Y_{P}=(N+h) \cdot \cos \phi \cdot \operatorname{sen} \lambda \\
& Z_{P}=\left[N \cdot\left(1-e^{2}\right)+h\right] \cdot \operatorname{sen} \phi
\end{aligned}
$$

onde a grande normal $N$ é:

$$
N=\frac{a}{\sqrt{1-\left(e^{2} \cdot \operatorname{sen}^{2} \phi\right)}}
$$

e a primeira excentricidade do elipsóide " $e$ ” é: 


$$
e^{2}=\frac{a^{2}-b^{2}}{a^{2}}
$$

onde $a$ e $b$ são semi-eixo maior e menor do elipsóide, sendo que $b$ é:

$$
b=a-(a \cdot f)
$$

onde $f$ é o achatamento do elipsóide de revolução:

$$
f=1-\sqrt{\left(1-e^{2}\right)}
$$

Para a transformação inversa, tem-se, FORTES et al. (1984):

$$
\begin{aligned}
& \phi=\operatorname{arctg}\left[\frac{Z_{P}+e^{2} \cdot b \cdot \operatorname{sen}^{3} u}{\left(X_{P}^{2}+Y_{P}^{2}\right)^{0.5}-e^{2} \cdot a \cdot \cos ^{3} u}\right] \\
& \lambda=\operatorname{arctg}\left(\frac{Y_{P}}{X_{P}}\right) \\
& h=\frac{\left(X_{P}^{2}+Y_{P}^{2}\right)^{0.5}}{\cos \phi}-N
\end{aligned}
$$

onde:

$$
\begin{aligned}
& e^{2}=\frac{e^{2}}{1-e^{2}} \\
& \operatorname{sen} u=\frac{\operatorname{tg} u}{\left(1+\operatorname{tg}^{2} u\right)^{0,5}} \\
& \cos u=\frac{1}{\left(1+\operatorname{tg}^{2} u\right)^{0,5}} \\
& \operatorname{tg} u=\left[\frac{Z_{P}}{\left(X_{P}^{2}+Y_{P}^{2}\right)^{0,5}}\right] \cdot\left(\frac{a}{b}\right)
\end{aligned}
$$




\section{CAPÍTULO 3 - REDES GEODÉSICAS}

\subsection{Introdução}

A determinação da forma e do comprimento da Terra é um dos principais objetivos da Geodésia.

Os corpos vinculados à Terra acham-se sujeitos a uma força que resulta da força de atração, proporcionada pelas massas da Terra, e da força centrífuga decorrente do movimento de rotação da mesma. A esta força, chamamos de Força de Gravidade a qual está associada a um potencial chamado de Potencial da Gravidade.

Se unirmos todos os pontos de um mesmo potencial teremos uma superfície chamada de Equipotencial. Diz-se que Superfície Equipotencial é o lugar geométrico dos pontos de mesmo potencial. Em um corpo homogêneo, esférico e em repouso, as superfícies equipotenciais também são esféricas. No entanto, sabemos que a Terra está em movimento de rotação, não é homogênea e possui uma distribuição de massa por volume irregular. Em consequência desses fatos, as superfícies equipotenciais não são perfeitamente esféricas, ocorrendo um achatamento das mesmas nos pólos.

Existem uma infinidade de superfícies equipotenciais que se superpõem. Porém, dessas superfícies, uma delas nos interessa de maneira especial, que é a que mais se aproxima do nível médio dos mares não perturbado, denominada Geóide. É uma superfície irregular e não pode ser matematicamente definida, porém, reflete uma superfície de referência para as coordenadas verticais. 
A forma geométrica da Terra tem sido matematicamente definida por um elipsóide de revolução. A superfície elipsoidal é conveniente como referência e facilita as operações matemáticas.

Um elipsóide de referência especificadamente orientado constitui um datum geodésico. Em cada datum, estabelece-se uma rede de estações de controle para proporcionar à comunidade técnica e científica acesso a coordenadas precisas.

Os elipsóides não são geocêntricos, uma vez que os mesmos são posicionados para melhor atender às áreas de interesse. Como resultado disto temos que os centros dos diferentes elipsóides não são coincidentes, os semi-eixos maiores e os achatamentos são diferentes e estão ligeiramente rotacionados uns em relação aos outros, LANGLEY (1991).

Uma rede geodésica terrestre é um arcabouço de pontos cujas coordenadas geodésicas foram deduzidas de observações terrestres por processos de triangulação, trilateração ou poligonação.

Tanto as redes geodésicas de controle horizontal como as de controle vertical, são fundamentais para os trabalhos de engenharia civil, aerofotogrametria e todos que, porventura, venham a necessitar de pontos geodésicos de referência.

\subsection{Fundamentos das redes geodésicas}

A finalidade dos levantamentos geodésicos constituem na determinação de redes de controle para posição, altitude e gravidade, TORGE (1983).

A disposição ou o estabelecimento de uma rede de pontos de controle é necessário sempre que grandes áreas da superfície terrestre necessita ser levantada. Estes pontos de controle são especialmente construídos ou são definidos por pontos já existentes, por exemplo, torres de igreja como referencial de azimute. As posições destes pontos de controles são dadas por suas coordenadas em relação a um sistema de referência, definido com os devidos cuidados, SEGANTINE (1995a).

Os sistemas geodésicos podem cobrir uma área de um ou vários países, por exemplo, o Sistema Geodésico Norte Americano de 1927 (NAD-27) que cobre o México, Canadá, América Central, Groelândia, além dos Estados Unidos, SEGANTINE (1995a). 
A Assembléia Geral da Associação de Geodésia da União Geodésica Internacional em Madrid, no ano de 1924, indicou o Elipsóide de Hayford como o Elipsóide de Referência Internacional. Este elipsóide foi, por muitos anos, adotado como referência para o Datum de Córrego Alegre. A Fundação Instituto Nacional de Geografia e Estatística (IBGE), a partir de 1979, passou a adotar o South American Datum 69 - (SAD-69), cuja referência é o Elipsóide Internacional de 1967. As características deste sistema são, IBGE (1996):

- Superfície de Referência: Elipsóide Internacional de 1967;

- Semi-eixo maior: 6.378.160 metros;

- Achatamento: 1/298,25;

- Ponto datum: Vértice Chuá, localizado próximo à cidade de Uberaba (MG)

\begin{tabular}{ccc}
\hline Coordenadas & Astronômica & Geodésica \\
\hline Latitude & $19^{0} 45^{\prime} 14,34^{\prime \prime} \mathrm{S}$ & $19^{0} 45^{\prime} 41,6527^{\prime \prime} \mathrm{S}$ \\
Longitude & $48^{0} 06^{\prime} 07,80^{\prime \prime} \mathrm{W}$ & $48^{0} 06^{\prime} 04,0639^{\prime \prime} \mathrm{W}$ \\
Azimute & $271^{0} 30^{\prime} 05,42^{\prime \prime}$ & $271^{0} 30^{\prime} 04,05^{\prime \prime}$ \\
\hline
\end{tabular}

- Altitude ortométrica: 763,280 metros;

• Orientação elipsóide-geóide no ponto datum: $\xi=0,31 ", \eta=-3,52 ", N=0$ metros.

O SGB é um sistema parcialmente arbitrado, pois, determinou-se astronomicamente a latitude, a longitude e o azimute no vértice Chuá. As componentes do desvio da vertical foram obtidas via gravimetria. Assim, de posse das coordenadas astronômicas e das componentes do desvio da vertical estabeleceuse as coordenadas geodésicas no datum.

\subsection{Redes de controle horizontal}

Os pontos de controle de redes de controle horizontal denominam-se pontos trigonométricos (VT's). Os pontos de primeira ordem ou pontos de triangulação primaria estão separados uns dos outros de 30 a 60 Km, TORGE (1983). 
Os pontos de controle podem ser determinados por métodos de triangulação, trilateração e poligonação, ASHKENAZI (1973) apud TORGE (1983). Atualmente, o advento da tecnologia GPS mudou o conceito de posicionamento de pontos geodésicos. O sistema GPS permite aos usuários determinar coordenadas de pontos expressas em latitude, longitude e altura geométrica em função das coordenadas cartesianas $X, Y, Z$ em relação ao centro de massa da Terra.

\subsubsection{Determinação de pontos de controle horizontais através de triangulação}

A determinação da triangulação de primeira ordem (lados de 30-60 Km) tem por objetivos:

a) científico (como contribuição ao melhor conhecimento da forma da Terra);

b) cartográfico (fornecendo apoio uniforme aos trabalhos de mapeamento).

A determinação da triangulação de segunda ordem (lados de 10-20 Km) tem sempre o objetivo prático de fornecer apoio aos trabalhos de mapeamento ou a outras obras de engenharia.

A triangulação de primeira ordem é desenvolvida segundo cadeias de quadriláteros completos localizados ao longo de meridianos e paralelos afastados $2^{\circ}$ uns dos outros, constituindo as malhas de um arcabouço que se estende por toda uma região.

A triangulação de segunda ordem destina-se à decomposição das figuras de primeira ordem e ao preenchimento do espaço interior de cada malha.

A triangulação de terceira ordem é essencialmente descontínua e visa densificar o apoio básico às operações topográficas.

Nas regiões não abrangidas pelas cadeias de primeira ordem, o mapeamento pode ser apoiado em redes locais de segunda ou terceira ordem, que apresentam datum horizontal próprio, determinado por observações astronômicas. Atualmente este problema é contornado com o uso do GPS.

Em uma triangulação observa-se todos os ângulos dos triângulos formados pelos VT's do quadrilátero completo. A escala e a orientação da rede é obtida através da determinação do comprimento e do azimute de um dos lados do quadrilátero. Para evitar erros sistemáticos de escala, tais medidas devem ser feitas a 
cada $200 \mathrm{Km}$, TORGE (1983). A figura 3.1 ilustra um quadrilátero completo, onde, partindo-se da base $\mathrm{AB}$, triângulos são resolvidos até chegar à base $\mathrm{DC}$.

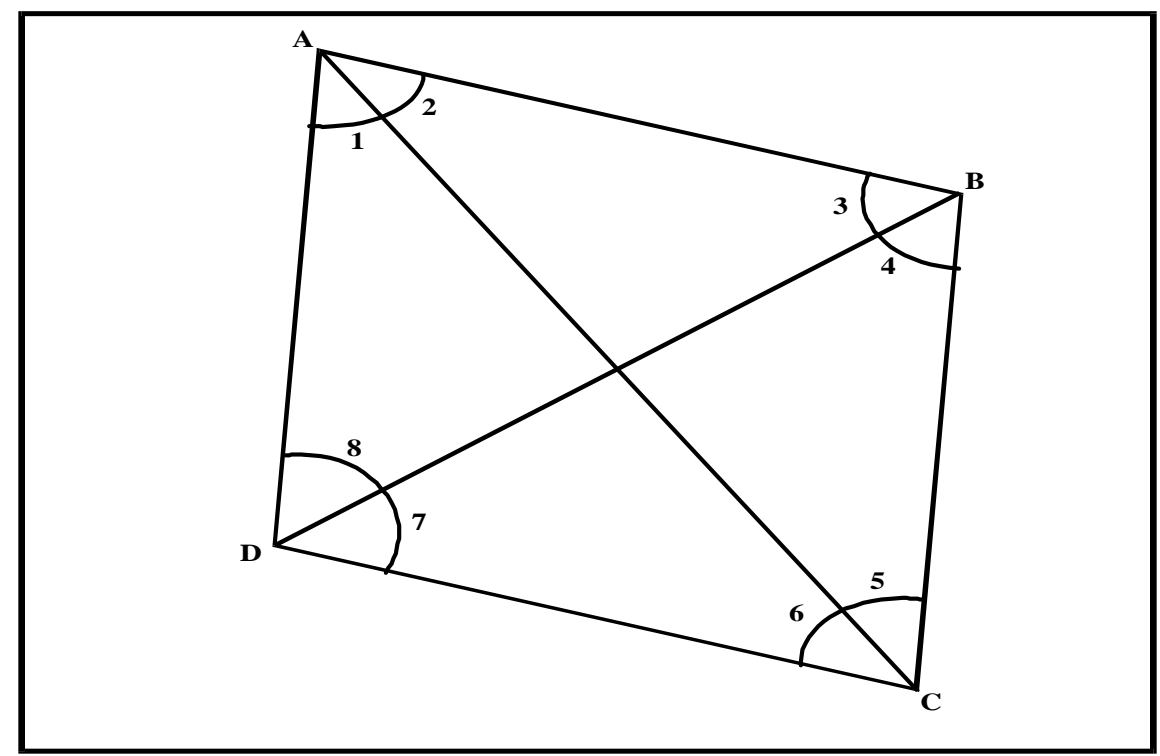

FIGURA 3.1 - Ilustração de um quadrilátero completo de uma triangulação

Com os ângulos observados, pode-se fazer os cálculos de uma triangulação clássica por quatro caminhos diferentes. Sabe-se, entretanto, que um deles fornecerá menor erro. O menor erro será cometido quando o cálculo é situado no triângulo que tem os ângulos melhores configurados. Essa melhor configuração é determinada pelo coeficiente de rigidez $(R)$, GEMAEL (1994):

$$
R=\frac{D-C}{D} \cdot \sum\left(\delta_{A_{i}}^{2}+\delta_{A_{i}} \cdot \delta_{B_{i}}+\delta_{B_{i}}{ }^{2}\right)
$$

onde:

- $D$ é igual ao número de novas direções observadas nos dois sentidos;

- $C$ é igual ao número de equações de condição;

- $\delta_{A} e \delta_{B}$ é igual às diferenças logarítmicas da variação do seno de 1" e unidade da sexta casa decimal dos ângulos distâncias. Os ângulos distâncias são os dois ângulos de um triângulo que se opõem ao lado conhecido e ao lado que se deseja calcular. Temos ainda, GEMAEL (1994): 


$$
\begin{aligned}
& D=L+L^{\prime}-2 \\
& C=\left(L^{\prime}-p^{\prime}+1\right)+(L-2 \cdot p+3)
\end{aligned}
$$

onde:

- L é igual ao número total de lados da figura;

- L' é igual ao número de lados observados em ambas as direções;

- $p$ é igual ao número total de vértices;

- $p^{\prime}$ é igual ao número de vértices ocupados.

\subsubsection{Ajustamento de uma triangulação geodésica}

Os lados de um triângulo geodésico são de dimensões tais que fogem do alcance da Topografia, e deve-se considerar a esfericidade da Terra. A soma dos ângulos internos é sempre maior que $180^{\circ}$, surgindo o denominado excesso esférico (ع). A figura 3.2 ilustra o problema:

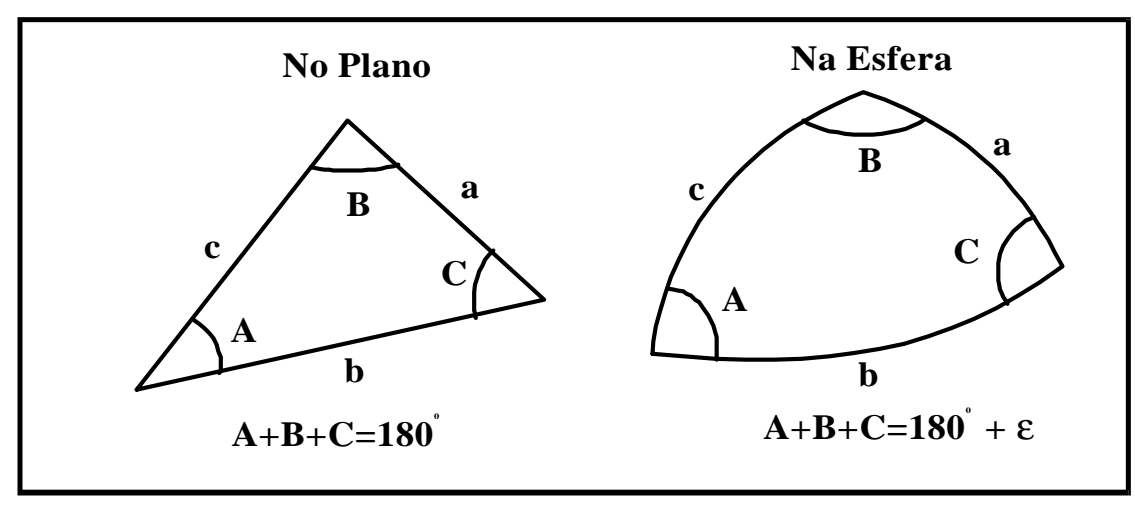

FIGURA 3.2 - Ilustração do excesso esférico em um triângulo geodésico

Para calcular o excesso esférico, utiliza-se do fato de que ele é proporcional à área do triângulo esférico, ou seja:

$$
\varepsilon_{\text {rad }}=\frac{S}{R^{2}}
$$

onde: 
- $\varepsilon$ é igual ao excesso esférico

- $S$ é igual a área do triângulo esférico;

$\checkmark R$ é igual ao raio médio da esfera local.

Considerando o triângulo esférico como se fosse plano, pode-se calcular a sua área por:

$$
S=\frac{1}{2} \cdot b \cdot h
$$

sendo:

$$
h=a \cdot \operatorname{sen} C
$$

Substituindo a (3.6) na (3.5) tem-se:

$$
S=\frac{1}{2} \cdot a \cdot b \cdot \operatorname{sen} C
$$

O raio da esfera é o raio médio e pode ser calculado por

$$
R=\sqrt{M \cdot N}
$$

onde:

- $R$ é igual ao Raio Médio de Curvatura da esfera;

- $M$ é igual ao raio de curvatura da seção meridiana;

- $N$ é igual ao raio de curvatura da seção primeira vertical.

Substituindo a (3.7) e a (3.8) na (3.4) tem-se a expressão que permite calcular o excesso esférico:

$$
\varepsilon^{\prime \prime}=\frac{a \cdot b \cdot \operatorname{sen} C}{2 \cdot M \cdot N \cdot \operatorname{sen} 1^{\prime \prime}}
$$


Pode-se realizar o ajustamento de redes de triangulações geodésicas tanto pelo método paramétrico quanto pelo método dos correlatos. Quando o método utilizado corresponde ao dos correlatos, formula-se equações de condições para os triângulos que formam o quadrilátero completo. Assim, é importante neste ajustamento a determinação do número de equações de condição.

\subsection{Número de equações de condição}

Formula-se em uma triangulação dois tipos de equações: de ângulos e de lados, onde o número total de equações é, GEMAEL (1994):

$$
c=n-2 v+4
$$

onde:

•v é o número total de vértice;

- $n$ é o número de ângulos medidos e independentes;

- c é o número total de equações.

O número de equações de ângulos é, GEMAEL (1994):

$$
c_{a}=I_{2}-v_{2}+1
$$

onde:

- $I_{2}$ é o número de linhas visadas em ambas as direções;

- $v_{2}$ é o numero de vértices ocupados;

- $c_{a}$ é o número de equações de ângulos.

No caso do quadrilátero completo tem-se três equações de ângulos, independentes entre si $\left(I_{2}=6\right.$ e $\left.v_{2}=4\right)$.

O número de equações de lado é, GEMAEL (1994):

$$
c_{L}=I-2 \cdot v+3
$$


onde

• I é o número total de linhas visadas;

- $v$ é o número total de vértices;

- $c_{L}$ é o número de equações de lado.

No caso do quadrilátero completo temos uma equação de lado $(I=6 e v=4)$.

Do quadrilátero pode-se tirar quatro triângulos, o que a primeira vista até parece que se pode formular 4 equações de ângulos. Porém, apenas três destes triângulos são independentes e que devem ser tomados na formulação das equações.

Na escolha dos triângulos, fixa-se um dos vértices como sendo polo, e tomase os três triângulos que possuem este em comum, excluindo o quarto triângulo. Para escolher o polo, utiliza-se o critério de que este deve ser o vértice que possua a maior soma dos ângulos. Para exemplificar um exemplo de ajustamento tomaremos como polo o vértice $\mathrm{C}$ do quadrilátero da figura 3.1. Neste caso os triângulos são: $\mathrm{ABC}, \mathrm{ADC}$ e CBD.

A equação do triângulo ABC poderá ser formulada da seguinte forma:

$$
(2)^{\mathrm{a}}+(3+4)^{\mathrm{a}}+(5)^{\mathrm{a}}=180+\varepsilon
$$

mas:

$$
\begin{aligned}
& (2)^{\mathrm{a}}=(2)+v_{2} \\
& (3+4)^{\mathrm{a}}=(3)+v_{3}+(4)+v_{4} \\
& (5)^{\mathrm{a}}=(5)+v_{5}
\end{aligned}
$$

onde $v_{\mathrm{i}}$ é o resíduo do ângulo e o índice "a" indica ângulo ajustado.

Substituindo (3.14), (3.15) e (3.16) na (3.13) tem-se:

$$
\begin{aligned}
& (2)+(3)+(4)+(5)+v_{2}+v_{3}+v_{4}+v_{5}=180+\varepsilon \\
& (2)+(3)+(4)+(5)-180-\varepsilon=w_{1}
\end{aligned}
$$

que é o erro de fechamento deste triângulo. 
Da mesma forma, para os demais triângulos elabora-se as duas equações restantes de condição de ângulos.

No que diz respeito à equação de lado, para a sua formulação usa-se o polo, escolhido conforme critério descrito anteriormente. Para isto utiliza-se o seguinte artifício:

$$
\frac{C B}{C A} \cdot \frac{C A}{C D} \cdot \frac{C D}{C B}=1
$$

Aplicando-se a lei dos senos nos triângulos escolhidos anteriormente, obtémse,

$$
\begin{aligned}
& \frac{C B}{C A}=\frac{\operatorname{sen}(a)^{a}}{\operatorname{sen}(3+4)^{a}} \\
& \frac{C A}{C D}=\frac{\operatorname{sen}(7+8)^{a}}{\operatorname{sen}(1)^{a}} \\
& \frac{C D}{C B}=\frac{\operatorname{sen}(4)^{a}}{\operatorname{sen}(7)^{a}}
\end{aligned}
$$

que substituindo na eq.(3.19) e considerando os resíduos tem-se:

$$
\frac{\operatorname{sen}\left(2+v_{2}\right)}{\operatorname{sen}\left(3+4+v_{3}+v_{4}\right)} \cdot \frac{\operatorname{sen}\left(7+8+v_{7}+v_{8}\right)}{\operatorname{sen}\left(1+v_{1}\right)} \cdot \frac{\operatorname{sen}\left(4+v_{4}\right)}{\operatorname{sen}\left(7+v_{7}\right)}=1
$$

A eq.(3.21) corresponde à equação de lado, que, como se pode perceber, não é uma equação linear, necessitando assim ser linearizada. Na literatura clássica, o método de linearização apresentado é o da logaritmação, podendo também ser linearizada através do desenvolvimento de Taylor.

Utilizando a logaritmação nos dois lados da igualdade da eq.(3.21), obtémse: 


$$
\log \frac{\operatorname{sen}\left(2+v_{2}\right)}{\operatorname{sen}\left(3+4+v_{3}+v_{4}\right)} \cdot \frac{\operatorname{sen}\left(7+8+v_{7}+v_{8}\right)}{\operatorname{sen}\left(1+v_{1}\right)} \cdot \frac{\operatorname{sen}\left(4+v_{4}\right)}{\operatorname{sen}\left(7+v_{7}\right)}=\log 1
$$

Desenvolvendo a (3.22) tem-se:

$$
\begin{aligned}
& \log \operatorname{sen}\left(2+v_{2}\right)+\log \operatorname{sen}\left(7+8+v_{7}+v_{8}\right)+\log \operatorname{sen}\left(4+v_{4}\right)-\log \operatorname{sen}\left(3+4+v_{3}+v_{4}\right) \\
& -\log \operatorname{sen}\left(1+v_{1}\right)-\log \operatorname{sen}\left(7+v_{7}\right)=0
\end{aligned}
$$

Mas os resíduos são muito pequenos, podendo-se fazer a seguinte simplificação:

$\log \operatorname{sen}\left(\mathrm{i}+v_{\mathrm{i}}\right) .=\log \operatorname{sen}(\mathrm{i})+v_{\mathrm{i}} \cdot \Delta_{\mathrm{i}}$, onde $\Delta_{\mathrm{i}}$ representa a variação de $1 "$ no arco, ou seja, a diferença tabular para 1" em unidades da sexta casa decimal. Para uma melhor compreensão, suponha o exemplo de um ângulo de $22^{\circ} 31^{\prime} 04,10^{\prime \prime}$. Neste caso tem-se:

$$
\begin{aligned}
& \Delta_{\mathrm{i}}=\log \operatorname{sen}\left(\mathrm{i}+1^{\prime \prime}\right)-\operatorname{logsen}(\mathrm{i}) \\
& \Delta_{\mathrm{i}}=\log \operatorname{sen}\left(22^{\circ} 31^{\prime} 05,10^{\prime \prime}\right)-\log \operatorname{sen}\left(22^{\circ} 31^{\prime} 04,10^{\prime \prime}\right) \\
& \Delta_{\mathrm{i}}=0,000005078
\end{aligned}
$$

Logo $\Delta_{\mathrm{i}}$ é igual a (+ 5,078). Assim retornando-se à equação de lado tem-se:

$$
\begin{aligned}
& \operatorname{logsen}(2)+v_{2} \cdot \Delta_{2}+\operatorname{logsen}(7+8)+\left(v_{7}+v_{8}\right) \cdot \Delta_{7+8}+\log \operatorname{sen}(4)+\left(v_{4}\right) \cdot \Delta_{4}- \\
& \operatorname{logsen}(3+4)-\left(v_{3}+v_{4}\right) \cdot \Delta_{3+4}-\log \operatorname{sen}(1)-\left(v_{1}\right) \cdot \Delta_{1}-\log \operatorname{sen}(7)-\left(v_{7}\right) \cdot \Delta_{7}=0
\end{aligned}
$$

$\log \operatorname{sen}(2)+\log \operatorname{sen}(7+8)+\log \operatorname{sen}(4)-\log \operatorname{sen}(3+4)-\log \operatorname{sen}(1)-\log \operatorname{sen}(7)+v_{2} \cdot \Delta_{2}$ $+\left(v_{7}+v_{8}\right) \cdot \Delta_{7+8}+\left(v_{4}\right) \cdot \Delta_{4}-\left(v_{3}+v_{4}\right) \cdot \Delta_{3+4}-\left(v_{1}\right) \cdot \Delta_{1}-\left(v_{7}\right) \cdot \Delta_{7}=0$

Assim o erro de fechamento e a equação de lado linearizada neste exemplo é:

$$
\begin{aligned}
& \log \operatorname{sen}(2)+\log \operatorname{sen}(7+8)+\log \operatorname{sen}(4)-\log \operatorname{sen}(3+4)-\log \operatorname{sen}(1)-\log \operatorname{sen}(7)=w_{4} \\
& v_{2} \cdot \Delta_{2}+\left(v_{7}+v_{8}\right) \cdot \Delta_{7+8}+\left(v_{4}\right) \cdot \Delta_{4}-\left(v_{3}+v_{4}\right) \cdot \Delta_{3+4}-\left(v_{1}\right) \cdot \Delta_{1}-\left(v_{7}\right) \cdot \Delta_{7} \cdot+w_{4}=0
\end{aligned}
$$


Tem-se então para este exemplo as quatro equações de condições completas:

$$
\begin{aligned}
& 0 \cdot v_{1}+1 \cdot v_{2}+1 \cdot v_{3}+1 \cdot v_{4}+1 \cdot v_{5}+0 \cdot v_{6}+0 \cdot v_{7}+0 \cdot v_{8}-w_{1}=0 \\
& 1 \cdot v_{1}+0 \cdot v_{2}+0 \cdot v_{3}+0 \cdot v_{4}+0 \cdot v_{5}+1 \cdot v_{6}+1 \cdot v_{7}+1 \cdot v_{8}-w_{2}=0 \\
& 0 \cdot v_{1}+0 \cdot v_{2}+0 \cdot v_{3}+1 \cdot v_{4}+1 \cdot v_{5}+1 \cdot v_{6}+1 \cdot v_{7}+0 \cdot v_{8}-w_{3}=0 \\
& -\left(v_{1}\right) \cdot \Delta_{1}+v_{2} \cdot \Delta_{2}+\left(v_{7}+v_{8}\right) \cdot \Delta_{7+8}+\left(v_{4}\right) \cdot \Delta_{4}-\left(v_{3}+v_{4}\right) \cdot \Delta_{3+4}-\left(v_{7}\right) \cdot \Delta_{7}+w_{4}=0
\end{aligned}
$$

Pode-se então colocar na forma matricial :

$$
B . V+W=0
$$

onde:

- $B$ é igual a matriz dos coeficientes;

- $V$ é o vetor dos resíduos;

- $W$ é o vetor dos erros de fechamento

Uma vez formuladas as equações de condições é só aplicar o método dos correlatos:

$$
\boldsymbol{V}=P^{-1} \cdot B^{T} \cdot K
$$

sendo $K$ o multiplicador de Lagrange e é obtido por:

$$
K=-\left(B \cdot P^{-1} \cdot B^{T}\right)^{-1} \cdot \boldsymbol{W}
$$

Conhecido o vetor dos resíduos, pode-se então chegar nas observações ajustadas que são os ângulos da triangulação.

$$
L_{a}=L_{b}+\boldsymbol{V}
$$




\subsubsection{Determinação de pontos de controle horizontais através da trilateração}

O método da trilateração possui o mesmo princípio da triangulação, onde neste caso em vez de ângulos medem-se as distâncias dos lados dos triângulos, bem como as diagonais possíveis para obter um número suficiente de determinações redundantes da rede. Atualmente, a trilateração vem adquirindo um papel importante na determinação de coordenadas horizontais devido ao desenvolvimento das estações totais eletrônicas.

\subsubsection{Determinação de pontos de controle horizontais através da poligonação}

O desenvolvimento de redes de controle através da poligonação é muito mais econômico. Neste método de determinação de posições horizontais, lados são medidos através de distanciômetros eletrônicos e os ângulos da poligonal com teodolitos. Atualmente, isto vem sendo feito com as estações totais.

Com o advento dos distanciômetros eletrônicos, e com um constante aprimoramento destes equipamentos, a poligonação passou a desenvolver um papel fundamental para os levantamentos geodésicos, pois é um método de determinação de coordenadas rápido e conveniente.

Na Geodésia, a poligonação é utilizada sempre que há uma restrição na visibilidade devido a acidentes naturais e construções, substituindo, neste caso, a triangulação.

Quanto a precisão, a poligonal pode ser dividida em:

- de primeira ordem, utilizada para controle preciso de estações horizontais;

- de segunda ordem, quando é apoiada em pontos de primeira ordem;

- de terceira ordem, quando é apoiada em pontos de segunda ordem.

Quanto ao controle as poligonais classificam em:

- poligonais abertas, quando o último vértice não está amarrado a nenhum vértice de coordenadas conhecidas, impossibilitando o controle azimutal e de escala;

-poligonais fechadas, quando parte de um vértice de coordenadas conhecidas e chega-se a outro também de coordenadas conhecidas. Neste caso tem-se um controle de escala e também azimutal. Nesta mesma classe 
de poligonais temos também às em "loop", ou seja, parte-se de um vértice de coordenadas conhecidas e chega-se no mesmo vértice, formando-se um polígono fechado. Este tipo de poligonal não é aconselhável para trabalhos de alta precisão, pois não se tem um controle de escala.

O cálculo de uma poligonal constitui no transporte das coordenadas do ponto de partida ao ponto de chegada, passando pelas estações intermediárias que realmente são objetos do levantamento, SILVA e GRIPP (1996).

Uma etapa que antecipa o cálculo de uma poligonal, há a necessidade de se reduzir os valores observados (ângulos e distâncias). Estas reduções são correções necessárias para a eliminação dos erros sistemáticos das grandezas envolvidas, ou melhor dizendo, situar estas grandezas em um mesmo modelo de cálculo.

\subsubsection{Cálculos das posições horizontais de uma rede geodésica}

Primeiramente, antes de entrar nos modelos matemáticos de cálculos de posições horizontais, é importante salientar alguns conceitos importantes envolvidos na Geodésia.

\subsubsection{Seções normais recíprocas}

A normal ao elipsóide no ponto $P_{1}$, no mesmo meridiano que $P_{2}$, intercepta o eixo menor em $Q_{1}$. A normal no ponto $P_{2}$ intercepta o eixo menor (eixo de rotação) em $Q_{2}$. Essas normais estão num mesmo plano e, portanto, se interceptam em " $i$ ", SILVA e GRIPP (1996). A figura 3.3 ilustra o problema: 


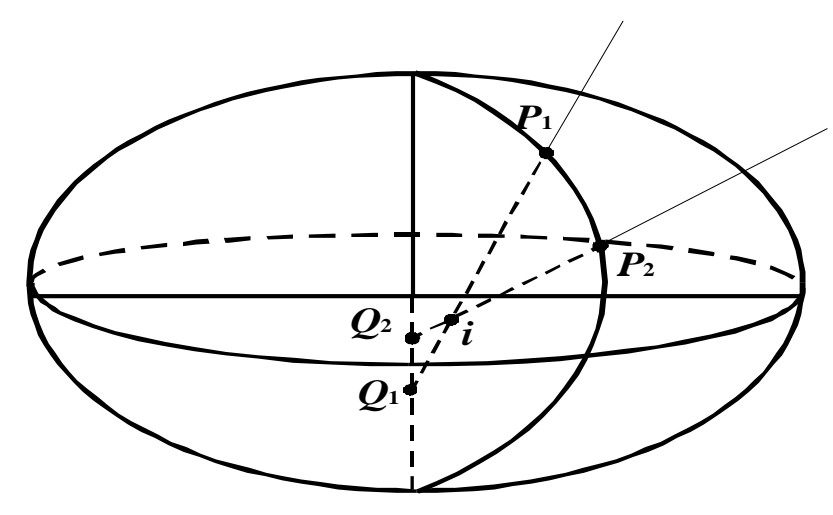

FIGURA 3.3 - Normais ao elipsóide em pontos de mesmo meridiano

Se, em vez de estarem no mesmo meridiano, as normais se situarem no mesmo paralelo, elas irão interceptar em $j$, situado sobre o eixo de rotação, SILVA e GRIPP (1996). A figura 3.4 ilustra o problema:

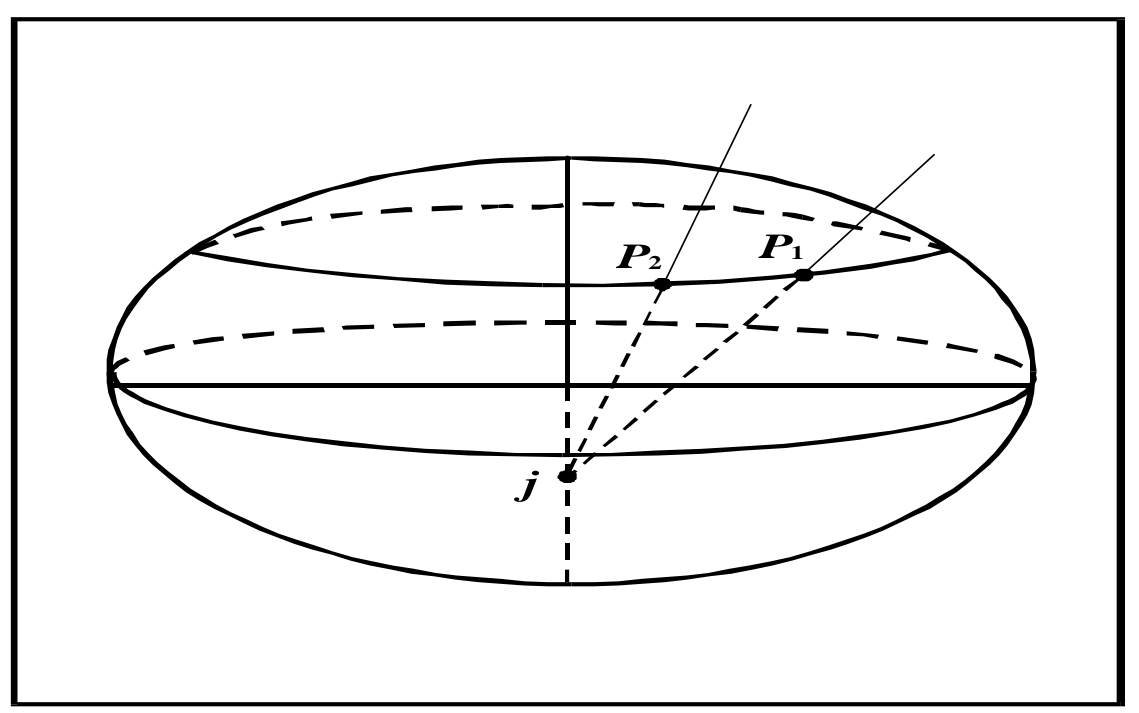

FIGURA 3.4 - Normais ao elipsóide em pontos de mesmo paralelo

Como as normais de um mesmo meridiano, estas também estão num mesmo plano. 
Se, no entanto, as normais ao elipsóide se encontrarem em paralelos e meridianos diferentes, como as normais $P_{1}$ e $P_{2}$ da figura 3.5 , elas não se interceptam, embora encontrem o eixo de rotação. Do exposto, vemos que elas não pertencem a um mesmo plano, SILVA e GRIPP (1996). A figura 3.5 ilustra o problema:

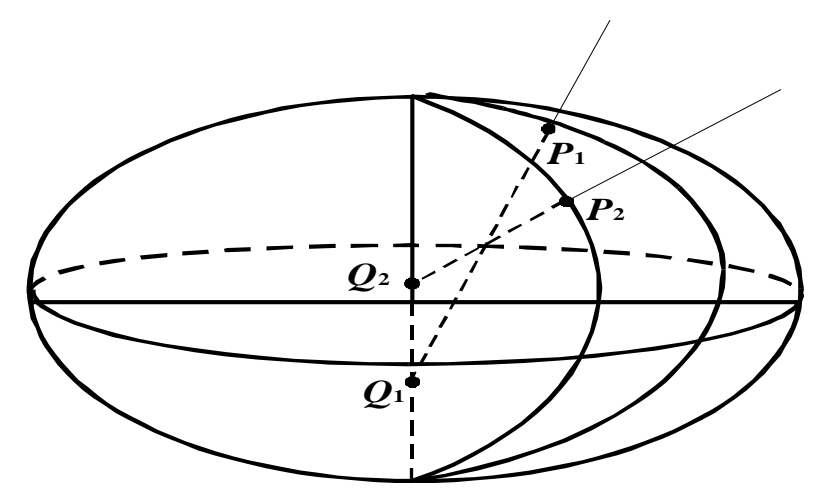

FIGURA 3.5 - Normais ao elipsóide em pontos localizados em paralelos e meridianos diferentes

Se imaginarmos um teodolito instalado e nivelado em $P_{1}$, quando visarmos o ponto $P_{2}$ tem-se o plano de visada $P_{1} P_{2}$. Se agora, o teodolito estiver instalado e nivelado em $P_{2}$, ao visar $P_{1}$ tem-se o plano de visada $P_{2} P_{1}$. Em outras palavras, no primeiro caso, o plano de visada contém a normal em $P_{1}$, não contendo a normal em $P_{2}$. No segundo caso, conterá a normal em $P_{2}$ não contendo a normal em $P_{1}$.

Do que foi escrito acima, pode-se inferir que no elipsóide, quando dois pontos não pertencem ao mesmo paralelo ou ao mesmo meridiano, tem entre eles duas seções normais. A estas seções normais é dado o nome de seções normais recíprocas. A seção normal que contém a normal em $P_{1}$ é dita direta em relação a $P_{1}$ e recíproca em relação a $P_{2}$. A seção que contém a normal em $P_{2}$ é dita direta em relação a este ponto e recíproca em relação a $P_{1}$, SILVA e GRIPP (1996).

Qual seria o menor caminho entre $P_{1}$ e $P_{2}$ sobre a superfície elipsoidal? O menor caminho entre $P_{1}$ e $P_{2}$ é uma linha, tal que, em todos os seus pontos o plano 
osculador é normal à superfície elipsoidal. Essa linha assim definida, chama-se linha geodésica.

O plano osculador é o plano normal à superfície e contém a tangente à linha geodésica, ou seja, a tangente à curva no ponto considerado, SILVA e GRIPP (1996).

Devido a não coincidência das seções normais direta e inversa entre dois pontos, as normais ao elipsóide nesses dois pontos não pertencem a um mesmo plano. Uma das normais estará inclinada em relação à outra. Em virtude disso, haverá um erro na observação do ângulo azimutal, dependendo da altitude do ponto que está sendo observado.

Supondo uma visada de A para B, em que o ponto B está situado a uma altura geométrica $h$, em um lugar de latitude $\phi$, e ainda sendo conhecido o azimute $A_{z}$ da direção $\mathrm{AB}$, podemos calcular a correção do ângulo azimutal pela eq.(3.29), TORGE (1983):

$$
\delta^{\prime \prime}=\frac{e^{2} \cdot \cos ^{2} \phi \cdot \operatorname{sen}\left(2 \cdot A_{z}\right)}{2 \cdot N \cdot\left(1-e^{2}\right) \cdot \operatorname{sen} 1^{\prime \prime}} \cdot h
$$

onde:

- $\delta^{\prime \prime}=$ correção do ângulo azimutal em segundos;

$\bullet \phi=$ latitude do ponto observado;

$\bullet A_{z}=$ azimute da direção observada;

- $h$ = altura geométrica da estação observada, em metros;

- $N=$ raio de curvatura da seção primeira vertical no ponto do observador;

$\bullet e^{2}=$ primeira excentricidade do elipsóide.

Para aplicar a correção deve-se observar o seguinte: quando o ponto observado está a nordeste ou sudoeste do observador, o azimute observado deve ser aumentado para se obter o azimute correto na superfície do elipsóide; quando o ponto observado se encontra a noroeste ou sudeste do observador, o azimute deve ser diminuído. Esta correção é negligenciável para pequenas alturas. 


\subsubsection{2 Ângulo entre a linha geodésica e a seção normal}

Supondo dois observadores (A e B) sobre a superfície do elipsóide e o ponto A tendo latitude menor que a do ponto B. Se o observador instalar em A um teodolito, de tal maneira que o eixo vertical coincida com a normal ao elipsóide em A, e visar o ponto B, o plano de visada seccionará o elipsóide segundo uma linha AB. Se o observador em B fizer o mesmo com o teodolito, o eixo vertical deste coincidindo com a normal em $\mathrm{B}$, e visar o ponto $\mathrm{A}$, o plano de visada irá descrever a linha BA. As linhas $\mathrm{AB}$ e $\mathrm{BA}$ são pertencentes a planos diferentes porque as normais em A e B são inclinadas uma em relação a outra e não reproduzem o menor caminho entre A e B, porque este é feito pela linha geodésica. A figura 3.6 ilustra a situação.

É importante lembrar que nos triângulos geodésicos os lados nem podem ser do tipo $\mathrm{AB}$, nem $\mathrm{BA}$. Estes lados terão que ser únicos, isto é, feito por linhas geodésicas. $\mathrm{O}$ ângulo formado entre duas linhas geodésicas não pode ser observado, uma vez que, elas não são curvas planas e por causa disso, o triângulo geodésico só pode ser obtido através do cálculo.

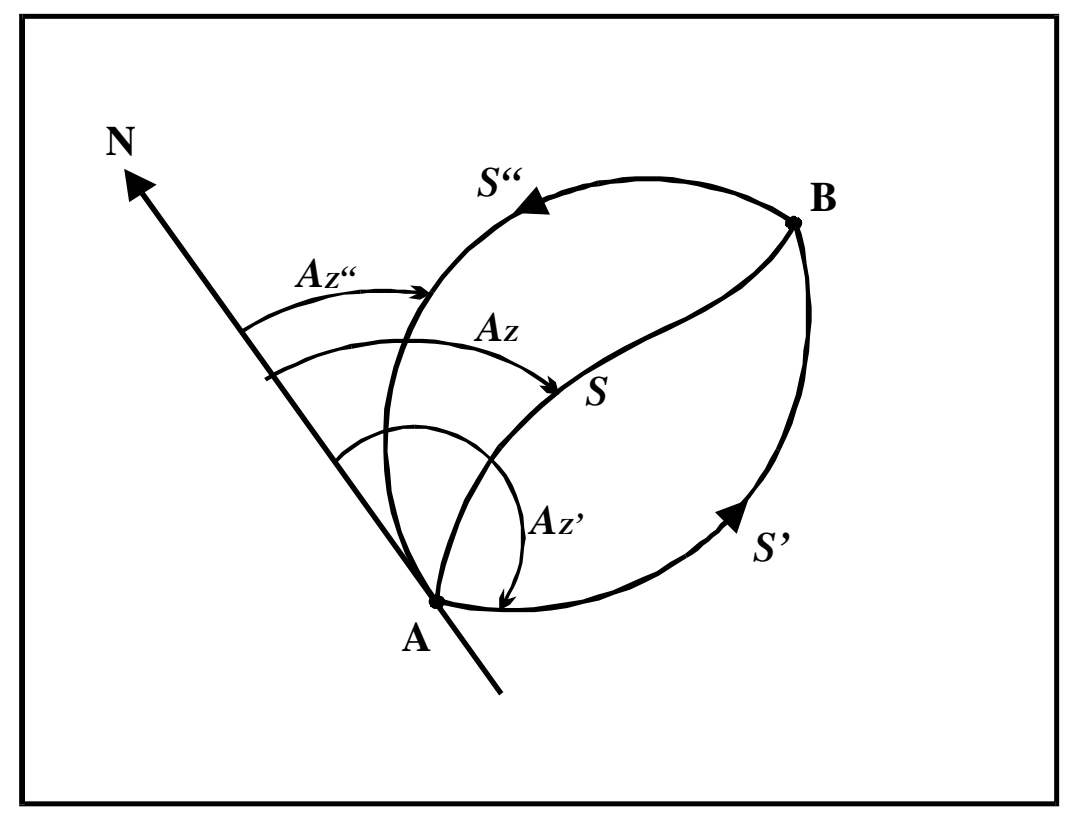

FIGURA 3.6 - Linha geodésica entre dois pontos. 
Através de uma expansão em série formula-se um importante sistema de equações diferenciais de primeira ordem relacionando azimute da seção normal direta $\left(A_{z}{ }^{\prime}\right)$, azimute da linha geodésica $\left(A_{z}\right)$, distância da seção normal direta $\left(S^{\prime}\right)$ e distância da linha geodésica $(S)$, TORGE (1983):

$$
\begin{aligned}
& A z^{\prime}-A z=\frac{e^{2}}{12 \cdot a^{2}} \cdot \cos ^{2} \phi_{A} \cdot S^{2} \operatorname{sen}^{2} 2 A z .+\ldots \ldots \ldots \ldots . \\
& S^{\prime}-S=\frac{e^{4}}{360 \cdot a^{4}} \cdot \cos ^{4} \phi_{A} \cdot S^{5} \operatorname{sen}^{2} 2 A z .+\ldots \ldots \ldots \ldots
\end{aligned}
$$

onde:

- $A z^{\prime}$ corresponde ao azimute da seção normal direta;

- Az corresponde ao azimute da linha geodésica;

- $S^{\prime}$ corresponde à distância da seção normal direta;

- $S$ corresponde à distância da linha geodésica;

- $\phi_{A}$ corresponde à latitude do ponto $\mathrm{A}$;

•" $a "$ corresponde ao semi-eixo maior do elipsóide.

Segundo VANICEK (1986), os cálculos elipsoidais podem ser substituídos por cálculos em uma esfera em uma triangulação de primeira ordem.

No cálculo de posições geodésicas utilizam-se diferentes fórmulas de geodesistas como Sodano, Robbins, Clarke, Puissant. No Brasil, geralmente utilizam-se as fórmulas de Puissant. Estas fórmulas fornecem resultados com precisão de 1ppm quando o comprimento dos lados envolvidos nos cálculos é menor que $80 \mathrm{Km}$. Para que essa precisão seja alcançada, os cálculos devem ser processados com pelo menos sete decimais, SILVA (1985).

Tanto na triangulação como na poligonação o transporte de coordenadas geodésicas se processa da mesma forma, obtendo-se as coordenadas geodésicas dos demais vértices.

Para efeito de cálculo o sinal da latitude é negativo no Hemisfério Sul e a longitude é negativa para pontos situados a oeste do Meridiano de Greenwich.

As fórmulas para a efetuação do transporte de coordenadas são baseadas em, SILVA (1985). 


\section{Formulário}

- $\phi_{1}=$ latitude do ponto inicial 1;

- $\phi_{2}=$ latitude do segundo ponto 2;

- $\lambda_{I}=$ longitude do ponto inicial 1 ;

$\bullet \lambda_{2}=$ longitude do segundo ponto 2 ;

- $A z_{12}=$ azimute da direção 1-2;

- $A z_{21}=$ azimute da direção 2-1;

- $S=$ distância de 1 a 2 (m).

\section{a) Problema direto}

São dados: $\phi_{1}, \lambda_{l}, A z_{12}, S$.

Calculam-se: $\phi_{2}, \lambda_{2}, A z_{21}$.

\section{a.1) Cálculo da latitude}

$$
\begin{aligned}
& \phi_{2}=\phi_{1}+\Delta \phi \\
& \Delta \phi^{\prime \prime}=\delta \phi^{\prime \prime}-D \cdot\left(\delta \phi^{\prime \prime}\right)^{2} \\
& \delta \phi^{\prime \prime}=(B \cdot S \cdot \cos A z)-\left(C \cdot S^{2} \cdot \operatorname{sen}^{2} A z\right)-\left(E \cdot h \cdot S^{2} \cdot \operatorname{sen}^{2} A z\right) \\
& h=B \cdot S \cdot \cos A z
\end{aligned}
$$

\section{a.2) Cálculo da longitude}

$$
\begin{aligned}
& \lambda_{2}=\lambda_{1}+\Delta \lambda \\
& \Delta \lambda^{\prime \prime}=\frac{S \cdot \operatorname{sen} A z}{\cos \phi_{2}} \cdot A
\end{aligned}
$$

\section{a.3) Cálculo do azimute da direção (2-1)}

$$
\begin{aligned}
& A z_{2-1}=A z_{1-2}+180^{\circ}+W \\
& W^{\prime \prime}=\frac{\operatorname{sen} \phi_{m} \cdot \Delta \lambda^{\prime \prime}}{\cos \left(\frac{\Delta \phi}{2}\right)}+\left(\Delta \lambda^{\prime \prime}\right)^{3} \cdot F m
\end{aligned}
$$


onde:

- $W^{\prime \prime}$ = convergência meridiana em segundos

- $\phi_{m}=\frac{\phi_{1}+\phi_{2}}{2}$

- $\frac{\Delta \phi}{2}=\frac{\phi_{2}-\phi_{1}}{2}$

- $\Delta \lambda^{\prime \prime}=\lambda_{2}-\lambda_{1}$

O índice " $m$ " nos coeficientes indica que no cálculo do coeficiente entra-se com a latitude média.

\section{b) Problema inverso}

São dados: $\phi_{2}, \lambda_{2}, \phi_{1}, \lambda_{1}$;

Calculam-se: $S, A z_{1-2}$.

\section{b.1) Cálculo de $X$ e $Y$}

$$
\begin{aligned}
& X=\frac{\Delta \lambda^{\prime \prime} \cdot \cos \phi_{2}}{A_{2}} \\
& Y=\frac{\Delta \phi^{\prime \prime}+X^{2} \cdot \Delta \phi^{\prime \prime} \cdot E m+\left(\Delta \phi^{\prime \prime}\right)^{2} \cdot D m}{B m}
\end{aligned}
$$

\section{b.2) Cálculo do azimute}

$$
\operatorname{tg} A z_{1-2}=\frac{X}{Y}
$$

\section{b.3) Cálculo da distância em metros}

$$
S=\sqrt{X^{2}+Y^{2}}
$$

Os coeficientes que aparecem nas expressões (3.32), (3.33), (3.34), (3.35), (3.36), (3.37) são calculados com as seguintes fórmulas: 


$$
\begin{aligned}
& A=\frac{1}{N \cdot \operatorname{sen} 1^{\prime \prime}} \\
& B=\frac{1}{M \cdot \operatorname{sen} 1^{\prime \prime}} \\
& C=\frac{\operatorname{tg} \phi}{2 \cdot M \cdot N \cdot \operatorname{sen} 1^{\prime \prime}} \\
& D=\frac{3 \cdot e^{2} \cdot \operatorname{sen} \phi \cdot \cos \phi \cdot \operatorname{sen} 1^{\prime \prime}}{2 \cdot\left(1-e^{2} \cdot \operatorname{sen}^{2} \phi\right)} \\
& E=\frac{1+3 \cdot \operatorname{tg}^{2} \phi}{6 \cdot N^{2}} \\
& F=\frac{\operatorname{sen} \phi \cdot \cos ^{2} \phi \cdot \operatorname{sen}^{2} 1^{\prime \prime}}{12}
\end{aligned}
$$

em que:

$$
\begin{aligned}
& M=\frac{a \cdot\left(1-e^{2}\right)}{\left(1-e^{2} \cdot \operatorname{sen}^{2} \phi\right)^{3 / 2}} \\
& N=\frac{a}{\left(1-e^{2} \cdot \operatorname{sen}^{2} \phi\right)^{1 / 2}}
\end{aligned}
$$

\subsubsection{Determinação de pontos de controle utilizando o sistema GPS}

O advento da tecnologia GPS mudou o conceito de rede geodésica. Os primeiros levantamentos realizados em 1983 obtiveram uma precisão interna da ordem de $1 \mathrm{ppm}$ e os valores discrepavam dos obtidos nas redes existentes, que apresentavam precisões da ordem de 10-20ppm, SEGANTINE (1995).

As observações com GPS, depois de processadas, fornecem coordenadas tridimensionais dos pontos da rede referenciadas no sistema geocêntrico WGS-84 $(X, Y, Z)$. De posse destas coordenadas cartesianas as mesmas podem ser transformadas para latitude e longitude e altura geométrica. Cabe verificar se este sistema condiz com o adotado na região (ou país) onde se desenvolve o trabalho. 
Os levantamentos executados com GPS apresentam, como característica, observar em quaisquer condições atmosféricas, e hoje, com a constelação de satélites completa, garante-se 24 horas por dia de operações de campo.

O planejamento estratégico de uma rede geodésica pode ser baseada nos seguintes princípios, SEGANTINE (1995):

- todas as estações devem ser consideradas da mesma maneira (conhecidas ou não);

- somente vetores independentes devem ser considerados no planejamento: este princípio tem o efeito de conferir, à rede uma forte correlação entre todas as combinações de linhas bases, formadas geometricamente;

- a rede pode se formadas por quadriláteros com vetores independentes: este princípio implica numa grande rede na qual o número de graus de liberdade seja igual ao número de incógnitas. Este método permite uma alta precisão relativa, em particular se os quadriláteros forem subdivididos em triângulos, mas esta operação é muito laboriosa.

Assim, segundo SEEBER (1993), são três as estratégicas básicas de observação:

- Posicionamento absoluto: uma posição absoluta pode ser determinada continuamente com uma precisão de 10 a $15 \mathrm{~m}$, sem o efeito do SA (Selective Availability), e com precisão de 30 a 50m sob o efeito do SA. Mesmo executando observações de vários dias, a melhor precisão alcançada é da ordem de 3 a $5 \mathrm{~m}^{*}$;

- Posicionamento relativo: pode ser aplicado para uma antena móvel ou estacionária;

- Conceito de multi-estação: este método ocupa pontos adjacentes, formando quadriláteros ou triângulos e permite uma alta precisão relativa. $\mathrm{O}$ uso de mais de dois receptores é mais rápido e econômico, mesmo para pequenas

\footnotetext{
"Nos dias atuais, comprovou-se em algumas pesquisas realizadas no Departamento de Transportes da Escola de Engenharia de São Carlos - USP, utilizando receptores da LEICA, que precisões da ordem de 0,60 a $1,0 \mathrm{~m}$ podem ser obtidas em posicionamento absoluto realizando observações entre seis a oito horas.
} 
redes. Quando dois ou mais receptores observam simultaneamente, a rede consiste de todas as estações co-observadas e apresenta uma correlação entre os vetores dos pontos considerados.

Existem vários parâmetros que indicam a qualidade do levantamento realizado. $\mathrm{O}$ primeiro envolve análises relativas à estatísticas dos vetores individuais. O critério para se determinar quais vetores são ruins, é comparar estatisticamente uma base boa com uma base ruim. A variação brusca do Erro Médio Quadrático (RMS) é um bom indicador de que uma base apresenta problemas. No caso de redes, o procedimento de verificação de bases problemáticas é o uso de programas que processam fechamento de figuras geométricas.

Eliminadas as bases problemáticas, um ajustamento pelo método dos mínimos quadrados é realizado, onde para isso a fixação de uma estação é feito. Esta fixação das coordenadas recebe o nome de injunção mínima. Assim, as demais coordenadas calculadas no ajustamento serão obtidas em função destas coordenadas.

No Brasil, pode-se citar um exemplo de rede geodésica com GPS que é a rede GPS no Estado de São Paulo composta por 25 estações, SEGANTINE (1995).

Internacionalmente, podemos citar como exemplo de rede GPS a rede CIGNET (Cooperative International GPS Network). Esta rede é formada por mais de 140 estações (apenas 59 destas estações são consideradas integrantes da rede global). São mantidas por várias agências nacionais. Esta rede opera em colaboração com a National Geodetic Survey (NGS), com estações monitoras que utilizam o Very Long Baseline Interferometer (VLBI) e o rastreamento contínuo com o GPS.

\subsection{Redes de controle vertical}

As redes altimétricas ou verticais, segundo CASTAÑEDA (1986), correspondem à conjuntos de estações terrestres para cada uma das quais se determina com precisão apenas sua altitude ortométrica $(H)$.

O motivo da disjunção entre as redes horizontais e verticais é eminentemente histórico, pois no passado, era mais vantajoso, tanto no aspecto operacional, quanto no econômico, proceder-se determinações altimétricas e planimétricas separadamente. 
É evidente, contudo, que as estações de uma rede vertical devem dispor de pares coordenados $(\phi, \lambda)$ referentes a algum sistema geodésico, ainda que imprecisos, de maneira a possibilitar sua representação cartográfica.

Foi introduzido no item 3.1 que o Geóide corresponde a uma superfície de referência para as altitudes ortométricas. Na prática, a materialização de um datum geodésico vertical se dá através da especificação de um ponto com altitude ortométrica nula $(H=0)$ com o propósito de vincular uma rede vertical numa região qualquer de interesse.

No Brasil, definiu-se a cota zero da rede altimétrica fundamental na baia de Imbituba, Estado de Santa Catarina, em trabalho supervisionado pela fundação IBGE.

As operações de campo que originam as principais informações necessárias ao transporte de altitudes ortométricas, a partir de estações já definidas altimetricamente, recebem a denominação geral de nivelamento, CASTAÑEDA (1986).

Metodologicamente, podemos dividir um nivelamento em três classes: geométrico, trigonométrico e barométrico.

O nivelamento geométrico proporciona a mais elevada exatidão. O mesmo é conduzido ao longo de circuitos fechados, possibilitando um controle da propagação de erros.

Durante o percurso são implantadas as Referências de Níveis (RN's ), que são pontos cotados correspondentes às extremidades de seções de nivelamento que normalmente acompanham margens de rodovias e ferrovias. Em média, a extensão de uma seção de nivelamento é da ordem de $3 \mathrm{~km}$, os quais se subdividem em segmentos de no máximo 200m, denominados lances de nivelamento. Nestes lances se realizam leituras a ré e a vante por um instrumento nivelador (nível), com réguas especiais (miras), verticalmente posicionadas a meio lance de cada mira. Nos trabalhos mais rigorosos ( $1^{\mathrm{a}}$ ordem), cada seção é nivelada nos dois sentidos.

A precisão de um nivelamento é obtido através de uma propagação de erros entre as diferenças de leitura de ré e de vante (figura 3.7). Esta precisão é demonstrado a seguir: 


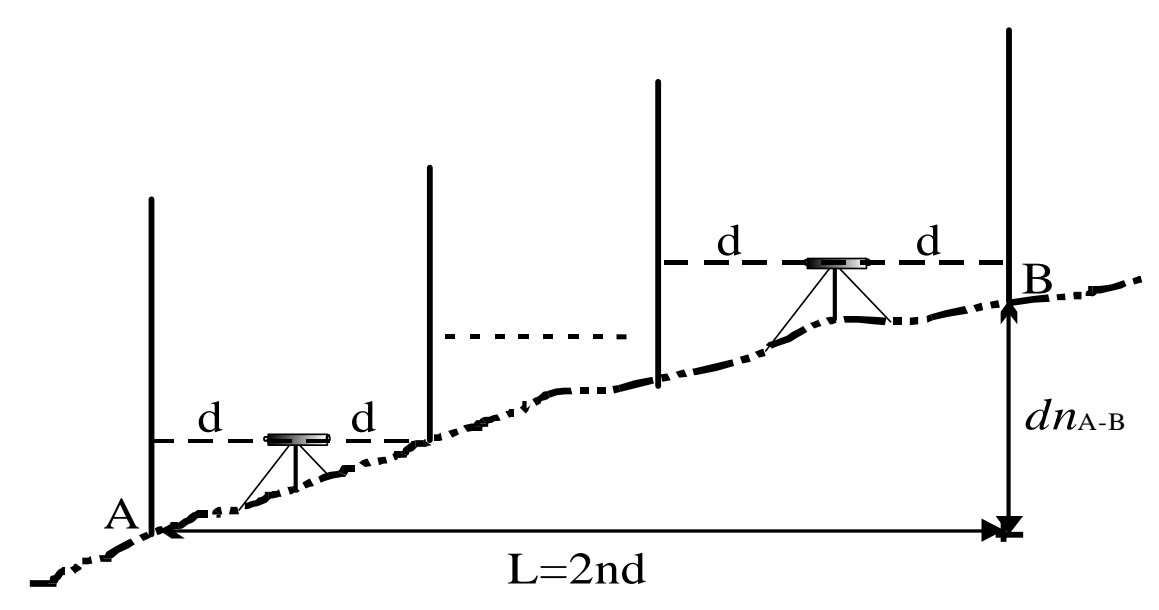

FIGURA 3.7 - Ilustração de um nivelamento geométrico

$$
d n_{A-B}=\left(V_{1}-R_{1}\right)+\left(V_{2}-R_{2}\right)+\left(V_{3}-R_{3}\right)+\ldots \ldots \ldots \ldots \ldots\left(V_{N}-R_{N}\right)
$$

Ao considerar $\sigma_{V 1}^{2}=\sigma_{R 1}^{2}=\ldots \ldots \ldots \sigma_{V n}^{2}=\sigma_{R n}^{2}=\sigma^{2}$, tem-se:

$$
\begin{aligned}
& \sigma_{d n A-B}^{2}=2 \cdot n \cdot \sigma^{2} \\
& 2 \cdot n=\frac{L}{d} \\
& \sigma_{d n A-B}= \pm \sigma \cdot \sqrt{\frac{L}{d}}
\end{aligned}
$$

onde:

- $V_{i} \operatorname{com} i=1,2, \ldots, n$ corresponde a leitura na mira à vante;

- $d$ distância de visada a ré e a vante. O valor de " $d$ " é igual em todas as visadas;

$\checkmark R_{i} \operatorname{com} i=1,2, \ldots, n$ corresponde a leitura na mira à ré;

$\bullet \sigma_{V}^{2}$ corresponde a precisão na leitura à vante;

$\bullet \sigma_{R}^{2}$ corresponde a precisão na leitura à ré;

- $\sigma_{d n A-B}$ corresponde a precisão na diferença de nível entre os pontos A e B.

Nivelamento trigonométrico é aquele em que a diferença de nível é determinada em função da distância e do ângulo zenital (ou vertical) entre estes dois 
pontos considerados. Já, o nivelamento barométrico, é aquele onde a diferença de nível é determinada em função da variação da pressão atmosférica existente, entre pontos de diferentes altitudes da superfície terrestre.

As operações dos nivelamentos trigonométrico e barométrico normalmente são apoiadas em RN's. Ao contrário do nivelamento de alta precisão, o trigonométrico se adapta bem a terrenos acidentados, correspondendo à técnica mais usual para determinação das altitudes dos vértices de redes planimétricas. Segundo CASTAÑEDA (1986), o nivelamento trigonométrico pode ser executado alternativamente por dois métodos: visadas unilaterais, para o qual bastam um teodolito e um alvo, ou visadas recíprocas simultâneas, realizável com dois teodolitos, operando simultaneamente. Sob condições operacionais adequadas, esta segunda técnica pode proporcionar precisão da ordem de $\pm 1 \mathrm{~m}$ por desnível entre estações afastadas em até $25 \mathrm{~km}$ (por cancelamento matemático ela praticamente elimina o problema crítico de refração).

No que diz respeito ao nivelamento barométrico, trata-se de uma técnica de obtenção de desníveis entre estações a partir das diferenças de pressão atmosférica. Tais medições são realizadas por barômetros aneróides e recorre-se a este tipo de nivelamento quando o emprego de outras técnicas mostra-se inviável (caso da Amazônia) ou em trabalhos nos quais se admitem erros da ordem de $2 \mathrm{~m}$ por desnível determinado.

Atualmente, com o uso do sistema GPS associado a alguns artifícios, já é possível a determinação de altitudes ortométricas com boa precisão. Por se tratar de um assunto ainda novo para a comunidade técnica, o item a seguir detalhará a metodologia. Maiores informações podem ser obtidas em PACCILEO NETTO et al. (1996).

\subsubsection{Nivelamento de precisão utilizando o GPS}

O advento do GPS facilitou em muito a vida do engenheiro, principalmente em economia de tempo no posicionamento de pontos. As coordenadas cartesianas são transformadas em latitude, longitude e altura geométrica, referenciadas ao elipsóide WGS-84. Enquanto as coordenadas horizontais apresentam a mesma 
precisão, a vertical possui uma qualidade um pouco inferior, mas mesmo assim, adequada a uma série de aplicações, MONICO et al. (1996).

A altura geométrica GPS é uma grandeza puramente geométrica. Na maior parte dos trabalhos, associados à engenharia, o que interessa é a altitude ortométrica, sendo esta relacionada ao campo gravitacional, ou seja, ao Geóide.

Com toda a potencialidade do GPS na obtenção de coordenadas horizontais, hoje, um dos grandes objetivos, é obter também altitudes ortométricas com boa exatidão. Para isto, há a necessidade do conhecimento da ondulação geoidal com boa precisão.

Infelizmente, no Brasil não se conhece a ondulação geoidal com precisões adequadas. Fazendo um paralelo entre o Brasil e os Estados Unidos, as discrepâncias no nível de precisão absoluta do geóide entre estes países é gritante. Segundo BLITZKOW et al. (1993) apud MONICO et al. (1996), o nível de precisão do mapa geoidal MGB-92 adotado no Brasil é da ordem de 3m absoluto e de $1 \mathrm{~cm} / \mathrm{km}$, relativamente. Nos Estados Unidos a precisão é da ordem de $10 \mathrm{~cm}$ absolutamente e a relativa varia de 4 a $0,1 \mathrm{ppm}$ para distâncias de até $1000 \mathrm{~km}$, SIDERIS \& SHE (1995) apud MONICO et al. (1996).

Verifica-se que, para a obtenção de altitudes ortométricas utilizando o GPS, no Brasil, é um objetivo de longa duração. Até que se atinja estes objetivos soluções locais devem ser realizadas. Logo, este item procura mostrar uma solução local para obtenção de altitudes ortométricas com boa precisão.

\subsubsection{Definição do processo de nivelamento utilizando o GPS}

Para determinar altitudes ortométricas $(H)$, a partir de alturas geométricas $(h)$ advindas do GPS, há a necessidade do conhecimento da ondulação geoidal. A figura (3.8) ilustra o problema: 


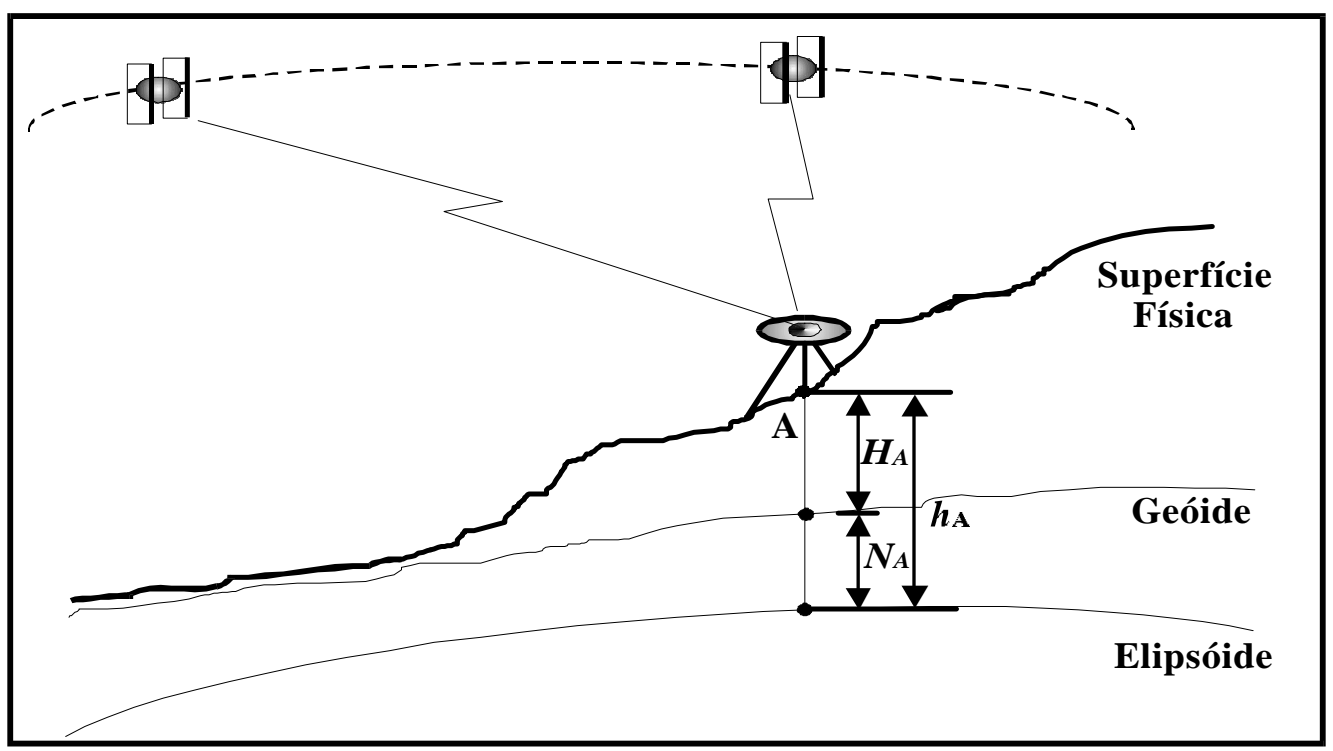

FIGURA 3.8 - Relação entre altura geométrica e altitude ortométrica

De uma forma simplificada, mas com boa aproximação, pode-se escrever, GEMAEL (1981):

$$
H=h-N
$$

sendo:

$\checkmark H$ igual a altitude ortométrica;

- $h$ igual a altura geométrica;

- $N$ igual a ondulação geoidal.

O mapa geoidal, oficialmente adotado no Brasil, é o MGB-92 (IBGE/EPUSP) com precisão absoluta de $3 \mathrm{~m}$ e relativa de $1 \mathrm{~cm} / \mathrm{Km}$. Estas precisões acabam sendo incompatíveis com o objetivo que é obter altitudes ortométricas compatíveis com a precisão de um nivelamento geométrico.

Algumas pesquisas mostram com grande sucesso que, a nível local, é possível obter altitudes ortométricas utilizando o GPS com exatidão. Para isso é necessário o ajuste de uma superfície à valores de ondulações geoidais, determinadas sobre referências de nível. 
A ocupação de referências de nível com o GPS, permite melhorar o conhecimento do geóide, local ou regionalmente, permitindo a determinação da altitude ortométrica com boa exatidão.

Existem várias superfícies que podem ser ajustadas à valores de ondulações geoidais. MONICO et al. (1996), utilizando a superfície gerada pela eq.(3.48), obtiveram resultados satisfatórios na região de Presidente Prudente - SP.

$$
N=a \cdot E_{p}+b \cdot N_{p}+c
$$

onde:

- $N$ é igual a ondulação geoidal;

$\bullet a, b, c$ são parâmetros a serem determinados;

- $E_{p}$ e $N_{p}$ são as coordenadas UTM resultantes de rastreamento em RN.

FIELDER (1992), também com o objetivo de determinar altitudes ortométricas utilizando o GPS, ajustou várias superfícies no município de Boulder, Colorado (EUA):

$$
\begin{aligned}
& N=a \cdot E_{p}+b \cdot N_{p}+c \\
& N=a \cdot E_{p}+b \cdot N_{p}+c \cdot E_{p} \cdot N_{p}+d \\
& N=a \cdot E_{p}+b \cdot N_{p}+c \cdot E_{p}{ }^{2}+d \cdot N_{p}{ }^{2}+e \\
& N=a \cdot E_{p}+b \cdot N_{p}+c \cdot E_{p} \cdot N_{p}+d \cdot E_{p}{ }^{2}+e \cdot N_{p}{ }^{2}+f
\end{aligned}
$$

onde:

- $N$ é igual a ondulação geoidal;

$\diamond a, b, c, d, e, f$ são parâmetros a serem determinados;

- $E_{p}$ e $N_{p}$ são as coordenadas UTM resultantes de rastreamento em RN.

FIELDER (1992), verificou nos modelos estudados que, o aumento do número de parâmetros reflete em uma leve melhora na obtenção final da altitude ortométrica.

Observa-se que, para determinar os parâmetros dos modelos, há a necessidade do estabelecimento de um número maior de equações do que 
incógnitas, para que se possa realizar um ajustamento dos parâmetros pelo método dos mínimos quadrados.

Uma vez ajustada a superfície à valores de ondulações geoidais determinadas sobre referências de nível de uma determinada região, é possível determinar altitudes ortométricas com precisão satisfatória.

A tecnologia GPS é sempre utilizada no método diferencial ou relativo, o que implica em dispor de um ponto com coordenadas geodésicas conhecidas como base para um levantamento. Se neste ponto a altitude ortométrica for conhecida através do nivelamento geométrico, a determinação da altitude ortométrica também pode ser obtida no método relativo, SOARES (1996).

Considerando o ponto 1 de coordenadas $\left(\phi_{1}, \lambda_{1}, h_{1}\right)$ conhecidas e o ponto 2 $\left(\phi_{2}, \lambda_{2}, h_{2}\right)$ a ser determinado:

$$
\begin{aligned}
& h_{1}=H_{1}+N_{1} \\
& h_{2}=H_{2}+N_{2}
\end{aligned}
$$

Admite-se igualmente $H_{l}$ conhecido.

Conhecendo-se as coordenadas geodésicas dos pontos 1 e 2 e ajustada uma determinada superfície à região de estudo, determina-se as ondulações geoidais $N_{l} \mathrm{e}$ $N_{2}$.

Fazendo a diferença entre as expressões (3.50) e (3.51), tem-se:

$$
\begin{aligned}
& h_{2}-h_{1}=\left(H_{2}+N_{2}\right)-\left(H_{1}+N_{1}\right)=\left(H_{2}-H_{1}\right)+\left(N_{2}-N_{1}\right) \\
& \Delta h=H_{2}-H_{1}+\Delta N \\
& H_{2}=H_{1}+\Delta h-\Delta N
\end{aligned}
$$

Evidentemente que um erro na determinação $H_{1}$ se propaga diretamente sobre $\mathrm{H}_{2}$. Entretanto, há uma importante vantagem na metodologia diferencial. A incerteza nas coordenadas do ponto 1 , em particular na altura geométrica $h_{1}$, é transmitida diretamente para $h_{2}$, e é eliminada na diferença. O mesmo ocorre com a ondulação geoidal nos pontos 1 e 2, PACCILEO NETTO et al. (1996). 


\section{CAPÍTULO 4 - MODELOS MATEMÁTICOS DE TRANSFORMAÇÃO DE COORDENADAS UTILIZADOS NA COMBINAÇÃO DE REDES GEODÉSICAS}

\subsection{Introdução}

O estabelecimento da Rede Planimétrica do Sistema Geodésico Brasileiro na década de 40 foi o passo inicial para o desenvolvimento sistemático da Geodésia no Brasil. Desde então, a rede planimétrica de alta precisão vem sofrendo modificações devido a evolução dos métodos e instrumentos utilizados na obtenção de coordenadas.

Os processos de estabelecimento e cálculo das antigas redes geodésicas introduziram erros sistemáticos que ao se propagarem através dos diversos ajustes, resultaram em distorções da rede como um todo.

Técnicas de levantamentos mais precisos tais como a análise do efeito DOPPLER e o sistema GPS estão sendo adotadas no processo de expansão das redes geodésicas. Como consequência, surge não só a necessidade de novo ajustamento de caráter global e integrado às observações GPS, de forma a reduzir ao máximo as inconsistências encontradas na rede, mas também a necessidade de encontrar parâmetros de transformação adequados entre os sistemas.

Existem vários modelos usados para avaliar o relacionamento entre dois sistemas de coordenadas por meio de parâmetros de transformação. 
Neste trabalho, será apresentado a transformação de Helmert no espaço, a transformação de Bursa e a primeira e a segunda versão da transformação de Molodenskii, conhecidas como transformação isogonal ou de similaridade. Os modelos expressam a relação entre dois sistemas de coordenadas por meio de três translações $\left(T_{X}, T_{Y}, T_{Z}\right)$, três rotações $\left(\alpha_{1}, \alpha_{2}, \alpha_{3}\right)$ e um fator de escala $(\mu)$. As três translações são justificadas pela não coincidência da origem entre o sistema geocêntrico e o geodésico local; as três rotações são necessárias para expressar o não

paralelismo dos eixos coordenados destes dois sistemas e um fator de escala é requerido para homogeneizar os sistemas, devido à utilização de diferentes instrumentos.

Assim, é necessário que se tenham pontos comuns nos dois sistemas para aplicar a transformação, sendo um mínimo de três pontos requeridos para a obtenção dos sete parâmetros. Porém, para um melhor ajustamento, recomenda que se tenha mais pontos.

\subsection{Transformação tridimensional de Helmert}

Considere dois sistemas de coordenadas cartesianas tridimensionais formando os vetores $\boldsymbol{X}$ e $\boldsymbol{X}_{\boldsymbol{T}}$, estando associados, respectivamente, aos sistemas geodésico local e geocêntrico.

A transformação entre os dois sistemas pode ser formulada pela relação, HOFMANN-WELLENHOF (1994):

$$
X_{T}=T+\mu \cdot R \cdot X
$$

Esta relação é chamada de transformação de Helmert no espaço onde:

- $\mu$ corresponde ao fator de escala;

- $\boldsymbol{T}$ corresponde ao vetor de translação;

- $R$ corresponde a uma matriz resultante de um produto de três matrizes ortogonais de rotação em torno dos eixos $X, Y$ e $Z$, respectivamente; 
- $\boldsymbol{X}_{\boldsymbol{T}}$ corresponde a um vetor com origem no sistema de coordenadas geocêntrico, que une um ponto na superfície da Terra;

- $\boldsymbol{X}$ corresponde a um vetor com origem no sistema de coordenadas geodésico local, que une um ponto na superfície da Terra.

As componentes do vetor translação, que parte do sistema de coordenadas geocêntrico até o sistema geodésico local é:

$$
\boldsymbol{T}=\left(\begin{array}{c}
T_{X} \\
T_{Y} \\
T_{Z}
\end{array}\right)
$$

A matriz de rotação $R$ é uma matriz ortogonal a qual é composta de três rotações sucessivas:

$$
R=R_{X}\left(\alpha_{1}\right) \cdot R_{Y}\left(\alpha_{2}\right) \cdot R_{Z}\left(\alpha_{3}\right)
$$

A figura 4.1 ilustra melhor o problema:

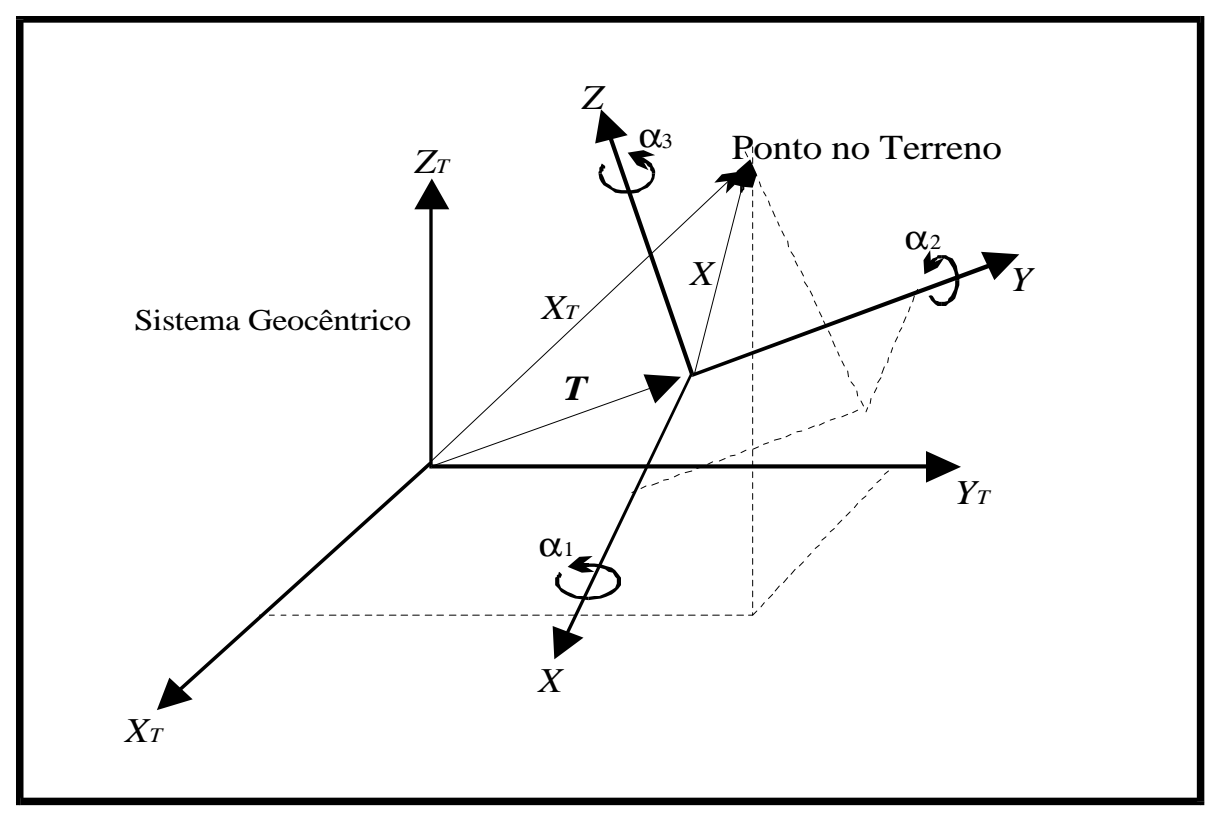

FIGURA 4.1 - Ilustração da transformação tridimensional de Helmert 
Fazendo o produto das três matrizes ortogonais temos:

$$
R=\left(\begin{array}{ccc}
\cos \alpha_{2} \cos \alpha_{3} & \cos \alpha_{1} \operatorname{sen} \alpha_{3}+\operatorname{sen} \alpha_{1} \operatorname{sen} \alpha_{2} \cos \alpha_{3} & \operatorname{sen} \alpha_{1} \operatorname{sen} \alpha_{3}-\cos \alpha_{1} \operatorname{sen} \alpha_{2} \cos \alpha_{3} \\
-\cos \alpha_{1} \operatorname{sen} \alpha_{3} & \cos \alpha_{1} \cos \alpha_{3}-\operatorname{sen} \alpha_{1} \operatorname{sen} \alpha_{2} \operatorname{sen} \alpha_{3} & \operatorname{sen} \alpha_{1} \cos \alpha_{3}+\cos \alpha_{1} \operatorname{sen} \alpha_{2} \operatorname{sen} \alpha_{3} \\
\operatorname{sen} \alpha_{2} & -\operatorname{sen} \alpha_{1} \cos \alpha_{2} & \cos \alpha_{1} \cos \alpha_{2}
\end{array}\right) \text { (4.4) }
$$

No caso de conhecermos os parâmetros de transformação $\boldsymbol{T}, \mu e R$, um ponto associado ao sistema geocêntrico $\boldsymbol{X}_{\boldsymbol{T}}$ pode ser transformado para um sistema geodésico local $\boldsymbol{X}$ através da eq.(4.1).

\subsubsection{Formulação do problema pelo Método dos Mínimos Quadrados (MMQ)}

Vários são os modelos que utilizam o princípio do método dos mínimos quadrados. No entanto, o que será apresentado é o método paramétrico.

No caso de observações indiretas, deseja-se estimar grandezas que se vinculam às observações através de um modelo matemático. Usualmente, estas grandezas são chamadas de parâmetros, o que explica a denominação de método paramétrico.

Quando os valores observados ajustados podem ser expressos explicitamente como uma função dos parâmetros ajustados, isto é, quando se verifica o modelo matemático:

$$
\boldsymbol{L}_{\boldsymbol{a}}=F\left(\boldsymbol{X}_{\boldsymbol{a}}\right)
$$

dizemos que o ajustamento se processa pelo método paramétrico.

Sendo:

$$
L_{a}=L_{b}+V
$$

onde: 
$\checkmark \boldsymbol{L}_{\boldsymbol{b}}$ igual ao vetor dos valores observados;

- $\boldsymbol{V}$ igual ao vetor dos resíduos;

$\bullet \boldsymbol{L}_{\boldsymbol{a}}$ igual ao vetor dos valores observados ajustados.

E também:

$$
X_{a}=X_{0}+X
$$

onde:

- $\boldsymbol{X}_{\boldsymbol{0}}$ igual a um vetor cujas componentes são os valores aproximados dos parâmetros;

$\bullet X$ igual ao vetor correção ;

- $\boldsymbol{X}_{\boldsymbol{a}}$ igual ao vetor dos parâmetros ajustados.

Substituindo as equações (4.6) e (4.7) na (4.5) e linearizando o modelo pela fórmula de Taylor, tem-se:

$$
\boldsymbol{L}_{\boldsymbol{b}}+\boldsymbol{V}=F\left(\boldsymbol{X}_{\boldsymbol{0}}+\boldsymbol{X}\right)=F\left(\boldsymbol{X}_{\boldsymbol{0}}\right)+\left.\frac{\partial F}{\partial \boldsymbol{X}_{a}}\right|_{\boldsymbol{X}_{a}=\boldsymbol{X}_{0}} \cdot \boldsymbol{X}
$$

Designando a função dos parâmetros aproximados por $\boldsymbol{L}_{\boldsymbol{0}}$ :

$$
\boldsymbol{L}_{\boldsymbol{0}}=F\left(\boldsymbol{X}_{0}\right)
$$

e a matriz das derivadas parciais por $A$ :

$$
A=\left.\frac{\partial F}{\partial X_{a}}\right|_{X_{a}=X_{0}}
$$

a eq.(4.8) se escreve como:

$$
\begin{aligned}
& \boldsymbol{L}_{\boldsymbol{b}}+\boldsymbol{V}=\boldsymbol{L}_{\boldsymbol{0}}+A . \boldsymbol{X} \\
& \boldsymbol{V}=A . \boldsymbol{X}+\boldsymbol{L}_{\boldsymbol{0}}-\boldsymbol{L}_{\boldsymbol{b}}=A . \boldsymbol{X}-\left(\boldsymbol{L}_{\boldsymbol{b}}-\boldsymbol{L}_{\boldsymbol{0}}\right)
\end{aligned}
$$


E, finalmente, fazendo

$$
L=L_{b}-L_{0}
$$

obtém-se o modelo linearizado do método dos parâmetros:

$$
{ }_{n} \boldsymbol{V}_{1}={ }_{u} A_{u} \cdot{ }_{u} \boldsymbol{X}_{1}-{ }_{n} \boldsymbol{L}_{1}
$$

Minimizando a forma quadrática fundamental, obtém-se:

$$
\phi=\boldsymbol{V}^{T} \cdot P \cdot \boldsymbol{V}=\min
$$

Substituindo a eq.(4.12) na (4.13), fazendo algumas manipulações algébricas e igualando a zero a derivada primeira com relação a $X$, tem-se:

$$
\begin{aligned}
& A^{T} . P . A . \boldsymbol{X}-A^{T} . P . \boldsymbol{L}=0 \\
& A^{T} . P . A . \boldsymbol{X}=A^{T} . P . \boldsymbol{L}
\end{aligned}
$$

Fazendo:

$$
\begin{aligned}
& N=A^{T} . P . A \\
& U=A^{T} . P . L
\end{aligned}
$$

resulta:

$$
N . \boldsymbol{X}=U
$$

A equação matricial (4.17) representa um sistema de $\underline{u}$ equações normais cuja solução é dada por:

$$
\boldsymbol{X}=N^{-1} \cdot U
$$


cujas componentes convertem os parâmetros aproximados em ajustados:

$$
X_{a}=X_{0}+X
$$

O vetor dos resíduos pode ser obtido pela (4.12).

Para qualquer ponto " $i$ " do terreno, tem-se as suas coordenadas $\left(X_{T i}, Y_{T i}, Z_{T i}\right)$ relativas ao sistema geocêntrico e $\left(X_{i}, Y_{i}, Z_{i}\right)$ relativas a um determinado sistema geodésico local.

Os vetores $\boldsymbol{X}_{T}$ e $\boldsymbol{X}$ são usados como observáveis e estão associados, respectivamente, aos sistemas geocêntrico e geodésico local. Assim, a equação de observação pode ser derivada diretamente da eq.(4.1):

$$
\boldsymbol{F}_{i}=\boldsymbol{T}+\mu \cdot R \cdot \boldsymbol{X}-\boldsymbol{X}_{\boldsymbol{T}}=0
$$

Os ângulos de rotação sendo valores pequenos, a matriz de rotação $R$ tem a forma:

$$
R=\left(\begin{array}{ccc}
1 & d \alpha_{3} & -d \alpha_{2} \\
-d \alpha_{3} & 1 & d \alpha_{1} \\
d \alpha_{2} & -d \alpha_{1} & 1
\end{array}\right)
$$

onde $R$ é dada por:

$$
R=R_{0}+d R
$$

Assim, a aproximação $R_{0}=I$ é válida e a (4.22) se escreve como:

$$
R=I+d R
$$

com $I$ sendo uma matriz unitária e $d R$ uma matriz diferencial. 
A matriz diferencial $d R$ tem a forma:

$$
d R=\left(\begin{array}{ccc}
0 & d \alpha_{3} & -d \alpha_{2} \\
-d \alpha_{3} & 0 & d \alpha_{1} \\
d \alpha_{2} & -d \alpha_{1} & 0
\end{array}\right)
$$

O fator de escala é dado por:

$$
\mu=\mu_{0}+d \mu
$$

No caso de uma transformação entre dois data que se admitem próximos, a aproximação $\mu_{0}=1$ é válida, HOFMANN-WELLENHOF (1994) e a (4.25) se escreve como:

$$
\mu=1+d \mu
$$

Finalmente, pode-se obter o vetor translação por:

$$
T=T_{0}+d T
$$

onde o valor aproximado do vetor translação pode ser obtido pela eq.(4.28):

$$
T_{0}=X_{T}-X
$$

Introduzindo agora as equações (4.22), (4.26) e (4.27) na eq.(4.1) tem-se:

$$
\boldsymbol{X}_{T}=\boldsymbol{T}_{0}+\boldsymbol{d T}+(1+d \mu) \cdot\left(R_{0}+d R\right) \cdot \boldsymbol{X}
$$

Fazendo as devidas multiplicações tem-se:

$$
\boldsymbol{X}_{T}-\boldsymbol{X}-\boldsymbol{T}_{0}=\boldsymbol{d} \boldsymbol{T}+(d R \cdot \boldsymbol{X})+(d \mu \cdot \boldsymbol{X})
$$


Para um único ponto, fazendo as devidas multiplicações na eq.(4.29) tem-se:

$$
\begin{aligned}
& {\left[X_{T 1}-X_{1}-\left(T_{X}\right)_{0}\right]=d T_{X}+d \mu \cdot X_{1}+0 \cdot X_{1}+d \alpha_{3} \cdot Y_{1}-d \alpha_{2} \cdot Z_{1}} \\
& {\left[Y_{T 1}-Y_{1}-\left(T_{Y}\right)_{0}\right]=d T_{Y}+d \mu \cdot Y_{1}-d \alpha_{3} \cdot X_{1}+0 \cdot Y_{1}+d \alpha_{1} \cdot Z_{1}} \\
& {\left[Z_{T 1}-Z_{1}-\left(T_{Z}\right)_{0}\right]=d T_{Z}+d \mu \cdot Z_{1}-d \alpha_{2} \cdot X_{1}-d \alpha_{1} \cdot Y_{1}-0 \cdot Z_{1}}
\end{aligned}
$$

Verifica-se pelo sistema de equações expresso pela (4.30) que o mesmo está na forma linearizada e que matricialmente tem-se:

$$
\left(\begin{array}{c}
X_{T 1}-X_{1}-\left(T_{X}\right)_{0} \\
Y_{T 1}-Y_{1}-\left(T_{Y}\right)_{0} \\
Z_{T 1}-Z_{1}-\left(T_{Z}\right)_{0}
\end{array}\right)=\left(\begin{array}{c}
d T_{X} \\
d T_{Y} \\
d T_{Z}
\end{array}\right)+d \mu \cdot\left(\begin{array}{c}
X_{1} \\
Y_{1} \\
Z_{1}
\end{array}\right)+\left(\begin{array}{c}
X_{1} \\
Y_{1} \\
Z_{1}
\end{array}\right) \cdot\left(\begin{array}{ccc}
0 & d \alpha_{3} & -d \alpha_{2} \\
-d \alpha_{3} & 0 & d \alpha_{1} \\
d \alpha_{2} & -d \alpha_{1} & 0
\end{array}\right)
$$

Os valores aproximados de $\left(T_{X}\right)_{0},\left(T_{Y}\right)_{0},\left(T_{Z}\right)_{0}$ podem ser obtidos, por exemplo, por:

$$
\begin{aligned}
& \left(T_{X}\right)_{0}=\frac{\sum_{i=1}^{n} X_{T i}-X_{i}}{n} \\
& \left(T_{Y}\right)_{0}=\frac{\sum_{i=1}^{n} Y_{T i}-Y_{i}}{n} \\
& \left(T_{Z}\right)_{0}=\frac{\sum_{i=1}^{n} Z_{T i}-Z_{i}}{n}
\end{aligned}
$$

Através da (4.31) já é possível estruturar as matrizes $A$ e $L$ que serão mostradas a seguir para três pontos. Com estas matrizes já é possível aplicar o método dos mínimos quadrados. Da eq.(4.31) verifica-se que o termo do lado esquerdo constitui $\boldsymbol{L}=\boldsymbol{L}_{\boldsymbol{b}}-\boldsymbol{L}_{\boldsymbol{0}}$, onde $\boldsymbol{L}_{\boldsymbol{b}}$ corresponde ao vetor das observações brutas e $\boldsymbol{L}_{\boldsymbol{0}}$ corresponde ao vetor das observações aproximadas que são em função dos parâmetros aproximados. Assim: 


$$
\boldsymbol{L}_{\boldsymbol{b}}=\left(\begin{array}{c}
X_{T i}-X_{i} \\
Y_{T i}-Y_{i} \\
Z_{T i}-Z_{i}
\end{array}\right)
$$

$\boldsymbol{L}_{\boldsymbol{0}}$ pode ser obtida pela (4.32).

$$
\begin{gathered}
\boldsymbol{L}=\left(\begin{array}{c}
X_{T i}-X_{i}-\left(T_{X}\right)_{0} \\
Y_{T i}-Y_{i}-\left(T_{Y}\right)_{0} \\
Z_{T i}-Z_{i}-\left(T_{Z}\right)_{0}
\end{array}\right), \operatorname{com} i=(1,2, \ldots, \mathrm{n}) \\
A=\left(\begin{array}{ccccccc}
1 & 0 & 0 & X_{1} & 0 & -Z_{1} & Y_{1} \\
0 & 1 & 0 & Y_{1} & Z_{1} & 0 & -X_{1} \\
0 & 0 & 1 & Z_{1} & -Y_{1} & X_{1} & 0 \\
1 & 0 & 0 & X_{2} & 0 & -Z_{2} & Y_{2} \\
0 & 1 & 0 & Y_{2} & Z_{2} & 0 & -X_{2} \\
0 & 0 & 1 & Z_{2} & -Y_{2} & X_{2} & 0 \\
1 & 0 & 0 & X_{3} & 0 & -Z_{3} & Y_{3} \\
0 & 1 & 0 & Y_{3} & Z_{3} & 0 & -X_{3} \\
0 & 0 & 1 & Z_{3} & -Y_{3} & X_{3} & 0
\end{array}\right)
\end{gathered}
$$

\subsubsection{Definição da matriz peso}

O peso de uma observação é inversamente proporcional ao quadrado do desvio padrão correspondente. Assim, tendo-se $L_{1}, L_{2}, L_{3}, \ldots \ldots ., L_{n}$ observações, de desvios padrões $\sigma_{1}, \sigma_{2}, \ldots \sigma_{n}$, os pesos serão:

$p 1=\frac{\sigma_{0}{ }^{2}}{\sigma_{1}{ }^{2}} ; \quad p 2=\frac{\sigma_{0}{ }^{2}}{\sigma_{2}{ }^{2}} ;----------; \quad p n=\frac{\sigma_{0}{ }^{2}}{\sigma_{n}{ }^{2}} ;$ onde $\sigma_{0}{ }^{2}$ é definida como sendo a precisão de uma dada observação de peso igual a 1 (variância a priori).

Assim tem-se que a matriz peso das observações para a determinação dos parâmetros de transformação entre os sistemas geocêntrico e geodésico local é dado por $P_{X}=\sigma_{0}{ }^{2} \cdot \sum X^{-1}$ onde $\sum X^{-1}$ é o inverso da matriz variância-covariância das observações.

Tem-se que as observações são dadas pela diferença das coordenadas entre os sistemas de satélite e geodésico, havendo a necessidade de se fazer uma 
propagação de erros entre estas diferenças de coordenadas. Assim para cada ponto tem-se:

$$
\begin{aligned}
& \Delta X=X_{T}-X \\
& \Delta Y=Y_{T}-Y \\
& \Delta Z=Z_{T}-Z
\end{aligned}
$$

A matriz variância-covariância de $\Delta_{p i},(i=1,2,3,------, n)$, onde o índice $p$ indica o ponto, é dada por:

$$
\Sigma \Delta p i=G \cdot \Sigma_{\text {coord }} \cdot G^{T}
$$

Por serem as diferenças, equações lineares, a matriz $G$ dos coeficientes é (para cada ponto):

$$
\begin{aligned}
& G=\left(\begin{array}{cccccc}
1 & -1 & 0 & 0 & 0 & 0 \\
0 & 0 & 1 & -1 & 0 & 0 \\
0 & 0 & 0 & 0 & 1 & -1
\end{array}\right) \\
& \Sigma_{\text {coord. }}=\left(\begin{array}{cccccc}
\sigma_{X_{T}}^{2} & 0 & 0 & 0 & 0 & 0 \\
0 & \sigma_{X}^{2} & 0 & 0 & 0 & 0 \\
0 & 0 & \sigma_{Y_{T}}^{2} & 0 & 0 & 0 \\
0 & 0 & 0 & \sigma_{Y}^{2} & 0 & 0 \\
0 & 0 & 0 & 0 & \sigma_{Z_{T}}^{2} & 0 \\
0 & 0 & 0 & 0 & 0 & \sigma_{Z}^{2}
\end{array}\right) \\
& G^{T}=\left(\begin{array}{ccc}
1 & 0 & 0 \\
-1 & 0 & 0 \\
0 & 1 & 0 \\
0 & -1 & 0 \\
0 & 0 & 1 \\
0 & 0 & -1
\end{array}\right)
\end{aligned}
$$


Fazendo-se as multiplicações $G \cdot \Sigma_{\text {coord. }} \cdot G^{T}$ tem-se como resultado a Matriz Variância Covariância (M.V.C) das diferenças de coordenadas ( $\Sigma \Delta p i$ ) para um único ponto:

$$
\sum \Delta p i=\left(\begin{array}{ccc}
\sigma_{X_{T}}^{2}+\sigma_{X}^{2} & 0 & 0 \\
0 & \sigma_{Y_{T}}^{2}+\sigma_{Y}^{2} & 0 \\
0 & 0 & \sigma_{Z_{T}}^{2}+\sigma_{Z}^{2}
\end{array}\right)
$$

Assim o cálculo da matriz peso é feito da seguinte forma:

$$
P=\sigma_{0}{ }^{2} \cdot\left(\begin{array}{ccc}
\Sigma \Delta_{p 1} & & 0 \\
& \Sigma \Delta_{p 2} & \\
0 & & \Sigma \Delta_{p n}
\end{array}\right)^{-1} \text {, onde } n \text { é o número de vértices }
$$

observados e $\sum \Delta_{p i} i=(1,2,------, n)$, são submatrizes quadradas $3 \times 3$.

Uma vez formulada todas as matrizes do sistema de equações normais o acréscimo $\boldsymbol{X}$ pode ser obtido por:

$$
\boldsymbol{X}=\left(A^{T} \cdot P \cdot A\right)^{-1} \cdot\left(A^{T} \cdot P \cdot L\right)
$$

O vetor $\boldsymbol{X}$ dos acréscimos é mostrado a seguir:

$$
\boldsymbol{X}=\left(\begin{array}{c}
d T_{X} \\
d T_{Y} \\
d T_{Z} \\
d \mu \\
d \alpha_{1} \\
d \alpha_{2} \\
d \alpha_{3}
\end{array}\right)
$$


De posse dos acréscimos obtidos pela eq.(4.42), as correções $\boldsymbol{d T}, d \alpha$ e o fator de escala $d \mu$, podem ser substituídos nas equações, respectivamente, (4.27), (4.23) e (4.26) e obter os sete parâmetros de transformação ajustados.

\subsection{Modelo de Bursa}

No modelo de Bursa, as coordenadas de um ponto na superfície da Terra, associadas aos sistemas, geodésico local $\boldsymbol{X}$ e geocêntrico $\boldsymbol{X}_{T}$ também são relacionadas através de três translações $\left(T_{X}, T_{Y}, T_{Z}\right)$, três rotações $\left(\alpha_{1}, \alpha_{2}, \alpha_{3}\right)$ e um fator de escala $\mu$. Isto pode ser verificado através da figura 4.2.

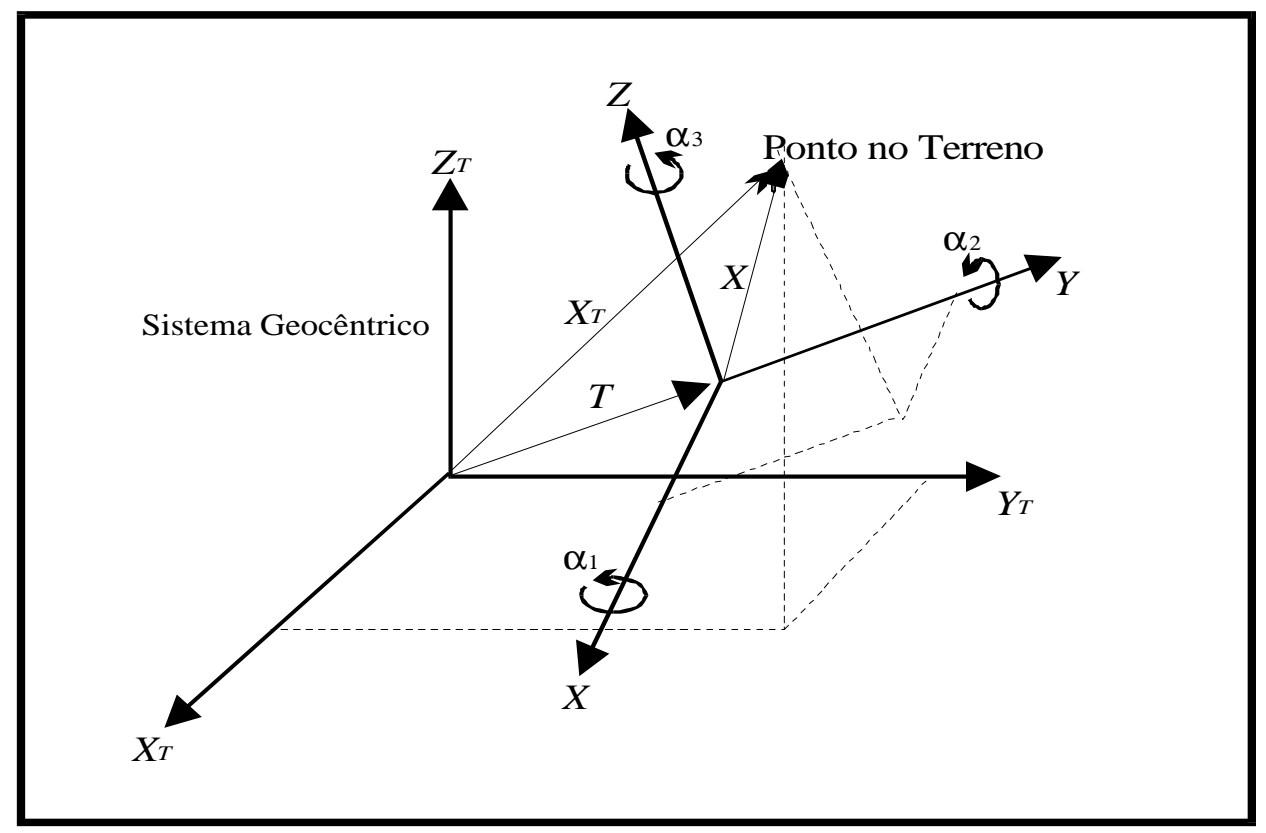

FIGURA 4.2 - Ilustração do modelo de Bursa

Para um ponto $i$ qualquer do terreno, o modelo matemático é, ROMÃO (1982):

$$
\boldsymbol{F}_{i}=\boldsymbol{T}+(1+\mu) \cdot R \cdot \boldsymbol{X}-\boldsymbol{X}_{\boldsymbol{T}}=0
$$

onde: 
- $\boldsymbol{T}$ representa o vetor de translação entre as origens dos dois sistemas, definido no sistema de satélite;

$\checkmark \mu$ indica a diferença de escala entre os dois sistemas;

$\checkmark R$ é a matriz resultante do produto de três matrizes ortogonais de rotação $R_{X}\left(\alpha_{1}\right), R_{Y}\left(\alpha_{2}\right)$ e $R_{Z}\left(\alpha_{3}\right) ; \alpha_{1}, \alpha_{2}, \alpha_{3}$ são rotações dadas nos eixos $X, Y, Z$ do sistema geodésico local, respectivamente;

- $\boldsymbol{X}$ e $\boldsymbol{X}_{T}$ são os vetores de posição do ponto $i$ no terreno dados pelas coordenadas $(X, Y, Z)$ e $\left(X_{T}, Y_{T}, Z_{T}\right)$, respectivamente, nos sistemas geodésico local e geocêntrico.

Fazendo-se um paralelo entre a transformação de Bursa e a transformação tridimensional de Helmert, através da eq.(4.44) observa-se que a diferença existente entre estes dois modelos fica restrito apenas ao fator $(1+\mu)$.

Pode-se reescrever a (4.44) da seguinte forma:

$$
\boldsymbol{F}_{i}=\left(\begin{array}{l}
T_{X} \\
T_{Y} \\
T_{Z}
\end{array}\right)+(1+\mu) \cdot R_{X}\left(\alpha_{1}\right) \cdot R_{Y}\left(\alpha_{2}\right) \cdot R_{Z}\left(\alpha_{3}\right) \cdot\left(\begin{array}{l}
X \\
Y \\
Z
\end{array}\right)-\left(\begin{array}{l}
X_{T} \\
Y_{T} \\
Z_{T}
\end{array}\right)=0
$$

No qual:

$$
\begin{aligned}
R_{X}\left(\alpha_{1}\right) & =\left(\begin{array}{ccc}
1 & 0 & 0 \\
0 & \cos \alpha_{1} & \operatorname{sen} \alpha_{1} \\
0 & -\operatorname{sen} \alpha_{1} & \cos \alpha_{1}
\end{array}\right) \\
R_{Y}\left(\alpha_{2}\right) & =\left(\begin{array}{ccc}
\cos \alpha_{2} & 0 & -\operatorname{sen} \alpha_{2} \\
0 & 1 & 0 \\
\operatorname{sen} \alpha_{2} & 0 & \cos \alpha_{2}
\end{array}\right) \\
R_{Z}\left(\alpha_{3}\right) & =\left(\begin{array}{ccc}
\cos \alpha_{3} & \operatorname{sen} \alpha_{3} & 0 \\
-\operatorname{sen} \alpha_{3} & \cos \alpha_{3} & 0 \\
0 & 0 & 1
\end{array}\right)
\end{aligned}
$$

Como os ângulos $\alpha_{1}, \alpha_{2}, \alpha_{3}$ são muito pequenos, fazendo as devidas simplificações, tem-se como produto das três matrizes de rotações: 


$$
R_{X}\left(\alpha_{1}\right) \cdot R_{Y}\left(\alpha_{2}\right) \cdot R_{Z}\left(\alpha_{3}\right)=\left(\begin{array}{lll}
1 & 0 & 0 \\
0 & 1 & 0 \\
0 & 0 & 1
\end{array}\right)+\left(\begin{array}{ccc}
0 & d \alpha_{3} & -d \alpha_{2} \\
-d \alpha_{3} & 0 & d \alpha_{1} \\
d \alpha_{2} & -d \alpha_{1} & 0
\end{array}\right)=I+d R
$$

A matriz produto $R$ pode ser substituída pela soma de uma matriz unidade $I$ com a matriz $d R$ dos ângulos de rotação $d \alpha_{1}, d \alpha_{2}, d \alpha_{3}$ dados em radianos. Desta forma, fazendo as devidas multiplicações e simplificações tem-se:

$$
\boldsymbol{F}_{i}=\boldsymbol{T}+\boldsymbol{X}+(\boldsymbol{\mu} \cdot \boldsymbol{X})+(d R \cdot \boldsymbol{X})-\boldsymbol{X}_{T}=0
$$

Matricialmente a visualização do modelo é mais clara, logo:

$$
\left(\begin{array}{l}
X_{T} \\
Y_{T} \\
Z_{T}
\end{array}\right)-\left(\begin{array}{l}
X \\
Y \\
Z
\end{array}\right)=\left(\begin{array}{l}
T_{X} \\
T_{Y} \\
T_{Z}
\end{array}\right)+\mu \cdot\left(\begin{array}{l}
X \\
Y \\
Z
\end{array}\right)+\left(\begin{array}{ccc}
0 & d \alpha_{3} & -d \alpha_{2} \\
-d \alpha_{3} & 0 & d \alpha_{1} \\
d \alpha_{2} & -d \alpha_{1} & 0
\end{array}\right) \cdot\left(\begin{array}{l}
X \\
Y \\
Z
\end{array}\right)
$$

Sendo assim, para cada ponto da superfície terrestre é formada uma equação do tipo (4.51).

No mínimo três pontos comuns nos dois sistemas são requeridos para que se possa realizar o ajustamento dos sete parâmetros de transformação pelo MMQ. O ajustamento neste caso é semelhante ao mostrado na transformação de Helmert no espaço, uma vez que, as estruturas das matrizes $(A, P$ e $L)$ do sistema de equações normais são idênticas.

\subsection{Modelo de Molodenskii}

Duas interpretações distintas são estabelecidas para o modelo de Molodenskii. Na primeira versão, há uma suposição de paralelismo entre o sistema geodésico local e o sistema geocêntrico. O que está sendo rotacionado é o sistema topocêntrico com origem no ponto inicial da rede. Já, na segunda versão, não considera-se a suposição de paralelismo entre o sistema geocêntrico e o geodésico 
local, mas sim, entre o sistema topocêntrico com origem no ponto inicial da rede e o sistema geodésico local.

\subsubsection{Modelo de Molodenskii - primeira versão}

A primeira versão do modelo pode ser compreendida de maneira mais clara através da figura 4.3 .

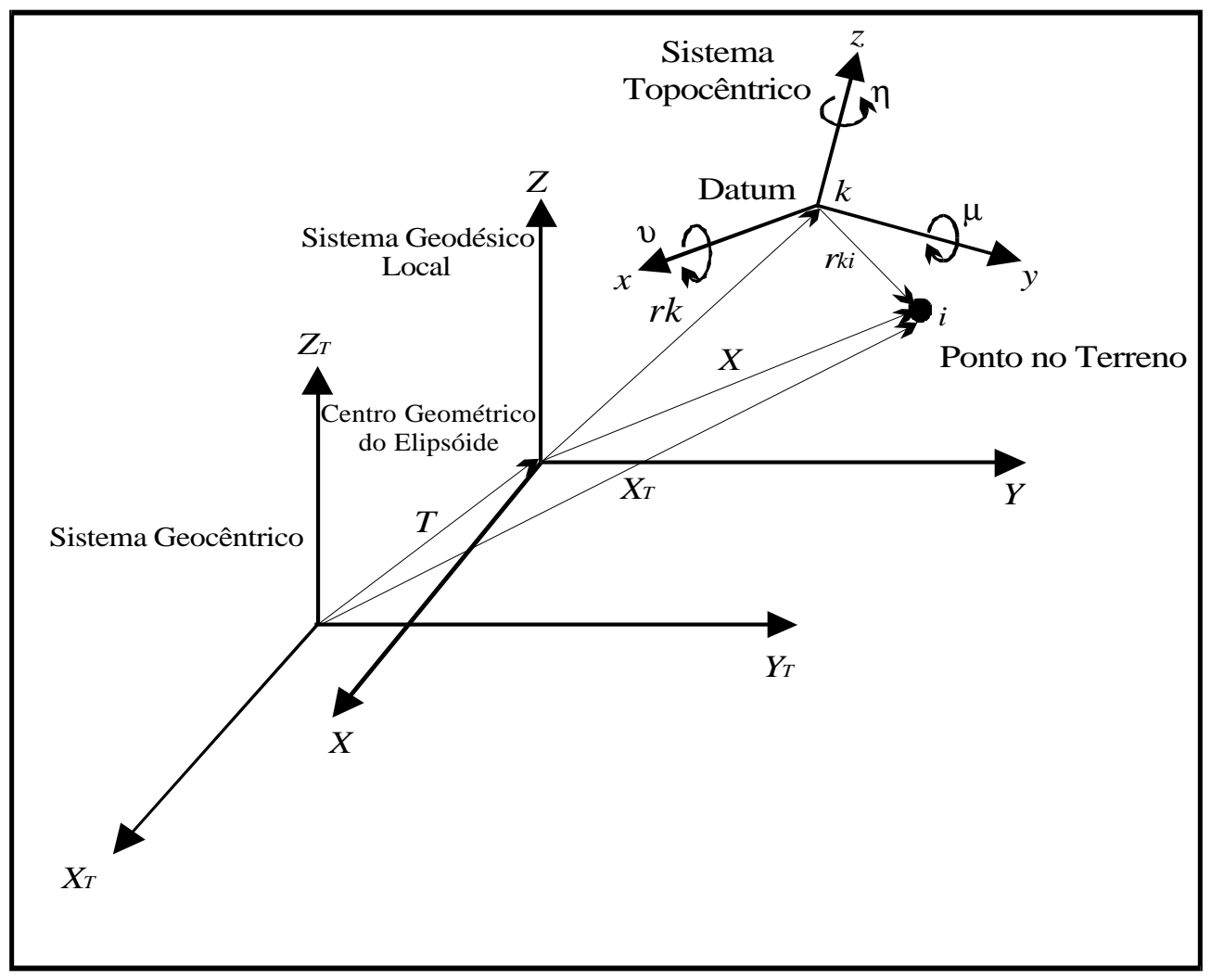

FIGURA 4.3 - Ilustração do modelo de Molodenskii - primeira versão

O modelo matemático é, ABIB (1978):

$$
\boldsymbol{F}_{i}=\boldsymbol{T}+\boldsymbol{r}_{k}+\left[(1+\mu) \cdot R \cdot \boldsymbol{r}_{k i}\right]-\boldsymbol{X}_{T}=0
$$

onde: 
- $\boldsymbol{T}$ é o vetor translação entre as origens dos sistemas geocêntrico e geodésico local;

$\bullet \boldsymbol{r}_{\boldsymbol{k}}$ é o vetor de posição do ponto inicial da rede terrestre estabelecido no sistema geodésico local;

$\bullet \boldsymbol{r}_{\boldsymbol{k}}$ é o vetor de posição de um ponto qualquer $i$ estabelecido no sistema topocêntrico com origem no datum;

- $R$ é uma matriz resultante do produto de três matrizes ortogonais de rotação em torno dos eixos $x, y$ e $z$, respectivamente;

- $\boldsymbol{X}$ e $\boldsymbol{X}_{T}$ são os vetores de posição do ponto $i$ no terreno dados pelas coordenadas $(X, Y, Z)$ e $\left(X_{T}, Y_{T}, Z_{T}\right)$, respectivamente, nos sistemas geodésico local e geocêntrico.

Neste modelo, a diferença de escala e as pequenas rotações $(\nu, \mu, \eta)$ são atribuídas à rede terrestre, ou seja, ela está sendo rotacionada e escalada, enquanto que o sistema de coordenadas geodésico local permanece inalterado. Assim:

$$
R=R_{x}(v) \cdot R_{y}(\mu) \cdot R_{z}(\eta) \approx I+d R
$$

Desenvolvendo matematicamente a eq.(4.52), tem-se:

$$
\begin{aligned}
& \boldsymbol{F}_{i}=\boldsymbol{T}+\boldsymbol{r}_{k}+(1+\mu) \cdot(I+d R) \cdot \boldsymbol{r}_{k i}-\boldsymbol{X}_{T}=0 \\
& \boldsymbol{F}_{i}=\boldsymbol{T}+\boldsymbol{r}_{k}+(I+d R+\mu \cdot I+\mu \cdot d R) \cdot \boldsymbol{r}_{k i}-\boldsymbol{X}_{T}=0 \\
& \boldsymbol{F}_{i}=\boldsymbol{T}+\boldsymbol{r}_{k}+\left(I \cdot \boldsymbol{r}_{k i}\right)+\left(d R \cdot \boldsymbol{r}_{k i}\right)+\left(\mu \cdot I \cdot \boldsymbol{r}_{k i}\right)-\boldsymbol{X}_{T}=0 \\
& \boldsymbol{F}_{i}=\boldsymbol{T}+\boldsymbol{r}_{k}+\boldsymbol{X}-\boldsymbol{r}_{k}+d R \cdot\left(\boldsymbol{X}-\boldsymbol{r}_{k}\right)+\mu \cdot\left(\boldsymbol{X}-\boldsymbol{r}_{k}\right)-\boldsymbol{X}_{T}=0 \\
& \boldsymbol{X}_{\boldsymbol{T}}-\boldsymbol{X}=\boldsymbol{T}+\mu \cdot\left(\boldsymbol{X}-\boldsymbol{r}_{\boldsymbol{k}}\right)+d R \cdot\left(\boldsymbol{X}-\boldsymbol{r}_{\boldsymbol{k}}\right)
\end{aligned}
$$

Para um único vértice é possível formular três equações. Assim tem-se:

$$
\begin{aligned}
& X_{T 1}-X_{1}=T_{X}+d \mu \cdot\left(X_{1}-X_{k}\right)+0 \cdot\left(X_{1}-X_{k}\right)-d \alpha_{2} \cdot\left(Z_{1}-Z_{k}\right)+d \alpha_{3} \cdot\left(Y_{1}-Y_{k}\right) \\
& Y_{T 1}-Y_{1}=T_{Y}+d \mu \cdot\left(Y_{1}-Y_{k}\right)+d \alpha_{1} \cdot\left(Z_{1}-Z_{k}\right)+0 \cdot\left(Y_{1}-Y_{k}\right)-d \alpha_{3} \cdot\left(X_{1}-X_{k}\right)(4.55) \\
& Z_{T 1}-Z_{1}=T_{Z}+d \mu \cdot\left(Z_{1}-Z_{k}\right)-d \alpha_{1} \cdot\left(Y_{1}-Y_{k}\right)+d \alpha_{2} \cdot\left(X_{1}-X_{k}\right)-0 \cdot\left(Z_{1}-Z_{k}\right)
\end{aligned}
$$


onde $T_{X}, T_{Y}$ e $T_{Z}$ são as translações em relação aos eixos $X, Y$ e $Z$, respectivamente.

O ajustamento pelo MMQ é semelhante aos modelos de Helmert e de Bursa com alteração apenas na estrutura da matriz $A$ que, para três vértices, é elucida a seguir:

$$
A=\left(\begin{array}{ccccccc}
1 & 0 & 0 & \left(X_{1}-X_{k}\right) & 0 & -\left(Z_{1}-Z_{k}\right) & \left(Y_{1}-Y_{k}\right) \\
0 & 1 & 0 & \left(Y_{1}-Y_{k}\right) & \left(Z_{1}-Z_{k}\right) & 0 & -\left(X_{1}-X_{k}\right) \\
0 & 0 & 1 & \left(Z_{1}-Z_{k}\right) & -\left(Y_{1}-Y_{k}\right) & \left(X_{1}-X_{k}\right) & 0 \\
1 & 0 & 0 & \left(X_{2}-X_{k}\right) & 0 & -\left(Z_{2}-Z_{k}\right) & \left(Y_{2}-Y_{k}\right) \\
0 & 1 & 0 & \left(Y_{2}-Y_{k}\right) & \left(Z_{2}-Z_{k}\right) & 0 & -\left(X_{2}-X_{k}\right) \\
0 & 0 & 1 & \left(Z_{2}-Z_{k}\right) & -\left(Y_{2}-Y_{k}\right) & \left(X_{2}-X_{k}\right) & 0 \\
1 & 0 & 0 & \left(X_{3}-X_{k}\right) & 0 & -\left(Z_{3}-Z_{k}\right) & \left(Y_{3}-Y_{k}\right) \\
0 & 1 & 0 & \left(Y_{3}-Y_{k}\right) & \left(Z_{3}-Z_{k}\right) & 0 & -\left(X_{3}-X_{k}\right) \\
0 & 0 & 1 & \left(Z_{3}-Z_{k}\right) & -\left(Y_{3}-Y_{k}\right) & \left(X_{3}-X_{k}\right) & 0
\end{array}\right)
$$

\subsubsection{Modelo de Molodenskii - segunda versão}

Nesta segunda versão do modelo de Molodenskii, ao contrário da primeira versão, não considera uma suposição de paralelismo entre os sistemas geocêntrico e geodésico local, mas sim, entre o sistema topocêntrico com origem no ponto inicial da rede e o sistema geodésico local. A figura 4.4 ilustra o problema:

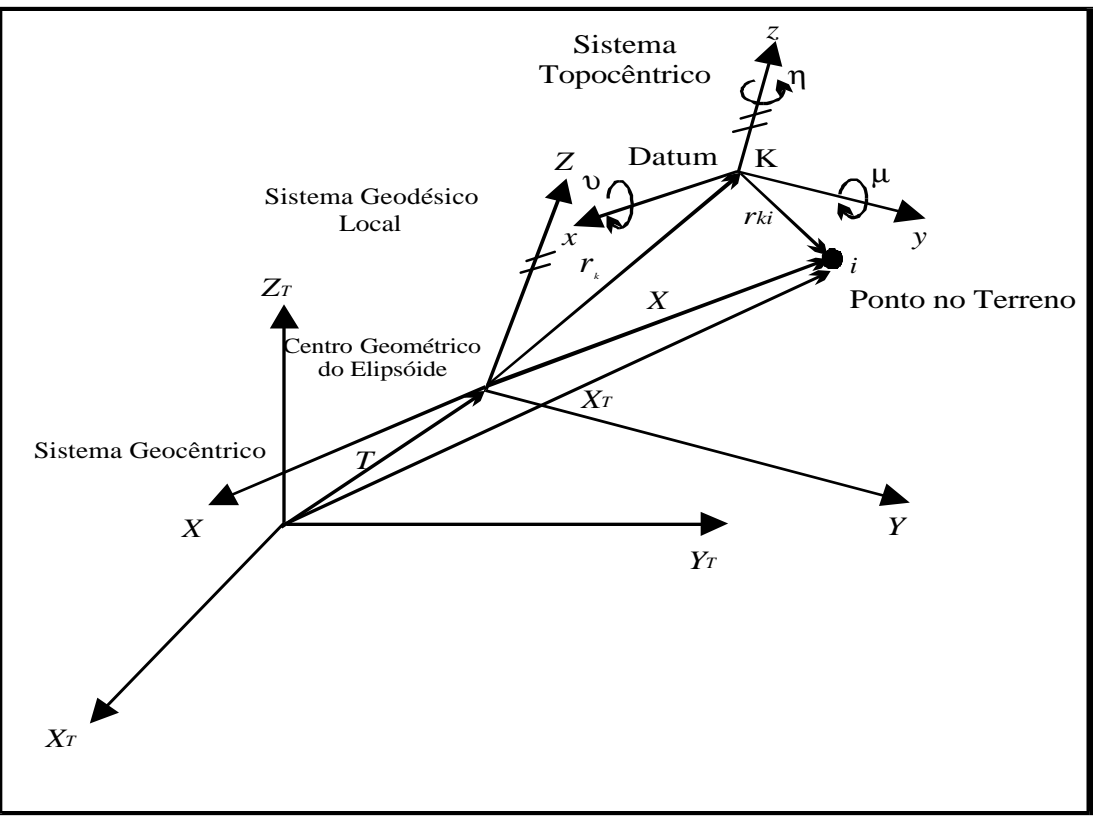

FIGURA 4.4 - Ilustração do modelo de Molodenskii - segunda versão 
O modelo matemático é, ROMÃO (1982):

$$
\boldsymbol{F}_{i}=\boldsymbol{T}+(1+\mu) \cdot R \cdot\left(\boldsymbol{r}_{k}+\boldsymbol{r}_{k i}\right)-\boldsymbol{X}_{T}=0
$$

As rotações são as mesmas do modelo anterior (primeira versão). As matrizes $A$ e $\boldsymbol{L}$ do modelo linearizado por Taylor são idênticas às dos modelos de Bursa e de Helmert.

Foi mostrado por SOLER apud ROMÃO (1982), que a segunda versão do modelo de Molodenskii, proporciona resultados equivalentes aos de Bursa para os sete parâmetros de transformação. 


\section{CAPÍTULO 5 - PROCEDIMENTO METODOLÓGICO}

\subsection{Introdução}

O conhecimento dos parâmetros de transformação entre os referenciais vinculados ao sistema GPS e o sistema geodésico adotado no Brasil, constitui uma necessidade da comunidade cartográfica nacional usuária das técnicas de posicionamento por satélite. Com o objetivo de sanar este problema, em 1987 um plano de trabalho foi elaborado pelo Departamento de Geodésia da Diretoria de Geociências do IBGE, onde, realizou-se um rastreamento de satélites durante 24 dias no vértice Chuá com o intuito de se obter os parâmetros de transformação entre os sistemas WGS-84 e o SAD-69. Desde então, estes parâmetros são divulgados oficialmente pelo IBGE para todo o território nacional. Segundo FORTES et al. (1989), o fato de levar em consideração apenas o vértice Chuá na determinação dos parâmetros de transformação consiste na não influência das distorções da rede e do mapa geoidal nos valores calculados, uma vez que foram utilizadas coordenadas definidas no datum. Os únicos erros incidentes nos valores dos parâmetros determinados correspondem aos advindos do rastreamento Doppler.

Em função desta metodologia utilizada pelo IBGE para a determinação dos parâmetros de transformação entre o WGS-84 e o SAD-69, alertou-se em verificar o que aconteceria com os valores das coordenadas transformadas quando aplicados parâmetros de transformação locais.

OLIVEIRA et al. (1995), encontrou discrepâncias significativas nos valores das coordenadas transformadas, advindas dos parâmetros de transformação divulgados pelo IBGE, em uma região próxima à cidade do Rio de Janeiro. 
É de se esperar que discrepâncias menores sejam encontradas nos valores das coordenadas em SAD-69 quando utilizados parâmetros locais, pois seriam levados em considerações na determinação dos parâmetros de transformação problemas de ondulação geoidal e distorções de rede.

Partindo-se do princípio de que a amostragem feita pelo IBGE para a determinação dos parâmetros de transformação não é representativa para todo o território nacional, este trabalho mostra o problema gerado pelo uso destes parâmetros na região de São Carlos-SP, numa região próxima à cidade do Rio de Janeiro e em uma região da cidade de Presidente Prudente-SP.

Para a realização de uma compatibilização entre dois referenciais é necessário observar mais do que três vértices comuns nos dois sistemas envolvidos, para que se possa ter abundância de informação, permitindo assim usar o método dos mínimos quadrados na determinação dos valores mais prováveis para os parâmetros de transformação.

Com o intuito de mostrar o problema gerado pelo uso dos parâmetros de transformação divulgados pelo IBGE, sem fugir dos objetivos do trabalho, o mesmo foi dividido em algumas etapas que serão apresentadas a seguir.

\subsection{Definição da área de estudo}

Em uma primeira instância a área de estudo seria apenas a região de São Carlos-SP. Por existir na região apenas 5 vértices pertencentes à rede do SGB, sendo que destes 5 foram encontrados apenas 4, incorporou-se na elaboração do trabalho outros vértices localizados próximos à cidade do Rio de Janeiro e no Campus da UNESP de Presidente Prudente-SP. Estes vértices incorporados pertencem à rede do SGB, conhecendo-se também suas coordenadas no sistema WGS-84. A inclusão destes vértices na elaboração do trabalho proporcionou algumas vantagens:

- Além da região de São Carlos-SP, uma maior abrangência por parte dos parâmetros determinados;

- Maior validade na determinação dos parâmetros, uma vez que um número maior de vértices foram utilizados no ajustamento;

A figura 5.1 ilustra a definição da área de estudo. 


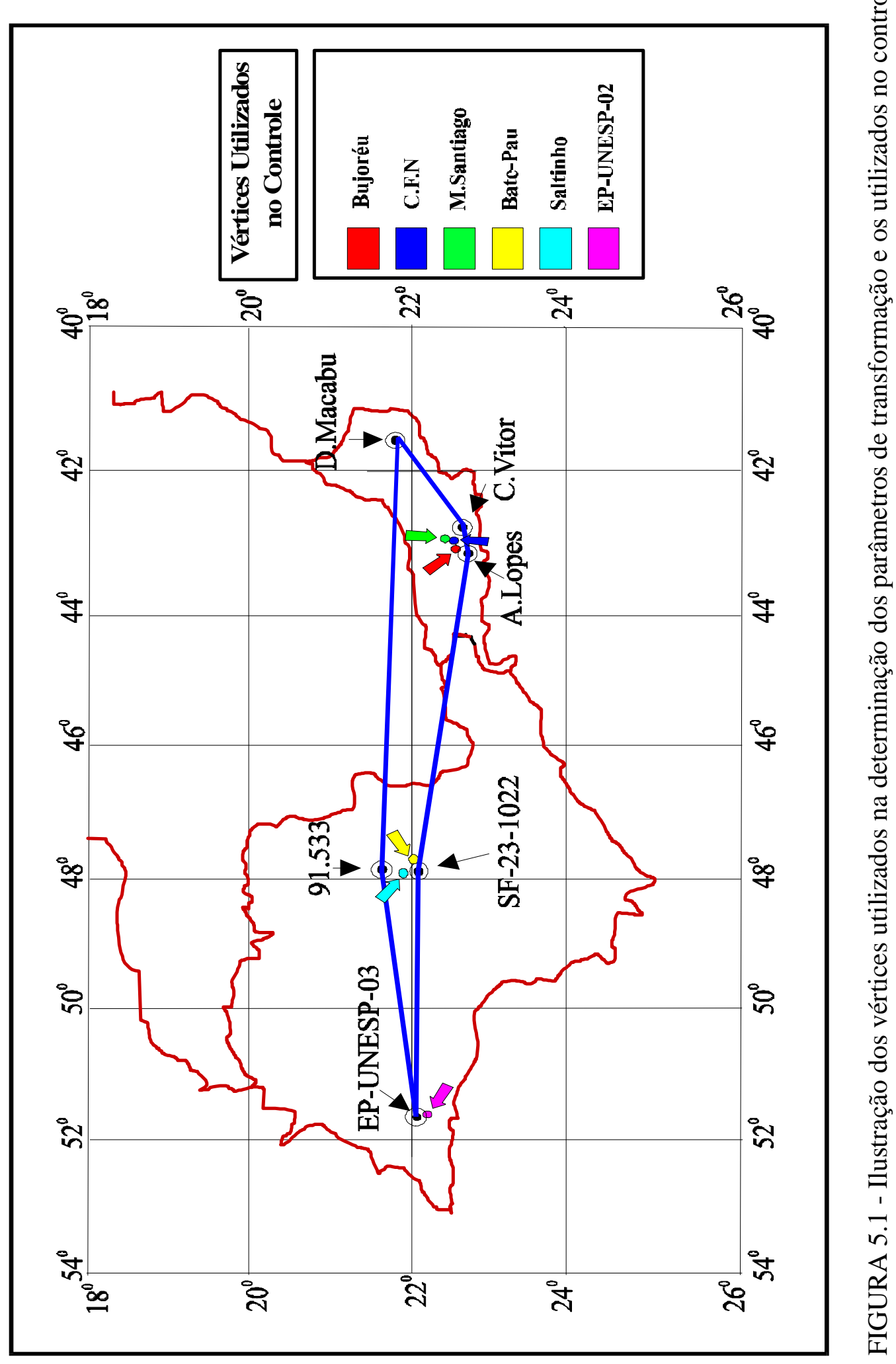


As posições geodésicas dos vértices nos sistemas WGS-84 e SAD-69 utilizados na determinação dos parâmetros de transformação e no controle são mostradas nas tabelas 5.1, 5.2, 5.3 e 5.4.

TABELA 5.1 - Coordenadas geodésicas no sistema SAD-69 dos vértices utilizados na determinação dos parâmetros de transformação considerando a ondulação geoidal.

\begin{tabular}{|c|c|c|c|c|c|c|}
\hline \multirow{2}{*}{$\begin{array}{l}\text { Nome } \\
\text { do } \\
\text { Vértice }\end{array}$} & \multirow{2}{*}{$\begin{array}{c}\text { Coordenadas } \\
\text { Latitude } \\
\left({ }^{\circ} \text { '“Sul }\right)\end{array}$} & \multicolumn{2}{|c|}{ Geodésicas } & \multicolumn{2}{|c|}{ Coordenadas } & Cartesianas \\
\hline & & $\begin{array}{c}\text { Longitude } \\
\left({ }^{\circ} \text { " "Oeste }\right)\end{array}$ & $\begin{array}{c}\text { Altura } \\
\text { (Geométrica) }\end{array}$ & $\mathrm{X}(\mathrm{m})$ & $\mathrm{Y}(\mathrm{m})$ & $\mathrm{Z}(\mathrm{m})$ \\
\hline EP-UNESP-03 & 220725,501 & 512430,709 & 446,160 & $3.687 .546,704$ & $-4.620 .720,761$ & $-2.387 .288,814$ \\
\hline A. Lopes ${ }^{*}$ & 225704,895 & 431235,905 & 703,939 & $4.283 .361,293$ & $-4.023 .747,345$ & $-2.472 .043,085$ \\
\hline C. Vitor ${ }^{*}$ & $2244 \quad 14,835$ & 424911,333 & 94,640 & $4.316 .995,882$ & $-4.000 .356,064$ & $-2.449 .974,855$ \\
\hline D. Macabu* & 215920,211 & 413013,420 & 22,750 & $4.431 .305,560$ & $-3.921 .001,995$ & $-2.373 .294,838$ \\
\hline SF-23-1022 & 220442,051 & 474419,462 & 1016,640 & $3.977 .367,665$ & $-4.377 .011,586$ & $-2.382 .844,796$ \\
\hline 91533 & 214445,416 & 474615,341 & 677,810 & $3.983 .929,604$ & $-4.389 .184,624$ & $-2.348 .566,508$ \\
\hline
\end{tabular}

TABELA 5.2 - Coordenadas geodésicas no sistema WGS-84 dos vértices utilizados na determinação dos parâmetros de transformação.

\begin{tabular}{|c|c|c|c|c|c|c|}
\hline \multirow{2}{*}{$\begin{array}{c}\text { Nome } \\
\text { do } \\
\text { Vértice }\end{array}$} & Coordenadas & \multicolumn{2}{|c|}{ Geodésicas } & \multicolumn{2}{|c|}{ Coordenadas } & artesianas \\
\hline & $\begin{array}{l}\text { Latitude } \\
\left({ }^{\circ} \text { “" Sul }\right)\end{array}$ & $\begin{array}{c}\text { Longitude } \\
\text { (c ““Oeste) }\end{array}$ & $\begin{array}{c}\text { Altura } \\
\text { (Geométrica) }\end{array}$ & $X(m)$ & $\mathrm{Y}(\mathrm{m})$ & $\mathrm{Z}(\mathrm{m})$ \\
\hline EP-UNESP-03 ${ }^{* *}$ & 220727,043 & 512432,418 & 439,742 & $3.687 .480,2391$ & $-4.620 .715,9800$ & $-2.387 .322,0936$ \\
\hline A. Lopes ${ }^{*}$ & 225706,581 & $43 \quad 1237,420$ & 695,550 & $4.283 .295,8616$ & $-4.023 .745,1131$ & $-2.472 .079,0450$ \\
\hline C. Vitor ${ }^{*}$ & 224416,507 & 424912,835 & 85,558 & $4.316 .930,3994$ & $-4.000 .353,8328$ & $-2.450 .010,3100$ \\
\hline D. Macabu* & 215921,865 & 413014,908 & 13,236 & $4.431 .240,3650$ & $-3.921 .001,3096$ & $-2.373 .330,2610$ \\
\hline SF-23-1022 & 220443,623 & 474421,081 & 1013,491 & $3.977 .304,7279$ & $-4.377 .011,3667$ & $-2.382 .880,1988$ \\
\hline 91533 & 214447,145 & 474616,950 & 670,124 & $3.983 .862,9100$ & $-4.389 .179,9540$ & $-2.348 .604,9470$ \\
\hline
\end{tabular}

\footnotetext{
**** As alturas geométricas $(h)$ foram obtidas através da expressão $h=H+N$, sendo " $H$ " a altitude ortométrica, advinda do nivelamento trigonométrico e " $N$ " a ondulação geoidal.

** Coordenadas obtidas através da UNESP - Campus de Presidente Prudente

* Informações advindas de: Oliveira, L.C., Ferreira, L.F., Blitzkow, D. Um Estudo Particular Sobre a Transformação SAD-69/WGS-84. In Anais do XVII Congresso Brasileiro de Cartografia, Salvador - Bahia, 1995.
} 
TABELA 5.3 - Coordenadas geodésicas no sistema SAD-69 dos vértices utilizados no Controle.

\begin{tabular}{|c|c|c|c|c|c|c|}
\hline \multirow{2}{*}{$\begin{array}{c}\text { Nome } \\
\text { do } \\
\text { Vértice }\end{array}$} & Coordenadas & \multicolumn{2}{|c|}{ Geodésicas } & \multicolumn{2}{|c|}{ Coordenadas } & Cartesianas \\
\hline & $\begin{array}{l}\text { Latitude } \\
\left({ }^{\circ} \text { “"Sul }\right)\end{array}$ & $\begin{array}{c}\text { Longitude } \\
\left({ }^{\circ} \text { “" Oeste }\right)\end{array}$ & $\begin{array}{c}\text { Altura } \\
\text { (Geométrica) }\end{array}$ & $\mathrm{X}(\mathrm{m})$ & $\mathrm{Y}(\mathrm{m})$ & $\mathrm{Z}(\mathrm{m})$ \\
\hline Bujoréu ${ }^{*}$ & 225247,841 & 430742,828 & 165,220 & $4.290 .959,3443$ & $-4.019 .422,9869$ & $-2.464 .549,3934$ \\
\hline C.F.N ${ }^{*}$ & 224711,657 & 431002,624 & 85,500 & $4.291 .107,6217$ & $-4.025 .025,5141$ & $-2.454 .987,0712$ \\
\hline M.Santiago ${ }^{*}$ & 225502,090 & 430435,417 & 351,090 & $4.293 .560,8728$ & $-4.014 .542,0153$ & $-2.468 .426,1838$ \\
\hline Bate Pau* & 220324,082 & 474704,317 & 974,585 & $3.974 .447,5595$ & $-4.380 .827,4953$ & $-2.380 .606,0989$ \\
\hline Saltinho ${ }^{*}$ & 215249,359 & 475503,617 & 836,202 & $3.969 .066,4409$ & -4.395 .377 .3039 & $-2.362 .446,2704$ \\
\hline EP-UNESP-02 ${ }^{* *}$ & 220719,566 & 512426,362 & 442,126 & $3.687 .684,9862$ & $-4.620 .694,2756$ & $-2.387 .118,4014$ \\
\hline
\end{tabular}

TABELA 5.4 - Coordenadas geodésicas no sistema WGS-84 dos vértices utilizados no Controle.

\begin{tabular}{|c|c|c|c|c|c|c|}
\hline \multirow{2}{*}{$\begin{array}{l}\text { Nome } \\
\text { do } \\
\text { Vértice }\end{array}$} & Coordenadas & \multicolumn{2}{|c|}{ Geodésicas } & \multicolumn{2}{|c|}{ Coordenadas } & Cartesianas \\
\hline & $\begin{array}{c}\text { Latitude } \\
\left({ }^{\circ} \text { ‘ } " \mathrm{Sul}\right) \\
\end{array}$ & $\begin{array}{c}\text { Longitude } \\
\left({ }^{\circ} \text { “" Oeste }\right) \\
\end{array}$ & $\begin{array}{c}\text { Altura } \\
\text { (Geométrica) } \\
\end{array}$ & $\mathrm{X}(\mathrm{m})$ & $\mathrm{Y}(\mathrm{m})$ & $\mathrm{Z}(\mathrm{m})$ \\
\hline Bujoréu* & 225249,520 & 430744,336 & 156,874 & $4.290 .894,1613$ & $-4.019 .420,8324$ & $-2.464 .585,2199$ \\
\hline C.F.N* & 224713,331 & 431004,134 & 76,586 & $4.291 .042,0908$ & $-4.025 .023,1001$ & $-2.455 .022,6069$ \\
\hline M.Santiago ${ }^{*}$ & 225503,775 & 430436,932 & 342,009 & $4.293 .495,4505$ & $-4.014 .539,5221$ & $-2.468 .461,8671$ \\
\hline Bate-Pau & 220325,694 & 474705,927 & 967,779 & $3.974 .382,1100$ & $-4.380 .824,3152$ & $-2.380 .641,3003$ \\
\hline Saltinho & 215250,967 & 475505,234 & 831,402 & $3.969 .002,2685$ & $-4.395 .375,5470$ & $-2.362 .482,2327$ \\
\hline EP-UNESP- $02^{* *}$ & 220721,151 & 512428,075 & 436,716 & $3.687 .618,3619$ & $-4.620 .689,4877$ & $-2.387 .153,0643$ \\
\hline
\end{tabular}

As informações referentes aos vértices localizados na região de São Carlos foram cedidas pela Diretoria de Geociências do Departamento de Geodésia da Fundação Instituto de Geografia e Estatística-IBGE. Estas informações consistem de um relatório contendo as posições horizontais e verticais dos vértices, bem como um itinerário da localização dos mesmos. Estes vértices fazem parte da rede do Sistema Geodésico Brasileiro, onde as posições horizontais estão associadas ao sistema de referência SAD-69 e as verticais, que correspondem às altitudes ortométricas, estão associadas ao datum Imbituba. As altitudes ortométricas são provenientes de nivelamento trigonométrico. Segundo o relatório fornecido pelo IBGE, existem 5 vértices na região de São Carlos. Foi realizado um trabalho de reconhecimento dos

\footnotetext{
** Coordenadas obtidas através da UNESP - Campus de Presidente Prudente

* Informações advindas de: Oliveira, L.C., Ferreira, L.F., Blitzkow, D. Um Estudo Particular Sobre a Transformação SAD-69/WGS-84. In Anais do XVII Congresso Brasileiro de Cartografia, Salvador - Bahia, 1995.
} 
vértices onde foi possível reconhecer 4. A identificação destes vértices são: SF-23-1022, 91533, Bate-Pau e Saltinho. O vértice não reconhecido possui a identificação de Janelinha e, segundo o IBGE, ele está localizado no município de Descalvado na parte mais elevada de um morro conhecido na região pelo nome de "Morro Janelinha". O local é constituído de uma pequena mata, de difícil acesso, e só é possível atingir a parte mais elevada do morro por meio de trilhas. Além da não localização do vértice, o local praticamente não possui nenhum horizonte para rastreio. Encontra-se deteriorado a parte superior do marco Bate-Pau, além de possuir algumas obstruções devido ao fato de estar localizado em uma plantação de café. O vértice Saltinho possui bastante obstruções. O restante possui um excelente horizonte para rastreio.

Todas as informações concernentes aos vértices reconhecidos na região de São Carlos são mostradas em Anexo.

\subsection{Determinação das ondulações geoidais dos vértices}

Em uma compatibilização de referenciais geodésicos, utiliza-se coordenadas geodésicas cartesianas nos modelos matemáticos de transformação. As coordenadas geodésicas cartesianas estão relacionadas com a latitude, longitude e altura geométrica do ponto. Isto passa a ser um problema para o sistema SAD-69, onde, para a obtenção da altura geométrica do ponto, há a necessidade do conhecimento da ondulação geoidal (o mesmo não ocorre com o sistema WGS-84).

Para o estabelecimento das ondulações geoidais dos doze vértices, utilizou-se o Mapa Geoidal do Brasil (1992) desenvolvido pelo IBGE em conjunto com a Escola Politécnica da Universidade de São Paulo (EPUSP/PTR). O mapa geoidal possui uma precisão absoluta de 3 metros e relativa de 1 centímetro por quilômetro. As ondulações geoidais destes vértices são mostradas na tabela 5.5. 
TABELA 5.5 - Valores das ondulações geoidais dos vértices utilizados na elaboração do trabalho

\begin{tabular}{ccc}
\hline Nome do & Localização & $\begin{array}{c}\text { Ondulação Geoidal } \\
\text { em SAD-69 }(\mathrm{m})\end{array}$ \\
\hline Aértice & & 3,29 \\
C. Lopes & Rio de Janeiro & 3,45 \\
D. Macabu & Rio de Janeiro & 3,12 \\
Bujoréu & Rio de Janeiro & 3,35 \\
C.F.N & Rio de Janeiro & 3,44 \\
M.Santiago & Rio de Janeiro & 3,32 \\
EP-UNESP-03 & Rio de Janeiro & 1,94 \\
EP-UNESP-02 & Pres. Prud. (SP) & 1,93 \\
SF-23-1022 & Pres. Prud. (SP) & $-3,67$ \\
91533 & São Carlos (SP) & $-2,90$ \\
Bate-Pau & São Carlos (SP) & $-3,74$ \\
Saltinho & São Carlos (SP) & $-3,62$ \\
\hline
\end{tabular}

\subsection{Rastreio com o sistema GPS nos quatro vértices da rede do SGB localizados na região de São Carlos-SP}

$\mathrm{Na}$ determinação das coordenadas através dos satélites do sistema GPS, usou-se o método com posicionamento relativo empregando a fase da portadora para as observações. Este é um método já de uso consagrado nas observações geodésicas e nos fornece boa precisão se comparado com outros métodos, HOFMANNWELLENHOF (1994).

O equipamento utilizado foi um TRIMBLE SST 4000 com as duas frequências $L_{1}$ e $L_{2}$. Utilizou-se um equipamento com duas frequências, pois, os comprimentos das bases observadas eram superiores a $10 \mathrm{Km}$, minimizando assim os efeitos da ionosfera. O vértice de referência utilizado foi o STTU, localizado no 
Departamento de Transportes da USP de São Carlos, que está ligado à da rede GPS do Estado de São Paulo.

Para cada vetor foi realizado duas seções de observações de aproximadamente uma hora e meia cada, com um ângulo de corte de $10^{\circ}$, numa taxa de observação de 15 segundos.

Os comprimentos das linhas bases são mostrados na tabela 5.6.

TABELA 5.6 - Comprimento das linhas bases rastreadas com o sistema GPS na Região de São Carlos-SP.

\begin{tabular}{cc}
\hline Linhas Bases & Comprimento (m) \\
\hline STTU - SF-23-1022 & 18432,462 \\
STTU - 91.533 & 31528,744 \\
STTU - Bate Pau & 13132,587 \\
STTU - Saltinho & 13883,823 \\
\hline
\end{tabular}

\subsection{Processamento dos dados GPS}

As informações coletadas nos receptores GPS foram processadas com o software GPSURVEY 2.2 da TRIMBLE. Durante o processamento das informações, procurou-se estabelecer alguns critérios necessários em um trabalho de precisão:

- Foi utilizado no processamento um ângulo de corte de $15^{\circ}$;

- Os satélites com muita perda de ciclos foram eliminados do processamento;

- Tomou-se sempre como satélite referência o de maior elevação;

- Utilizou-se o modelo troposférico Hopfield. É importante salientar que, o usuário não deve esperar bons resultados se ele não considerar nenhum modelo de troposfera;

- Quanto ao modelo ionosférico, a experiência tem mostrado que é recomendável a sua aplicação para linhas bases com comprimentos superiores a $15 \mathrm{Km}$. Por ter utilizado um equipamento $\mathrm{L}_{1}$ e $\mathrm{L}_{2}$ e mesmo não sendo os comprimentos de todas as linhas bases superiores a $15 \mathrm{Km}$, para 
minimizar os efeitos de ionosfera optou-se no processamento de $\mathrm{L}_{3}$ ("IonoFree"), que corresponde a uma combinação linear de $\mathrm{L}_{1}$ e $\mathrm{L}_{2}$. Maiores informações podem ser obtidas em SEGANTINE (1995a) e SEGANTINE (1995b).

A tabela 5.7 resume as soluções encontradas das linhas bases:

TABELA 5.7 - Quadro resumo das soluções encontradas em $\mathrm{L}_{1}$ e $\mathrm{L}_{3}$ das linhas bases rastreadas

\begin{tabular}{ccccc}
\hline Linhas Bases & $\begin{array}{c}\text { Solução } \\
\text { em L } \mathrm{L}_{1}\end{array}$ & $\begin{array}{c}\text { RMS em } \\
\mathrm{L}_{1}(\mathrm{~mm})\end{array}$ & $\begin{array}{c}\text { Solução } \\
\text { em } \mathrm{L}_{3}\end{array}$ & $\begin{array}{c}\text { RMS em } \\
\mathrm{L}_{3}(\mathrm{~mm})\end{array}$ \\
\hline STTU - SF-23-1022 & "Float" & 28 & "Iono Free Float" & 15 \\
STTU - 91.533 & "Float" & 10 & "Iono Free Float" & 11 \\
STTU - Bate Pau & "Float" & 18 & "Iono Free Float" & 12 \\
STTU - Saltinho & "Float" & 25 & "Iono Free Float" & 25 \\
\hline
\end{tabular}

Um dos critérios de análise do resultado final de um processamento é observar o valor do RMS ("Root Mean Square"). O RMS corresponde ao desvio padrão obtido de um ajustamento pelos mínimos quadrados de uma simples diferença de fase, SEGANTINE (1997).

Observa-se pela tabela 5.7 que o maior RMS encontrado corresponde à linha base STTU-Saltinho. Isto pode ser explicado pelo fato de que o vértice Saltinho está localizado em uma região com muitas obstruções de árvores. Em todas as linhas bases a solução em $\mathrm{L}_{1}$ foi uma "Float Solution", pois:

- As distâncias das linhas bases STTU - SF-23-1022 e STTU - 91.533 são superiores ao valor limite do "default" do software utilizado no processamento dos dados;

- Os vértices Saltinho e Bate-Pau são sujeitos a obstruções. 
Diz-se que uma solução é "Float" quando não foi possível no processamento fixar um valor inteiro para a ambiguidade. A ambiguidade corresponde ao número inteiro de ciclos da onda portadora entre a antena do receptor e o satélite.

$\mathrm{Na}$ elaboração do trabalho, optou-se pela solução $\mathrm{L}_{3}$ ("Iono Free") por apresentar o menor valor para o RMS. Esta solução tem a vantagem de eliminar a influência da ionosfera nos resultados finais. Corresponde a solução "Iono Free Float Solution", pois, destroi a natureza inteira da ambiguidade, não sendo possível a sua solução, SEGANTINE (1997).

A tabela 5.8 mostra valores de RMS em função da distância da linha base e do tempo de observação.

TABELA 5.8 - Valores de RMS em função da distância da linha base e do tempo de observação, SEGANTINE (1997).

\begin{tabular}{ccccc}
\hline \multirow{2}{*}{ Distância } & \multicolumn{2}{c}{ Dia } & \multicolumn{2}{c}{ Noite } \\
\cline { 2 - 5 } & \multicolumn{2}{c}{ Tempo de Observação } & \multicolumn{2}{c}{ Tempo de Observação } \\
\cline { 2 - 5 } & $\leq 10 \mathrm{~min}$. & $>10 \mathrm{~min}$. & $\leq 10 \mathrm{~min}$. & $>10 \mathrm{~min}$. \\
\hline$>5 \mathrm{Km}$ & $<10 \mathrm{~mm}$ & $<10 \mathrm{~mm}$ & $<10 \mathrm{~mm}$ & $<10 \mathrm{~mm}$ \\
5 a $10 \mathrm{Km}$ & $<15 \mathrm{~mm}$ & $<25 \mathrm{~mm}$ & $<10 \mathrm{~mm}$ & $<15 \mathrm{~mm}$ \\
10 a $20 \mathrm{Km}$ & $<15 \mathrm{~mm}$ & $<40 \mathrm{~mm}$ & $<10 \mathrm{~mm}$ & $<15 \mathrm{~mm}$ \\
\hline
\end{tabular}

O resultado do processamento das quatro linhas bases são mostrados no Apêndice 1. 


\subsection{Determinação dos sete parâmetros de transformação entre os sistemas WGS-84 e SAD-69}

Nesta etapa do trabalho, aplicou-se os quatro modelos matemáticos de transformação de coordenadas apresentados no capítulo 4 com o objetivo de determinar parâmetros de transformação. Os vértices utilizados na determinação dos parâmetros, tanto no sistema SAD-69 quanto no sistema WGS-84, foram apresentados nas tabelas 5.1 e 5.2, respectivamente. Aplicou-se o Método dos Mínimos Quadrados na determinação dos parâmetros de transformação por possuir um número maior de equações do que incógnitas.

Utilizou-se na realização do ajustamento dos parâmetros um desvio padrão à priori $\left(\sigma_{0}=1\right)$, que corresponde a precisão de uma determinada observação de peso unitário. Esta é uma prática comum em qualquer ajustamento de observações pelo MMQ. Julgou-se necessário também estabelecer a matriz Peso como sendo unitária pela dificuldade de definição das precisões das coordenadas geodésicas relacionadas ao sistema SAD-69. Estas informações das precisões não foram divulgadas pelo IBGE, até mesmo pelo fato de que, o que interessa, são as precisões das coordenadas geodésicas cartesianas e as mesmas estão diretamente relacionadas com as precisões das ondulações geoidais, parâmetro este de complexa definição. Desta forma, foi possível analisar a soma dos quadrados dos resíduos $\left(V^{T} . P . V\right)$ do ajustamento dos parâmetros de cada modelo.

Pelo próprio MMQ, a média aritmética corresponde a um valor que melhor representa um conjunto de observações. Sendo assim, é conveniente estabelecer na definição da precisão de um determinado parâmetro ajustado, o desvio padrão da média. As precisões dos parâmetros ajustados são definidas através da Matriz Variância Covariância (MVC) dos parâmetros ajustados. A MVC corresponde a uma matriz quadrada e simétrica cujas componentes são variâncias e covariâncias devidamente dispostas. A definição da MVC e do desvio padrão da média é estabelecida pelas equações (5.1) e (5.2), respectivamente.

$$
\begin{aligned}
& \sum X_{a}=\sigma_{0}^{2} \cdot\left(A^{T} \cdot P \cdot A\right)^{-1} \\
& \sigma_{\bar{X}}= \pm \frac{\sigma}{\sqrt{n}}
\end{aligned}
$$


onde:

- $\sum X_{a}$ corresponde à MVC dos parâmetros ajustados;

- $\sigma_{\mathrm{o}}^{2}$ corresponde à variância a priori;

- $A$ corresponde a matriz " $A$ " do sistema de equações normais;

- $P$ corresponde a matriz peso do sistema de equações normais;

$\bullet \sigma_{\bar{X}}$ corresponde ao desvio padrão da média;

• $\sigma$ corresponde ao desvio padrão de uma observação isolada;

- $n$ corresponde ao número de observações.

Foram utilizados seis vértices de controle para testar a validade dos parâmetros determinados. São conhecidas também as coordenadas geodésicas, nos dois sistemas, destes seis vértices. Estas coordenadas foram apresentadas nas tabelas 5.3 e 5.4. A análise da validade dos parâmetros determinados procedeu-se conforme a eq.(5.3).

$$
\begin{aligned}
& \Delta_{X}=X_{\text {observado }}-X_{W G S-84 T} \\
& \Delta_{Y}=Y_{\text {observado }}-Y_{W G S-84 T} \\
& \Delta_{Z}=Z_{\text {observado }}-Z_{W G S-84 T}
\end{aligned}
$$

onde:

- $\Delta_{X}, \Delta_{Y} e \Delta_{Z}$ correspondem às discrepâncias encontradas nas coordenadas $X$, $Y$, e $Z$ decorrentes da diferença algébrica entre $X, Y$ e $Z$ observados em WGS-84 e as coordenadas $X, Y$ e $Z$ em WGS-84 transformadas, advindas da aplicação dos parâmetros de transformação determinados pelos quatro modelos estudados;

- $X_{\text {observado, }} Y_{\text {observado }}$ e $Z_{\text {observado }}$ correspondem às coordenadas observadas em WGS-84 dos vértices utilizados no controle;

- $X_{W G S-84 T}, Y_{W G S-84 T}$ e $Z_{W G S-84 T}$ correspondem às coordenadas transformadas em WGS-84 dos vértices utilizados no controle, advindas dos parâmetros de transformação determinados pelos quatro modelos estudados. 


\subsection{Determinação dos três parâmetros de transformação entre os sistemas WGS-84 e SAD-69}

Nesta etapa do trabalho a preocupação foi em verificar o que aconteceria com o valor do $V^{T} . P . V$ do ajustamento considerando apenas três parâmetros de transformação, que são as translações existentes entre os eixos coordenados dos sistemas SAD-69 e WGS-84. Verificou-se a validade dos parâmetros determinados através dos pontos de controle, com a mesma metodologia exposta no item 5.6 através da equação (5.3). Na determinação dos três parâmetros de transformação, há uma consideração de paralelismo entre os sistemas de referência WGS-84 e o SAD69, estabelecido de acordo com a definição do IBGE. O ajustamento de observações é relativamente simples, e a estrutura das matrizes $A$ e $L$, do sistema de equações normais, é mostrada a seguir. No ajustamento, foram aplicados os mesmos vértices utilizados na determinação dos sete parâmetros de transformação.

A figura 5.2 ilustra o vetor translação entre um sistema geocêntrico (WGS-84) e um Sistema Geodésico Local (SAD-69).

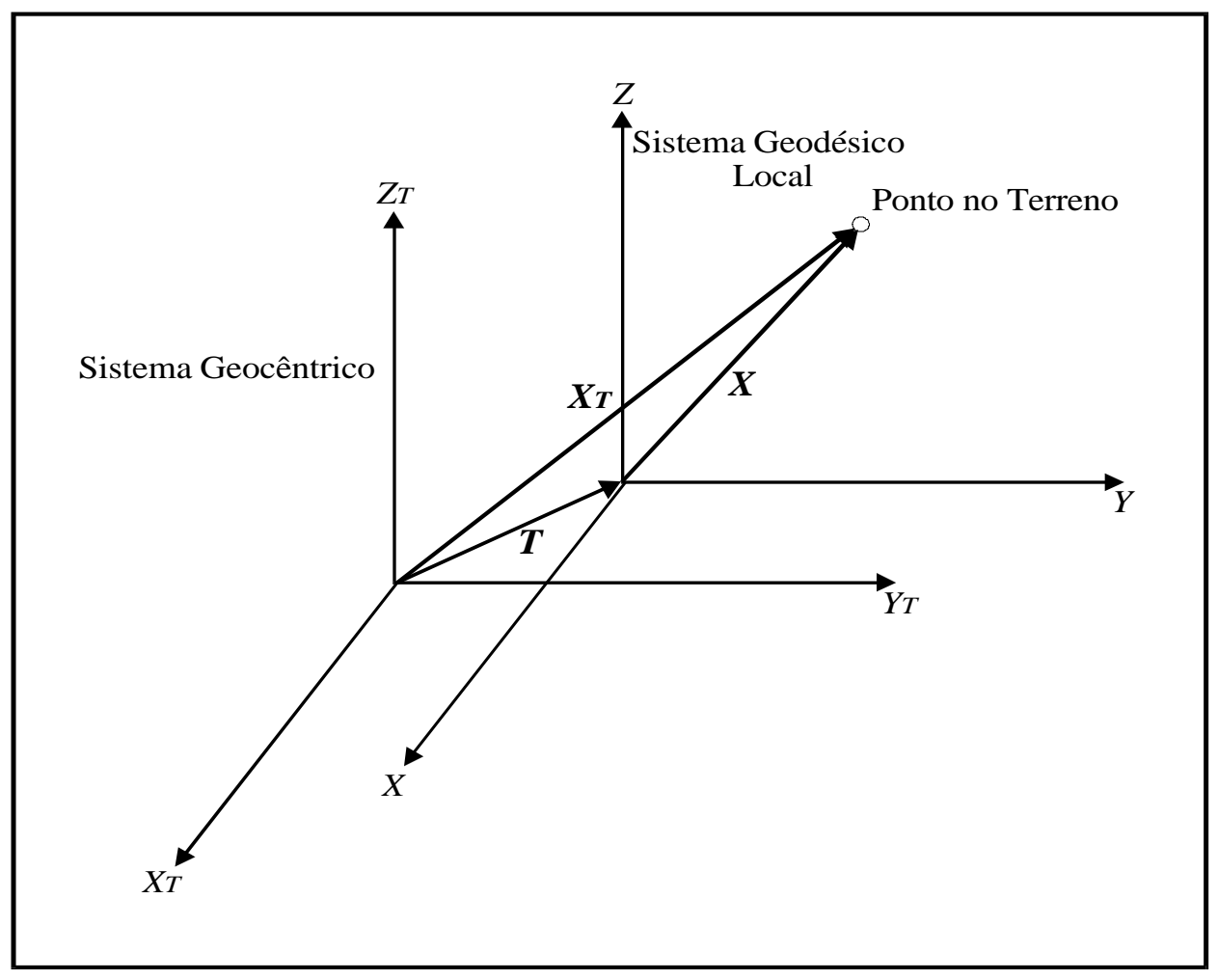

FIGURA 5.2 - Ilustração do vetor translação entre um sistema geodésico geocêntrico e um geodésico local 
O vetor translação é obtido por:

$$
X_{T}-X=T
$$

onde:

- $\boldsymbol{X}_{T}$ corresponde ao vetor com origem no sistema de coordenadas geocêntrico, que une um ponto na superfície da Terra, definido pelas coordenadas $X_{T}, Y_{T}, Z_{T}$;

$\checkmark \boldsymbol{X}$ corresponde ao vetor com origem no Sistema Geodésico Local, que une um ponto na superfície da Terra, definido pelas coordenadas $X, Y, Z$;

$\checkmark T$ corresponde ao vetor translação entre os dois sistemas geodésicos de referência. Suas componentes correspondem a $T_{X}, T_{Y}, T_{Z}$ que são as translações em $X, Y$ e $X$, respectivamente.

Para um único ponto tem-se:

$$
\begin{aligned}
& X_{T 1}-X_{1}=T_{X} \\
& Y_{T 1}-Y_{1}=T_{Y} \\
& Z_{T 1}-Z_{1}=T_{Z}
\end{aligned}
$$

A estrutura das matrizes $A$ e $L$ é mostrada a seguir:

$$
A=\left(\begin{array}{ccc}
1 & 0 & 0 \\
0 & 1 & 0 \\
0 & 0 & 1 \\
\cdots \cdots & \cdots \cdots & \cdots \cdots \\
\cdots \cdots & \cdots \cdots & \cdots \cdots \\
\cdots \cdots & \cdots \cdots & \cdots . . \\
1 & 0 & 0 \\
0 & 1 & 0 \\
0 & 0 & 1
\end{array}\right)
$$




$$
L=\left(\begin{array}{c}
\left(X_{T 1}-X_{1}\right) \\
\left(Y_{T 1}-Y_{1}\right) \\
\left(Z_{T 1}-Z_{1}\right) \\
\ldots \ldots \ldots . . . \\
\ldots \ldots \ldots . . . \\
\ldots \ldots \ldots \ldots . . \\
\left(X_{T n}-X_{n}\right) \\
\left(Y_{T n}-Y_{n}\right) \\
\left(Z_{T n}-Z_{n}\right)
\end{array}\right) \operatorname{com} i=(1,2, \ldots \ldots, n)
$$

A matriz peso $P$, é obtida da mesma forma do que foi exposta no item 4.2.1.1 do capítulo 4. Estruturada todas as matrizes do sistema de equações normais, os três parâmetros de transformação, bem como o vetor resíduo $\boldsymbol{V}$, podem ser obtidos pelas equações (5.8) e (5.9), respectivamente:

$$
\begin{aligned}
& \boldsymbol{X}=\left(A^{T} \cdot P \cdot A\right)^{-1} \cdot\left(A^{T} \cdot P \cdot L\right) \\
& \boldsymbol{V}=A \cdot \boldsymbol{X}-\boldsymbol{L}
\end{aligned}
$$

\subsection{Aplicação dos parâmetros de transformação oficiais divulgados pelo IBGE nos pontos de controle}

Procurou-se nesta etapa verificar as discrepâncias nos vértices de controle (através da equação 5.3) quando aplicados os parâmetros oficiais de transformação divulgados pelo IBGE, fazendo um paralelo com as discrepâncias encontradas com os parâmetros de transformação determinados neste trabalho.

\subsection{Efeito da ondulação geoidal na determinação dos parâmetros de transformação}

O objetivo principal desta etapa do trabalho, foi observar as consequências causadas na determinação dos parâmetros de transformação, não considerando a ondulação geoidal na determinação das coordenadas geodésicas cartesianas em SAD-69 dos seis vértices. Utilizou-se na determinação das coordenadas cartesianas 
geodésicas a altitude ortométrica ao invés da altura geométrica, ou seja, na equação (2.10) do item 2.3.3, ao invés de trabalhar com a altura geométrica $(h)$, trabalhou-se com a altitude ortométrica $(H)$. Nesta etapa realizou-se todas as metodologias apresentadas nos itens 5.6 e 5.7. As coordenadas geodésicas cartesianas dos seis vértices, não considerando a ondulação geoidal nas suas determinações $(h=H)$, são mostradas na tabela 5.9.

TABELA 5.9 - Coordenadas geodésicas cartesianas no sistema SAD-69 dos vértices utilizados na determinação dos parâmetros de transformação desconsiderando a ondulação geoidal.

\begin{tabular}{|c|c|c|c|}
\hline \multirow{2}{*}{$\begin{array}{c}\text { Nome } \\
\text { do } \\
\text { Vértice }\end{array}$} & \multicolumn{2}{|c|}{ Coordenadas } & artesianas \\
\hline & $X(m)$ & $\mathrm{Y}(\mathrm{m})$ & $\mathrm{Z}(\mathrm{m})$ \\
\hline EP-UNESP-03 & $3.687 .545,5884$ & $-4.620 .719,3479$ & $-2.387 .288,0908$ \\
\hline A. Lopes & 4.283.359,0851 & $-4.023 .745,2710$ & $-2.472 .041,8020$ \\
\hline C. Vitor & $4.316 .993,5477$ & $-4.000 .353,9015$ & $-2.449 .973,5216$ \\
\hline D. Macabu & $4.431 .303,3937$ & $-3.921 .000,0774$ & $-2.373 .293,6697$ \\
\hline SF-23-1022 & 3.977.369,9519 & $-4.377 .014,1033$ & $-2.382 .846,1756$ \\
\hline 91533 & $3.983 .931,4143$ & $-4.389 .186,6190$ & $-2.348 .567,5826$ \\
\hline
\end{tabular}




\section{CAPÍTULO 6 - RESULTADOS E DISCUSSÕES}

\subsection{Introdução}

Em toda a elaboração do trabalho a principal preocupação foi apresentar, da maneira mais objetiva possível, o problema de compatibilização de referenciais geodésicos (mais especificamente os referenciais WGS-84 e o SAD-69), quando se utiliza os parâmetros de transformação oficialmente divulgados pelo IBGE.

Para mostrar o problema, estabeleceu-se uma região de estudo compreendida pelos vértices mostrados nas tabelas 5.1 e 5.2 do item 5.2 do capítulo 5. Utilizandose estes vértices, aplicou-se alguns modelos matemáticos de transformação de coordenadas com o objetivo de determinar os parâmetros de transformação entre os referenciais WGS-84 e o SAD-69 para esta área de estudo. Estes parâmetros, juntamente com os divulgados oficialmente pelo IBGE, foram testados em alguns vértices de controle localizados dentro da região de estudo. Estes vértices são mostrados nas tabelas 5.3 e 5.4 do item 5.2 do capítulo 5 .

Sempre com a preocupação de atingir os objetivos do trabalho, analisou-se também, em todos os modelos estudados, o valor do $V^{T} . P . V$ do ajustamento dos parâmetros de transformação. 
$\mathrm{Na}$ abordagem tridimensional utilizada pelos modelos matemáticos de transformação de coordenadas, o conhecimento da ondulação geoidal para o estabelecimento da altura geométrica se faz necessário. Segundo SCHMITT et al. (1991) apud HOFMANN-WELLENHOF (1994), a altura geométrica pode ser substituída pela altitude ortométrica (no estabelecimento das coordenadas geodésicas cartesianas $X, Y, Z$ ) sem causar efeitos significativos nas coordenadas horizontais $(\phi, \lambda)$ e, consequentemente, na determinação dos parâmetros de transformação desde que a área levantada seja pequena. Sendo assim, uma das preocupações do trabalho foi também em determinar os parâmetros de transformação desconsiderando a ondulação geoidal e verificar o valor do $V^{T} . P . V$ do ajustamento. Estes parâmetros também foram utilizados nos vértices de controle e analisou-se as discrepâncias.

A seguir serão apresentados os resultados encontrados no decorrer de todo o desenvolvimento do trabalho, bem como algumas considerações que julgou-se necessário realizar.

\subsection{Valores encontrados para os parâmetros de transformação ajustados considerando a ondulação geoidal}

Os valores ajustados para os parâmetros de transformação considerando * a ondulação geoidal são mostrados nas tabelas abaixo. Na tabela 6.1 são mostrados os valores ajustados dos sete parâmetros de transformação bem como o valor do $V^{T}$.P.V. Na tabela 6.2 são mostrados apenas os valores dos três parâmetros de transformação ajustados que são as translações $T_{X}, T_{Y}, T_{Z}$ bem como o valor do $V^{T} . P . V$.

\footnotetext{
* A consideração da ondulação geoidal na determinação dos parâmetros de transformação está diretamente relacionado com a equação (2.10) do item 2.3.3. O termo $h$ (altura geométrica) da expressão é em função da ondulação geoidal $N$ obtida através do programa MAPGEO $(h=H+N)$.
} 
TABELA 6.1 - Resultado do ajustamento dos sete parâmetros de transformação considerando a ondulação geoidal

\begin{tabular}{|c|c|c|c|c|}
\hline Modelos & Parâmetros & Valores & $\sigma_{\bar{X}}$ & $V^{T} . P . V$ \\
\hline \multirow{7}{*}{ Helmert } & $T_{X}$ & $-21,248 \mathrm{~m}$ & $\pm 4,022 \mathrm{~m}$ & \multirow{7}{*}{31,411} \\
\hline & $T_{Y}$ & $-11,625 \mathrm{~m}$ & $\pm 3,681 \mathrm{~m}$ & \\
\hline & $T_{Z}$ & $36,106 \mathrm{~m}$ & $\pm 4,202 \mathrm{~m}$ & \\
\hline & $(1+\mu)$ & 0,99999830742 & $\pm 0,265.10^{-6}$ & \\
\hline & $\alpha_{1}$ & $-1,724$ seg. & $\pm 0,330 \mathrm{seg}$. & \\
\hline & $\alpha_{2}$ & $-2,033$ seg. & $\pm 0,331 \mathrm{seg}$ & \\
\hline & $\alpha_{3}$ & $0,658 \mathrm{seg}$. & $\pm 0,061 \mathrm{seg}$. & \\
\hline \multirow{7}{*}{ Bursa } & $T_{X}$ & $-21,248 \mathrm{~m}$ & $\pm 4,022 \mathrm{~m}$ & \multirow{7}{*}{31,411} \\
\hline & $T_{Y}$ & $-11,625 \mathrm{~m}$ & $\pm 3,681 \mathrm{~m}$ & \\
\hline & $T_{Z}$ & $36,106 \mathrm{~m}$ & $\pm 4,202 \mathrm{~m}$ & \\
\hline & $(1+\mu)$ & 0,99999830742 & $\pm 0,265.10^{-6}$ & \\
\hline & $\alpha_{1}$ & $-1,724$ seg. & $\pm 0,330 \mathrm{seg}$. & \\
\hline & $\alpha_{2}$ & $-2,033 \mathrm{seg}$. & $\pm 0,331 \mathrm{seg}$ & \\
\hline & $\alpha_{3}$ & $0,658 \mathrm{seg}$. & $\pm 0,061 \mathrm{seg}$. & \\
\hline \multirow{7}{*}{$\begin{array}{c}\text { Molodenskii } \\
\text { (Primeira Versão) }\end{array}$} & $T_{X}$ & $-67,207 \mathrm{~m}$ & $\pm 0,411 \mathrm{~m}$ & \multirow{7}{*}{33,378} \\
\hline & $T_{Y}$ & $4,741 \mathrm{~m}$ & $\pm 0,367 \mathrm{~m}$ & \\
\hline & $T_{Z}$ & $-35,451 \mathrm{~m}$ & $\pm 0,187 \mathrm{~m}$ & \\
\hline & $(1+\mu)$ & 0,999998120 & $\pm 0,267 \cdot 10^{-6}$ & \\
\hline & $\alpha_{1}$ & 1,232 seg. & $\pm 0,281 \mathrm{seg}$. & \\
\hline & $\alpha_{2}$ & 1,223 seg. & $\pm 0,339 \mathrm{seg}$. & \\
\hline & $\alpha_{3}$ & 0,406 seg. & $\pm 0,067 \mathrm{seg}$. & \\
\hline \multirow{7}{*}{$\begin{array}{c}\text { Molodenskii } \\
\text { (Segunda Versão) }\end{array}$} & $\overline{T_{X}}$ & $-21,248 \mathrm{~m}$ & $\pm 4,022 \mathrm{~m}$ & \multirow{7}{*}{31,411} \\
\hline & $T_{Y}$ & $-11,625 \mathrm{~m}$ & $\pm 3,681 \mathrm{~m}$ & \\
\hline & $T_{Z}$ & $36,106 \mathrm{~m}$ & $\pm 4,202 \mathrm{~m}$ & \\
\hline & $(1+\mu)$ & 0,99999830742 & $\pm 0,265.10^{-6}$ & \\
\hline & $\alpha_{1}$ & $-1,724$ seg. & $\pm 0,330 \mathrm{seg}$. & \\
\hline & $\alpha_{2}$ & $-2,033$ seg. & $\pm 0,331 \mathrm{seg}$ & \\
\hline & $\alpha_{3}$ & $0,658 \mathrm{seg}$. & $\pm 0,061 \mathrm{seg}$. & \\
\hline
\end{tabular}


TABELA 6.2 - Resultado do ajustamento dos três parâmetros de transformação considerando a ondulação geoidal

\begin{tabular}{cccc}
\hline Parâmetros & Valores $(\mathrm{m})$ & $\sigma_{\bar{X}}(\mathrm{~m})$ & $V^{T} \cdot P . V$ \\
\hline$T_{X}$ & $-65,368$ & $\pm 0,100$ & \\
$T_{Y}$ & 2,470 & $\pm 0,100$ & 41,106 \\
$T_{Z}$ & $-35,660$ & $\pm 0,100$ & \\
\hline
\end{tabular}

Analisando a tabela 6.1, pode-se observar que o modelo de Molodenskii (primeira versão) proporcionou um pequeno aumento no valor do $V^{T} . P . V$ do ajustamento em relação aos outros três modelos estudados. No que diz respeito aos parâmetros de transformação, observa-se que foram encontrados valores idênticos para os modelos de Bursa, Helmert e Molodenskii (segunda versão). O modelo de Molodenskii proporcionou resultados diferentes, principalmente nos valores das três translações $T_{X}, T_{Y}$ e $T_{Z}$. Isto tem uma explicação cabível. O centro de rotações no modelo de Bursa, Helmert e até mesmo do modelo de Molodenskii (segunda versão) situa-se nas proximidades do geocentro, muito afastado portanto da pequena área de distribuição dos vértices utilizados na determinação dos parâmetros de transformação. Torna-se, consequentemente, difícil separar os efeitos geométricos de translações e pequenas rotações, num processo de ajustamento a que se submeta um sistema de equações de observação constituídas com base nos modelos focalizados. Isto explica as fortes correlações existentes entre os parâmetros de translação e rotação. É possível que estas correlações tendam a diminuir quanto mais uniforme e abrangente for a distribuição dos vértices utilizados na determinação dos parâmetros de transformação sobre a superfície terrestre.

Estas fortes correlações entre as rotações e as translações não ocorrem com o modelo de Molodenskii (primeira versão), pois o centro de rotações deste modelo está mais próximo dos vértices utilizados na determinação dos parâmetros de transformação. Neste caso, o centro de rotações está localizado na origem da rede do SGB. 
As precisões encontradas para os parâmetros de transformação correspondem ao desvio padrão da média e observa-se na tabela 6.1 que, para os quatro modelos, as precisões encontradas para o fator de escala e para as três rotações são praticamente idênticas. O mesmo não ocorreu para as três translações, pois o modelo de Molodenskii (primeira versão) proporcionou uma melhora significativa na precisão em torno da média.

Analisando a tabela 6.2, os seus valores correspondem ao resultado do ajustamento dos três parâmetros de transformação (considerando a ondulação geoidal) que são as três translações. Fazendo um paralelo com a tabela 6.1, observase que houve um aumento significativo no valor do $V^{T} . P . V$. Este aumento deve estar relacionado com alguns possíveis erros sistemáticos existentes na definição do SAD-69, proporcionando assim pequenas rotações do mesmo em relação ao sistema de referência WGS-84. As translações encontradas diferem das divulgadas oficialmente pelo IBGE que são:

$$
\begin{aligned}
& T_{X}=-66,87 \mathrm{~m} \\
& T_{Y}=+4,37 \mathrm{~m} \\
& T_{Z}=-38,52 \mathrm{~m}
\end{aligned}
$$

A tabela 6.2 mostra também uma melhoria nas precisões das translações. Isto pode ser compreendido pela redução do número de incógnitas que passou de sete para três, proporcionando uma melhor consistência nos valores das precisões encontradas.

\subsection{Discrepâncias encontradas nos vértices de controle}

As discrepâncias encontradas nos vértices de controle, são apresentadas nas tabelas 6.3, 6.4 e 6.5. Na tabela 6.3, as discrepâncias encontradas são em função dos sete parâmetros de transformação, determinados pelo quatro modelos discutidos neste trabalho, considerando a ondulação geoidal. As tabelas 6.4 e 6.5, apresentam, respectivamente, as discrepâncias em função dos três parâmetros ajustados (levando em consideração a ondulação geoidal) e os parâmetros divulgados pelo IBGE. 
A análise das discrepâncias nos vértices de controle serviram para avaliar a validade dos parâmetros de transformação determinados neste trabalho, bem como os divulgados oficialmente pelo IBGE. Esta análise das discrepâncias são em função da expressão 5.3 do item 5.6 do capítulo 5 e que, a seguir, será apresentada novamente:

$$
\begin{aligned}
& \Delta_{X}=X_{\text {observado }}-X_{W G S-84 T} \\
& \Delta_{Y}=Y_{\text {observado }}-Y_{W G S-84 T} \\
& \Delta_{Z}=Z_{\text {observado }}-Z_{W G S-84 T}
\end{aligned}
$$


TABELA 6.3 - Discrepâncias encontradas nos vértices de controle em função dos sete parâmetros de transformação, considerando a ondulação geoidal.

\begin{tabular}{|c|c|c|c|c|}
\hline Modelos & Vértices & $\Delta_{X}(\mathrm{~m})$ & $\Delta_{Y}(\mathrm{~m})$ & $\Delta_{Z}(\mathrm{~m})$ \\
\hline \multirow{6}{*}{ Helmert } & Bujoréu & 0,453 & 0,077 & $-0,214$ \\
\hline & C.F.N & 0,028 & 0,407 & 0,141 \\
\hline & M.Santiago & 0,240 & 0,400 & $-0,093$ \\
\hline & EP-UNESP-02 & $-0,854$ & 0,414 & 0,157 \\
\hline & Bate-Pau & $-0,024$ & 0,182 & 0,452 \\
\hline & Saltinho & 1,231 & $-1,126$ & $-0,175$ \\
\hline \multirow{6}{*}{ Bursa } & Bujoréu & 0,453 & 0,077 & $-0,214$ \\
\hline & C.F.N & 0,028 & 0,407 & 0,141 \\
\hline & M.Santiago & 0,240 & 0,400 & $-0,093$ \\
\hline & EP-UNESP-02 & $-0,854$ & 0,414 & 0,157 \\
\hline & Bate-Pau & $-0,024$ & 0,182 & 0,452 \\
\hline & Saltinho & 1,231 & $-1,126$ & $-0,175$ \\
\hline \multirow{6}{*}{$\begin{array}{c}\text { Molodenskii } \\
\text { (Primeira Versão) }\end{array}$} & Bujoréu & $-0,473$ & 0,375 & 0,295 \\
\hline & C.F.N & $-0,752$ & 0,571 & 0,562 \\
\hline & M.Santiago & $-0,742$ & 0,747 & 0,448 \\
\hline & EP-UNESP-02 & $-0,926$ & $-0,296$ & 1,547 \\
\hline & Bate-Pau & 0,128 & $-1,117$ & 0,739 \\
\hline & Saltinho & 1,655 & $-1,670$ & $-0,023$ \\
\hline \multirow{6}{*}{$\begin{array}{c}\text { Molodenskii } \\
\text { (Segunda Versão) }\end{array}$} & Bujoréu & 0,453 & 0,077 & $-0,214$ \\
\hline & C.F.N & 0,028 & 0,407 & 0,141 \\
\hline & M.Santiago & 0,240 & 0,400 & $-0,093$ \\
\hline & EP-UNESP-02 & $-0,854$ & 0,414 & 0,157 \\
\hline & Bate-Pau & $-0,024$ & 0,182 & 0,452 \\
\hline & Saltinho & 1,231 & $-1,126$ & $-0,175$ \\
\hline
\end{tabular}


TABELA 6.4 - Discrepâncias encontradas nos vértices de controle em função dos três parâmetros de transformação, considerando a ondulação geoidal.

\begin{tabular}{cccc}
\hline Vértices & $\Delta_{X}(\mathrm{~m})$ & $\Delta_{Y}(\mathrm{~m})$ & $\Delta_{Z}(\mathrm{~m})$ \\
\hline Bujoréu & 0,184 & $-0,315$ & $-0,167$ \\
C.F.N & $-0,163$ & $-0,056$ & 0,124 \\
M.Santiago & $-0,055$ & 0,023 & $-0,023$ \\
EP-UNESP-02 & $-1,257$ & 2,318 & 0,997 \\
Bate-Pau & $-0,082$ & 0,710 & 0,458 \\
Saltinho & 1,315 & $-0,708$ & $-0,269$ \\
\hline
\end{tabular}

TABELA 6.5 - Discrepâncias encontradas nos vértices de controle considerando os parâmetros de transformação divulgados oficialmente pelo IBGE.

\begin{tabular}{cccc}
\hline Vértices & $\Delta_{X}(\mathrm{~m})$ & $\Delta_{Y}(\mathrm{~m})$ & $\Delta_{Z}(\mathrm{~m})$ \\
\hline Bujoréu & 1,687 & $-2,216$ & 2,693 \\
C.F.N & 1,339 & $-1,956$ & 2,984 \\
M.Santiago & 1,448 & $-1,877$ & 2,837 \\
EP-UNESP-02 & 0,246 & 0,418 & 3,857 \\
Bate-Pau & 1,420 & $-1,190$ & 3,319 \\
Saltinho & 2,817 & $-2,608$ & 2,591 \\
\hline
\end{tabular}

Pelos valores divulgados na tabela 6.3, pode-se observar que os modelos de Bursa, de Helmert e de Molodenskii (segunda versão) proporcionaram resultados levemente melhores na transformação de coordenadas do que o modelo de Molodenskii (primeira versão). Isto só vem a confirmar o resultado do ajustamento, pois o modelo de Molodenskii (primeira versão) proporcionou um pequeno aumento no valor do $V^{T}$.P. $V$ em relação aos outros três modelos. 
Fazendo um paralelo com os valores da tabela 6.3 e os da tabela 6.5, que correspondem às discrepâncias encontradas nos vértices de controle utilizando-se os parâmetros de transformação divulgados pelo IBGE, houve uma melhora significativa nos valores das coordenadas transformadas ao utilizar os sete parâmetros de transformação determinados por este trabalho para esta região de estudo, considerando a ondulação geoidal.

As discrepâncias encontradas nos vértices de controle decorrentes dos três parâmetros de transformação determinados neste trabalho, proporcionaram também para a região estudada, uma melhora significativa nos valores das coordenadas transformadas. Em todos os vértices de controle, as discrepâncias encontradas foram bem inferiores do que as encontradas utilizando-se os parâmetros de transformação divulgados pelo IBGE. Isto pode ser verificado nos valores apresentados nas tabelas 6.4 e 6.5 .

A seguir serão apresentados os resultados encontrados para os parâmetros de transformação desconsiderando a ondulação geoidal, bem como as discrepâncias encontradas nos vértices de controle ao utilizar estes parâmetros.

\subsection{Valores encontrados para os parâmetros de transformação desconsiderando a ondulação geoidal}

Os valores encontrados para os parâmetros de transformação, não levando em consideração a ondulação geoidal na determinação das coordenadas cartesianas em SAD-69, são mostrados nas tabelas 6.6 e 6.7. Na tabela 6.6 são mostrados os valores ajustados dos sete parâmetros de transformação bem como o valor do $V^{T}$.P.V. Na tabela 6.7 são mostrados apenas os valores dos três parâmetros de transformação ajustados que são as translações $T_{X}, T_{Y}, T_{Z}$ bem como o valor do $V^{T} . P . V$. 
TABELA 6.6 - Resultado do ajustamento dos sete parâmetros de transformação desconsiderando a ondulação geoidal.

\begin{tabular}{|c|c|c|c|c|}
\hline Modelos & Parâmetros & Valores & $\sigma_{\bar{X}}$ & $V^{T} . P . V$ \\
\hline \multirow{7}{*}{ Helmert } & $T_{X}$ & $-66,403 \mathrm{~m}$ & $\pm 4,662 \mathrm{~m}$ & \multirow{7}{*}{52,802} \\
\hline & $T_{Y}$ & $58,089 \mathrm{~m}$ & $\pm 3,680 \mathrm{~m}$ & \\
\hline & $T_{Z}$ & $-162,367 \mathrm{~m}$ & $\pm 4,202 \mathrm{~m}$ & \\
\hline & $(1+\mu)$ & 0,99999852443 & $\pm 0,265.10^{-6}$ & \\
\hline & $\alpha_{1}$ & 3,432 seg. & $\pm 0,330 \mathrm{seg}$ & \\
\hline & $\alpha_{2}$ & 2,637 seg. & $\pm 0,331$ seg. & \\
\hline & $\alpha_{3}$ & $1,123 \mathrm{seg}$. & $\pm 0,061$ seg. & \\
\hline \multirow{7}{*}{ Bursa } & $T_{X}$ & $-66,403 m$ & $\pm 4,662 \mathrm{~m}$ & \multirow{7}{*}{52,802} \\
\hline & $T_{Y}$ & $58,089 \mathrm{~m}$ & $\pm 3,680 \mathrm{~m}$ & \\
\hline & $T_{Z}$ & $-162,367 \mathrm{~m}$ & $\pm 4,202 \mathrm{~m}$ & \\
\hline & $(1+\mu)$ & 0,99999852443 & $\pm 0,265 \cdot 10^{-6}$ & \\
\hline & $\alpha_{1}$ & 3,432 seg. & $\pm 0,330 \mathrm{seg}$ & \\
\hline & $\alpha_{2}$ & 2,637 seg. & $\pm 0,331 \mathrm{seg}$ & \\
\hline & $\alpha_{3}$ & $1,123 \mathrm{seg}$. & $\pm 0,061$ seg. & \\
\hline \multirow{7}{*}{$\begin{array}{c}\text { Molodenskii } \\
\text { (Primeira Versão) }\end{array}$} & $T_{X}$ & $-69,258 \mathrm{~m}$ & $\pm 0,403 \mathrm{~m}$ & \multirow{7}{*}{50,421} \\
\hline & $T_{Y}$ & $7,198 \mathrm{~m}$ & $\pm 0,419 \mathrm{~m}$ & \\
\hline & $T_{Z}$ & $-33,571 \mathrm{~m}$ & $\pm 0,267 \mathrm{~m}$ & \\
\hline & $(1+\mu)$ & 0,999998524 & $\pm 0,265 \cdot 10^{-6}$ & \\
\hline & $\alpha_{1}$ & 3,431 seg. & $\pm 0,330$ seg. & \\
\hline & $\alpha_{2}$ & 2,636 seg. & $\pm 0,331 \mathrm{seg}$ & \\
\hline & $\alpha_{3}$ & 1,123 seg. & $\pm 0,061$ seg. & \\
\hline \multirow{7}{*}{$\begin{array}{c}\text { Molodenskii } \\
\text { (Segunda Versão) }\end{array}$} & $T_{X}$ & $-66,403 m$ & $\pm 4,662 \mathrm{~m}$ & \multirow{7}{*}{52,802} \\
\hline & $T_{Y}$ & $58,089 \mathrm{~m}$ & $\pm 3,680 \mathrm{~m}$ & \\
\hline & $T_{Z}$ & $-162,367 \mathrm{~m}$ & $\pm 4,202 \mathrm{~m}$ & \\
\hline & $(1+\mu)$ & 0,99999852443 & $\pm 0,265 \cdot 10^{-6}$ & \\
\hline & $\alpha_{1}$ & 3,432 seg. & $\pm 0,330 \mathrm{seg}$ & \\
\hline & $\alpha_{2}$ & 2,637 seg. & $\pm 0,331 \mathrm{seg}$ & \\
\hline & $\alpha_{3}$ & $1,123 \mathrm{seg}$. & $\pm 0,061 \mathrm{seg}$. & \\
\hline
\end{tabular}


TABELA 6.7 - Resultado do ajustamento dos três parâmetros de transformação desconsiderando a ondulação geoidal.

\begin{tabular}{cccc}
\hline Parâmetros & Valores $(\mathrm{m})$ & $\sigma_{\bar{X}}(\mathrm{~m})$ & $V^{T} . P . V$ \\
\hline$T_{X}$ & $-64,602$ & $\pm 0,100$ & \\
$T_{Y}$ & 1,751 & $\pm 0,100$ & 61,740 \\
$T_{Z}$ & $-35,373$ & $\pm 0,100$ & \\
\hline
\end{tabular}

Analisando a tabela 6.6, observa-se a grande influência da ondulação geoidal na determinação dos parâmetros de transformação. Para os quatro modelos, houve uma grande alteração nos valores das translações, das rotações e do fator de escala. Isto é um indício de que o uso incorreto de uma altura geométrica pode causar efeitos significativos nas coordenadas geodésicas horizontais $(\phi, \lambda)$, principalmente nesta situação, onde a ondulação geoidal sofre variações significativas entre os vértices utilizados para a determinação dos parâmetros de transformação. As precisões dos parâmetros ajustados praticamente não sofreram alteração em relação àquelas apresentadas na tabela 6.1. A desconsideração da ondulação geoidal proporcionou um aumento significativo no valor do $V^{T} . P . V$. Isto mostra que, para este caso específico, o uso de uma incorreta altura geométrica, proporciona um aumento nos resíduos do ajustamento dos sete parâmetros para os quatro modelos estudados.

Alterações nos valores dos três parâmetros de transformação também são evidentes ao negligenciar a ondulação geoidal. Verifica-se na tabela 6.7 que além das três translações o valor do $V^{T} . P . V$ sofreu alterações consideráveis.

É conveniente ressaltar que os resultados apresentados nas tabelas 6.6 e 6.7 correspondem apenas a um indicativo de que, problemas existirão na determinação dos parâmetros de transformação quando não é levado em consideração a ondulação geoidal $(N)$, pois este valor possui uma precisão absoluta de $3 \mathrm{~m}$. 


\subsection{Discrepâncias encontradas nos vértices de controle em função dos parâmetros de transformação obtidos a partir da desconsideração da ondulação geoidal}

As discrepâncias encontradas nos vértices de controle, não levando em consideração a ondulação geoidal na determinação dos parâmetros de transformação, são apresentadas nas tabelas 6.8 e 6.9. A tabela 6.8 apresenta as discrepâncias encontradas em função dos três parâmetros de transformação ajustados. A tabela 6.9 apresenta as discrepâncias encontradas em função dos sete parâmetros de transformação ajustados.

TABELA 6.8 - Discrepâncias encontradas nos vértices de controle em função dos três parâmetros de transformação, desconsiderando a ondulação geoidal.

\begin{tabular}{cccc}
\hline Vértices & $\Delta_{X}(\mathrm{~m})$ & $\Delta_{Y}(\mathrm{~m})$ & $\Delta_{Z}(\mathrm{~m})$ \\
\hline Bujoréu & $-0,581$ & 0,404 & $-0,453$ \\
C.F.N & $-0,929$ & 0,663 & $-0,163$ \\
M.Santiago & $-0,820$ & 0,742 & $-0,310$ \\
EP-UNESP-02 & $-2,022$ & 3,037 & 0,710 \\
Bate-Pau & $-0,847$ & 1,429 & 0,172 \\
Saltinho & 0,549 & 0,011 & $-0,555$ \\
\hline
\end{tabular}


TABELA 6.9 - Discrepâncias encontradas nos vértices de controle em função dos sete parâmetros de transformação, desconsiderando a ondulação geoidal.

\begin{tabular}{|c|c|c|c|c|}
\hline Modelos & Vértices & $\Delta_{X}(\mathrm{~m})$ & $\Delta_{Y}(\mathrm{~m})$ & $\Delta_{Z}(\mathrm{~m})$ \\
\hline \multirow{6}{*}{ Helmert } & Bujoréu & $-2,072$ & 2,494 & 1,185 \\
\hline & C.F.N & $-2,267$ & 2,587 & 1,395 \\
\hline & M.Santiago & $-2,384$ & 2,919 & 1,371 \\
\hline & EP-UNESP-02 & $-0,141$ & $-0,332$ & 0,171 \\
\hline & Bate-Pau & 0,234 & $-0,133$ & $-0,033$ \\
\hline & Saltinho & 1,934 & $-1,904$ & $-0,906$ \\
\hline \multirow{6}{*}{ Bursa } & Bujoréu & $-2,072$ & 2,494 & 1,185 \\
\hline & C.F.N & $-2,267$ & 2,587 & 1,395 \\
\hline & M.Santiago & $-2,384$ & 2,919 & 1,371 \\
\hline & EP-UNESP-02 & $-0,141$ & $-0,332$ & 0,171 \\
\hline & Bate-Pau & 0,234 & $-0,133$ & $-0,033$ \\
\hline & Saltinho & 1,934 & $-1,904$ & $-0,906$ \\
\hline \multirow{6}{*}{$\begin{array}{c}\text { Molodenskii } \\
\text { (Primeira Versão) }\end{array}$} & Bujoréu & $-2,072$ & 2,494 & 1,184 \\
\hline & C.F.N & $-2,267$ & 2,587 & 1,394 \\
\hline & M.Santiago & $-2,384$ & 2,919 & 1,370 \\
\hline & EP-UNESP-02 & $-0,142$ & $-0,332$ & 0,170 \\
\hline & Bate-Pau & 0,234 & $-0,133$ & $-0,033$ \\
\hline & Saltinho & 1,934 & $-1,904$ & $-0,907$ \\
\hline \multirow{6}{*}{$\begin{array}{c}\text { Molodenskii } \\
\text { (Segunda Versão) }\end{array}$} & Bujoréu & $-2,072$ & 2,494 & 1,185 \\
\hline & C.F.N & $-2,267$ & 2,587 & 1,395 \\
\hline & M.Santiago & $-2,384$ & 2,919 & 1,371 \\
\hline & EP-UNESP-02 & $-0,141$ & $-0,332$ & 0,171 \\
\hline & Bate-Pau & 0,234 & $-0,133$ & $-0,033$ \\
\hline & Saltinho & 1,934 & $-1,904$ & $-0,906$ \\
\hline
\end{tabular}


Mesmo desconsiderando a ondulação geoidal, a tabela 6.8 mostra que, para a região estudada, as discrepâncias encontradas nos vértices de controle são menores do que as discrepâncias encontradas utilizando-se os parâmetros de transformação divulgados oficialmente pelo IBGE. No entanto, pelos valores apresentados na tabela 6.9, verifica-se que o uso incorreto de uma altura geométrica na determinação dos sete parâmetros de transformação, pode ocasionar resultados não muito confiáveis nos valores das coordenadas transformadas. Isto ocorreu nos quatro modelos estudados. 


\section{CAPÍTULO 7 - CONCLUSÕES E RECOMENDAÇÕES}

O trabalho comprovou a existência de problemas no que diz respeito à compatibilização dos referenciais geodésicos WGS-84 e o SAD-69 ao utilizar os parâmetros de transformação divulgados oficialmente pelo IBGE.

Os modelos de Helmert, de Bursa e de Molodenskii (segunda versão) proporcionam uma forte correlação entre os parâmetros de translação e rotação devido ao fato de que o centro de rotação destes modelos, que está localizado na origem do sistema geodésico local, situa-se nas proximidades do geocentro, muito afastado portanto da pequena área de distribuição dos vértices utilizados na determinação dos parâmetros de transformação. Isto explica o fato dos três modelos apresentarem os mesmos valores para os sete parâmetros de transformação. O mesmo não ocorre com o modelo de Molodenskii (primeira versão) porque o centro de rotação deste modelo, que está localizado na origem do sistema topocêntrico, situa-se próximo da pequena área de distribuição dos vértices utilizados na determinação dos parâmetros de transformação.

Quanto ao valor do $V^{T} . P . V$, considerando os sete parâmetros de transformação, não houve muita variação em relação aos quatro modelos estudados. No que diz respeito às precisões, o modelo de Molodenskii (primeira versão) proporcionou melhores resultados em relação aos outros três modelos estudados. Este fato mostra que o modelo de Molodenskii (primeira versão) não apresenta grandes correlações entre os parâmetros de escala, translação e rotação, pelo próprio fato de que o seu centro de rotação está localizado próximo às estações envolvidas na determinação dos parâmetros de transformação. Considerando apenas o ajustamento 
dos três parâmetros de transformação, o valor do $V^{T} . P . V$ sofreu um aumento significativo. Com isto pode-se concluir que existe possíveis erros sistemáticos na definição do SAD-69, pelo IBGE, e que apenas as três translações não são suficientes para compatibilizar os referenciais WGS-84 e o SAD-69 (há a necessidade da consideração de um fator de escala e das três rotações).

A desconsideração da ondulação geoidal acarretou variações significativas nos valores dos parâmetros de transformação, além de um aumento significativo no valor do $V^{T} . P . V$. Isto vem a comprovar que, para as regiões onde o comportamento do geóide é bastante irregular, a utilização de incorreta altura geométrica pode provocar resultados pouco satisfatórios na determinação dos parâmetros de transformação e, consequentemente, nos valores das coordenadas transformadas.

No que diz respeito às discrepâncias nos pontos de controle, verificou-se que, melhores resultados são obtidos na transformação de coordenadas ao utilizar os sete parâmetros de transformação. Isso verificou-se para os quatro modelos. A utilização dos três parâmetros de transformação também proporcionou resultados satisfatórios. O mesmo não ocorreu ao utilizar os parâmetros de transformação determinados em função da desconsideração da ondulação geoidal.

Verificou-se também que, os parâmetros de transformação divulgados pelo IBGE proporcionaram discrepâncias significativas nos vértices de controle. Isto vem mostrar que, ao transformar as coordenadas geodésicas advindas do sistema GPS para o sistema SAD-69, utilizando-se os parâmetros de transformação divulgados pelo IBGE, na realidade as coordenadas transformadas não estariam referenciadas em SAD-69 mais sim em um outro sistema com características de definição bem próximas do mesmo. Pode-se assim considerar que estas coordenadas transformadas estariam referenciadas em um SAD-69 modificado.

Concluindo, melhores resultados são obtidos na transformação de coordenadas entre os sistemas WGS-84 e SAD-69 quando considerados parâmetros regionais e levando-se em consideração uma transformação completa, ou seja, com as três translações, um fator de escala e as três rotações. 
Em vista dos resultados apresentados neste trabalho considera-se oportuna uma revisão, por parte do IBGE, dos parâmetros publicados e considerados oficiais. Estes parâmetros de transformação deveriam ser determinados em função de vértices da rede do SGB distribuídos de maneira homogênea por todo o território nacional

Uma recomendação ideal para evitar os problemas de compatibilização entre os referenciais WGS-84 e o SAD-69 seria o país adotar um único referencial para os trabalhos geodésicos e cartográficos. Por exemplo, adotar como referencial o ITRF. Num país como o nosso, onde algumas localidades e até mesmo algumas empresas possuem datum próprio isto acaba sendo utópico, pois, toda esta base cartográfica brasileira teria que ser substituída.

Uma recomendação também viável é a que propõem este trabalho: trabalhar com parâmetros de transformação locais sobre a coordenação e a orientação das instituições de pesquisa na área de ciências geodésicas. 


\section{ANEXO}

Monografia dos quatro vértices pertencentes à rede do SGB localizados na região de São Carlos-SP 
MONOGRAFIA DE VÉRTICES

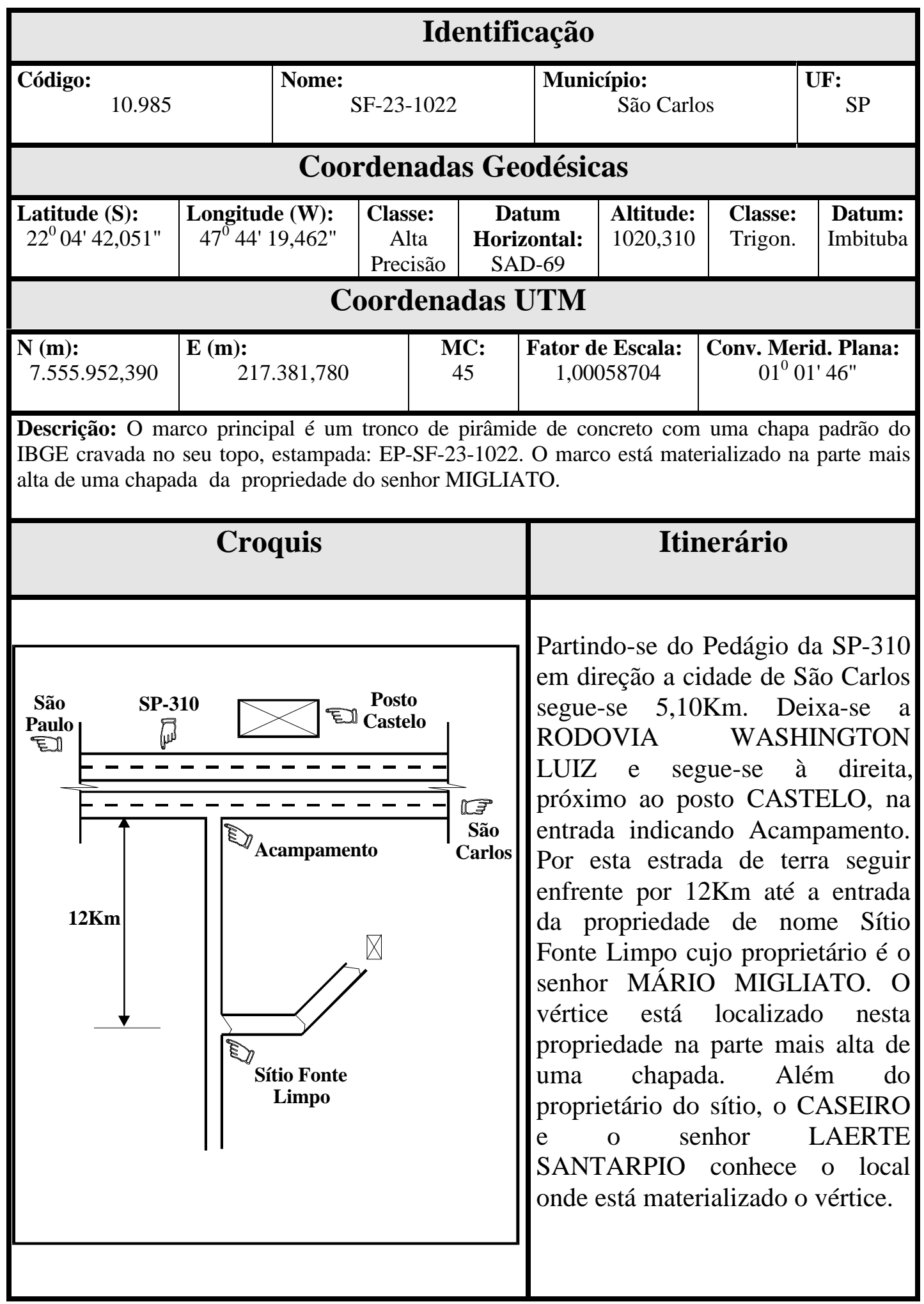




\section{MONOGRAFIA DE VÉRTICES}

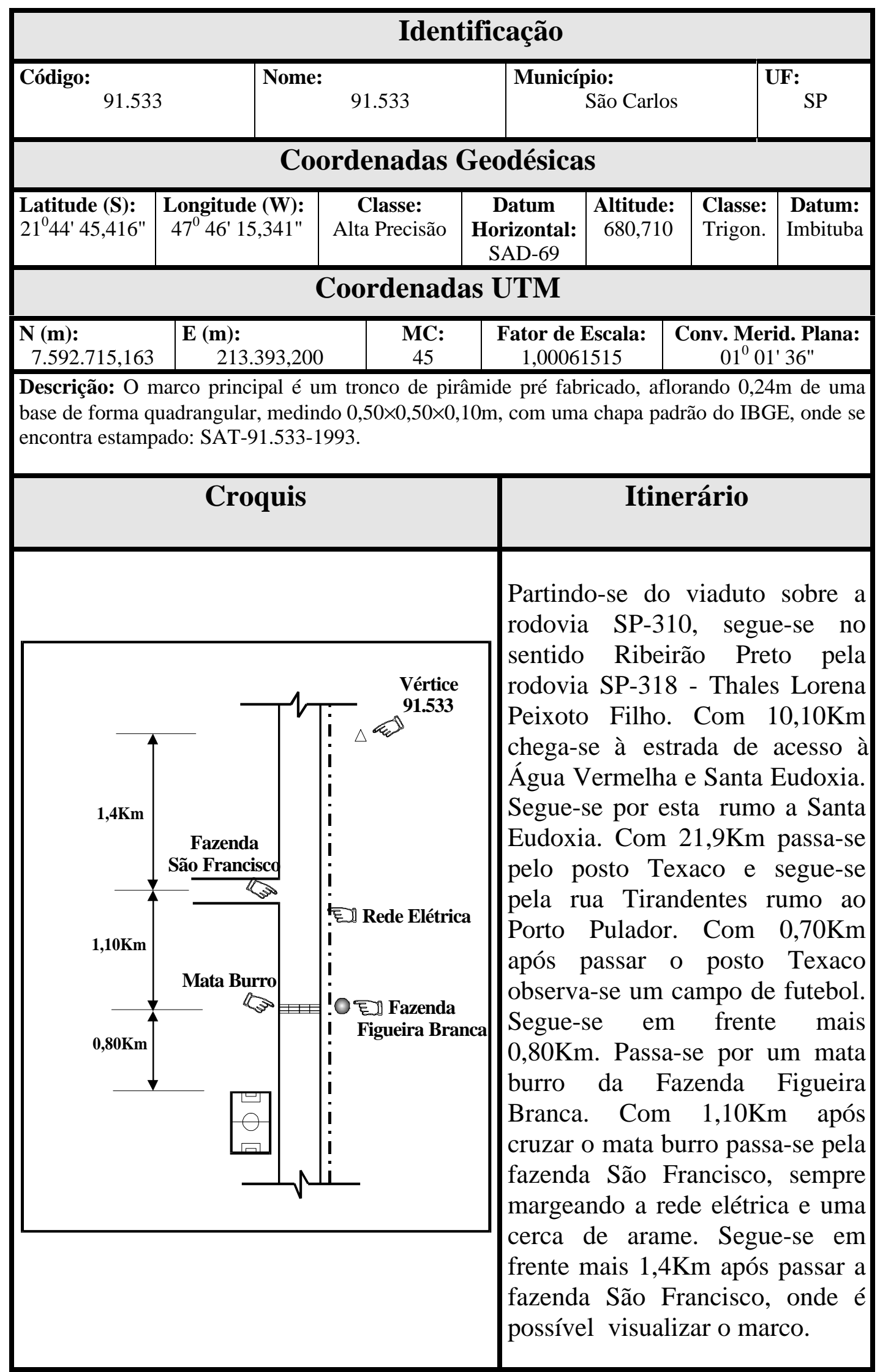




\section{MONOGRAFIA DE VÉRTICES}

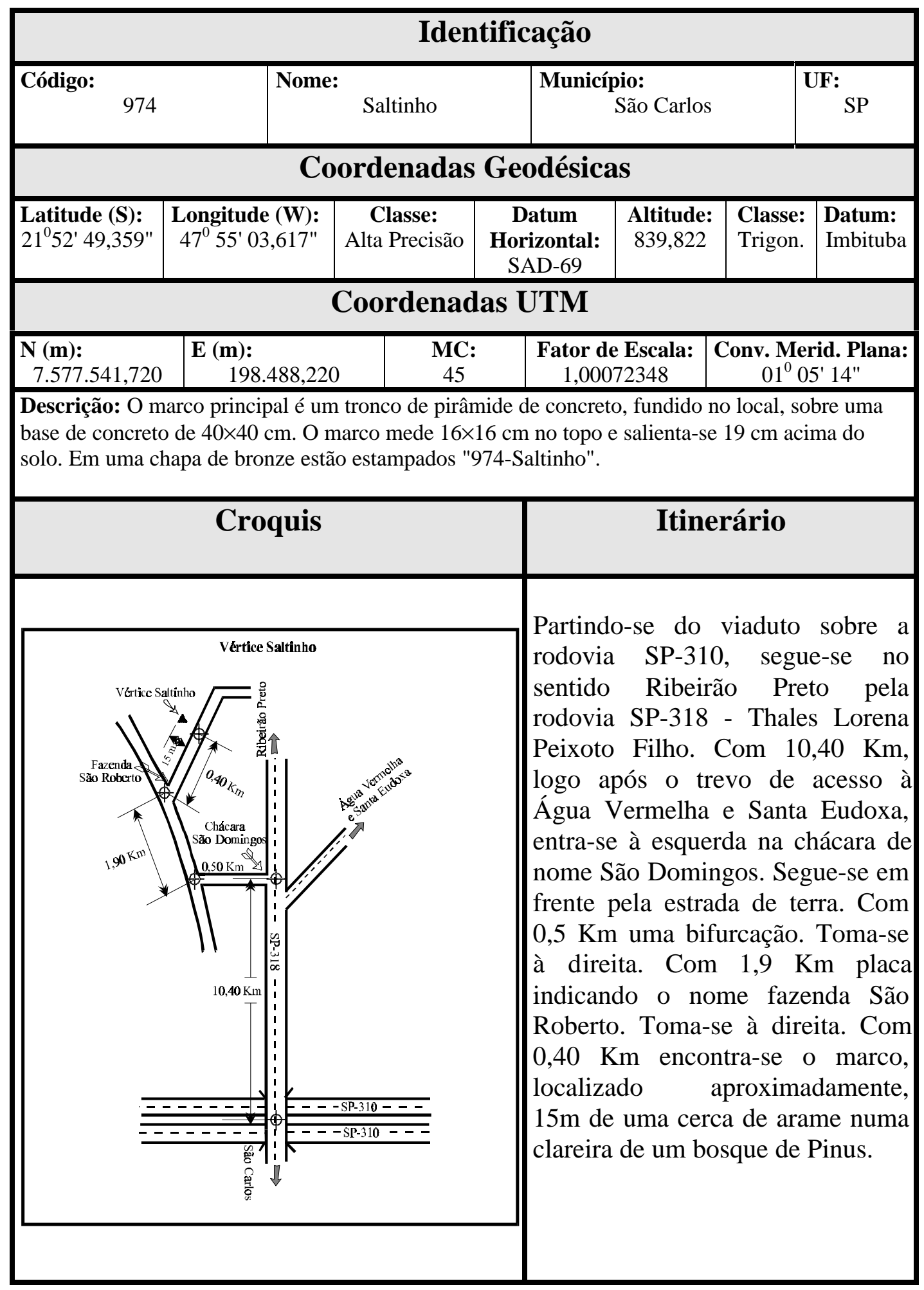


MONOGRAFIA DE VÉRTICES

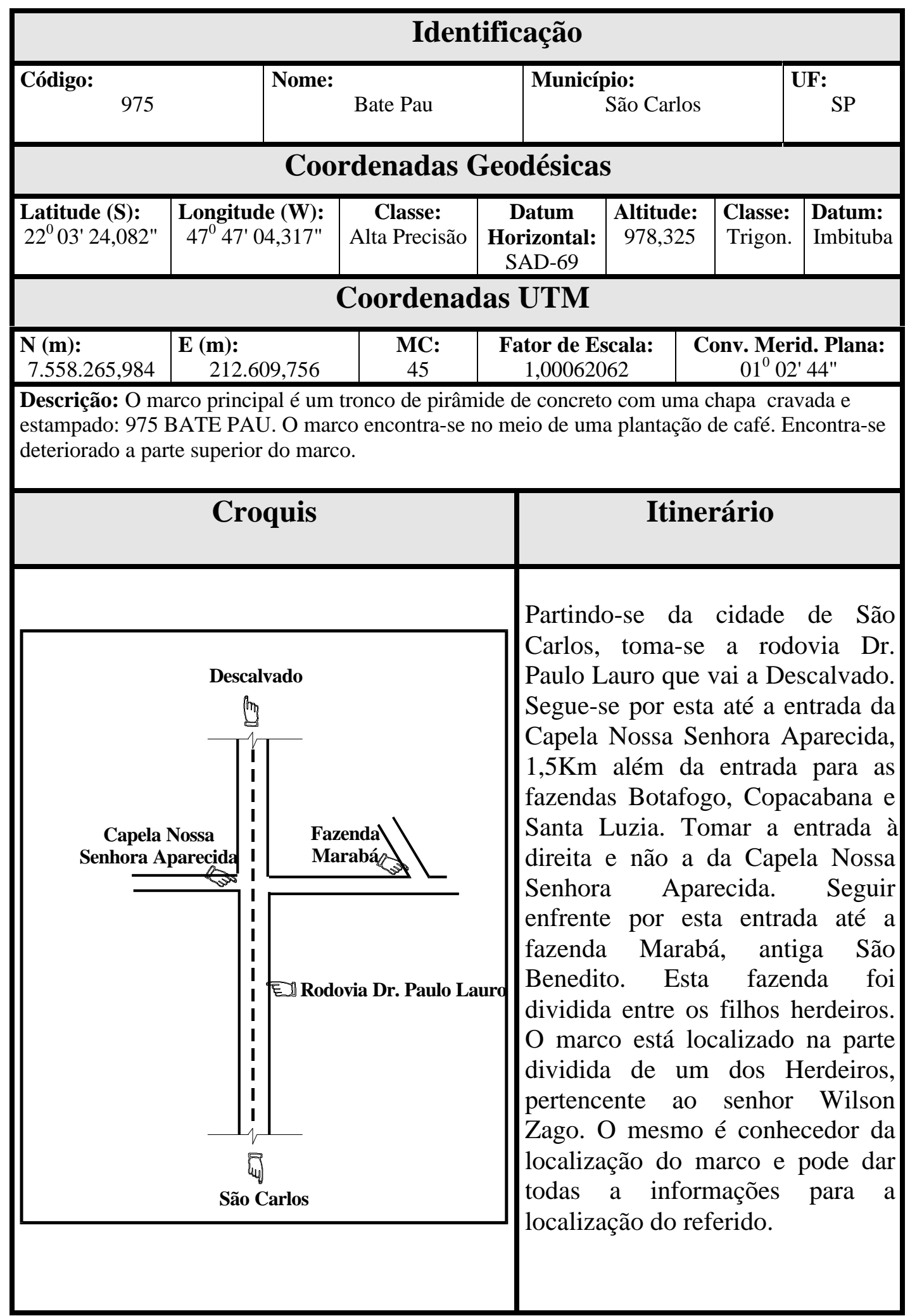




\section{REFERÊNCIAS BIBLIOGRÁFICAS}

ABIB, O.A. (1978). Parâmetros de transformação de datum WGS-72/SAD-69. Revista Brasileira de Cartografia, n. ${ }^{\circ}$ 20, p. 32-39, Rio de Janeiro - RJ.

ACHARYA, BISHWA and POPP, RICHARD. (1994). Project Planning for Geodetic Control Network.. Surveying and Land Information Systems, v. 2, n.2, p. 69-75.

ANDRADE, JOSÉ BITTENCOURT (1984). Determinação simultânea de parâmetros de transformação entre referenciais geodésicos e de desníveis geoidais. Boletim da Universidade Federal do Paraná, Universidade Federal do Paraná., n.30, 16p.

BAUER, K. W., BURKHOLDER, E.F. (1996). Simplified transformation between NAD-27 and NAD-83 in Southeastern Wisconsin. Journal of Surveying Engineering, p.26-39.

BLITZKOW, D., LAZARRO, ANA C. (1988). Parâmetros de Transformação de Sistemas Geodésicos: SAD-69-Córrego Alegre. In: V ENCONTRO NACIONAL DE ENGENHEIROS CARTÓGRAFOS, ENECART, Presidente Prudente - SP, p.16-25.

BOCK, YEHUDA AND LADD, W. JONATHAN. (1989). Simultaneous Orbit and Network Adjustment in Tennesse. Jounal of Survyeing Engineering, v.115, n.1, p.26-39. 
CASTAÑEDA, RAFAEL MARCH. (1982). Ensaio para determinação de parâmetros de transformação entre o SAD-69 e o NSWS-9Z2. Curitiba. 180p. Dissertação (Mestrado) - Universidade Federal do Paraná.

DRACUP, JOSEPH F. (1996). Some notes on adjustments, and accuracies directed to managers. Surveying and Land Information Systems, v.56, n.1, p.13-26.

ELMOTAAL, ABID HUSSEIN AND TOKHEY, EL MOHAMED. (1997). The role of the geoid in the coordinate transformation. Survey Reviews, n.34, p.31-40.

FIEDLER, JEROME. (1992). Orthometric heights from global positioning system. Journal of Surveying Engineering, v.118, n.3, p.70-79.

FORTES, LUIZ P. S. et al. (1989). Determinação dos parâmetros de transformação entre os sistemas NWL-10D, NSWC-9Z2 WGS-84 e o SAD-69. In: XIV CONGRESSO BRASILEIRO DE CARTOGRAFIA, Gramado - RS, p.157-165.

FUNDAÇÃO INSTITUTO BRASILEIRO DE GEOGRAFIA E ESTATÍSTICA (IBGE). (1993). Especificações e normas para levantamentos GPS. Versão preliminar, Rio de Janeiro - RJ, 16p.

GEMAEL, C. (1994). Introdução ao Ajustamento de Observações: Aplicações Geodésicas. Editora UFPR. Curitiba, 319p.

GEMAEL, C. (1991). Geodésia Celeste: Introdução. Curso de Pós Graduação em Ciências Geodésicas da UFPR. Curitiba - PR,. Cap. 12: p.2-17.

GEMAEL, C. (1988). Introdução à Geodésia Geométrica. Curso de Pós Graduação em Ciências Geodésicas da UFPR. Curitiba - PR, v.1.

HOFMANN-WELLENHOF, B., LICHTENEGGER, H., COLLINS, J. (1994). GPS: Theory and Practice. Third revised edition. Springer-Verlag Wien New York. $355 \mathrm{p}$. 
KADLEC, FRANCISCO ANTONIO E GOMES, P. JORGE. (1978). Cálculo de parâmetros de transferências de sistemas geodésicos. Revista Brasileira de Cartografia, n.22, p.27-34.

KUANG, SHANLONG. (1993). Geodetic network optimization: a handy tool for surveying engineers. Surveying and Land Information Systems, v.52, n.3, p.169-183.

LANGEY, R.B. (1991). Geodesia básica para GPS. Instituto Panamericano de Geografia e Historia. Revista Cartográfica n.59, p.71-82.

LEICK, A. (1995). GPS Satellite Surveying, Second Edition. John Wiley \& Sons, INC New York. 560p.

LEICK, A. (1993). Accuracy standards for modern three-dimensional geodetic networks. Surveying and Land Information Systems, v.53, n.2, p.111-116.

MARQUES, ARTUR PANTOJA. (1997). Análise de parâmetros geométricos de curvas horizontais de vias à luz do sistema de posicionamento global - GPS. São Carlos. 150p. Dissertação (Mestrado) - EESC, Universidade de São Paulo.

MONICO, GALERA J. F. E SEGANTINE, PAULO C. L. (1996). ITRF: definição, realizações e aplicações. Revista Cartografia e Cadastro, n.5, p.31 - 36.

MONICO, GALERA J. F, et al. (1996). Nivelamento de precisão usando o GPS e interpolação geométrica do Geóide. In: VII CONGRESSO NACIONAL DE ENGENHARIA DE AGRIMENSURA - CONEA, Salvador - BA.

PACILEO NETTO, NICOLA, et al. (1996). Altitude ortométrica e o GPS resultados parciais na grande São Paulo. In: VII CONGRESSO NACIONAL DE ENGENHARIA DE AGRIMENSURA - CONEA, Salvador - BA.

OLIVEIRA, L.C., FERREIRA, L.F., BLITZKOW, D. (1995). Um estudo particular sobre a transformação SAD-69 / WGS-84. In: XVII CONGRESSO BRASILEIRO DE CARTOGRAFIA. Salvador - Bahia. p.466-472. 
PEREIRA, KÁTIA D., COSTA, SÔNIA M. (1995).Conexão das redes brasileira, paraguaia e colombiana por GPS. In: XVII CONGRESSO BRASILEIRO DE CARTOGRAFIA. Salvador - Bahia, p.473-477.

RAPP, RICHARD H. (1993). Geoid ondulation accuracy. IEEE Transactions on Geoscience and Remote Sensing, v.31, n.2, p.365-370.

RODRIGUES, D. D. (1993). Relação entre coordenadas geodésicas e coordenadas topocêntricas. Revista Unimar 15(3), p.307-318.

ROMÃO, VERÔNICA M.C. (1982). Método Doppler de Posicionamento Por Satélite NNSS. Curitiba. 126p. Dissertação (Mestrado) - Universidade Federal do Paraná.

SCHWARZ, K. P.AND SIDERIS, M. G. (1993). Heights and GPS. GPS World, p.50-56.

SEEBER, G. (1993). Satellite Geodesy. Foundations, Methods and Applications. Walter de Gruyter Berlin New York, 530p.

SEGANTINE, PAULO C. L. (1995a). Estabelecimento e ajuste de uma rede geodésica no Estado de São Paulo, com o sistema de posicionamento NAVSTAR/GPS. São Paulo. 225p. Tese (Doutorado). Escola Politécnica, Universidade de São Paulo.

SEGANTINE, PAULO C. L. CINTRA, J. P. (1995b). Dados observados com GPS e suas combinações lineares. In: XVII CONGRESSO BRASILEIRO DE CARTOGRAFIA. Salvador - Bahia, p.161-172.

SEGANTINE, PAULO C. L. MONICO, J. F. G. (1997). Considerações a respeito do processamento de dados GPS. Revista Cartografia e Cadastro, n.6, p.13-17.

SEGANTINE, PAULO C. L. (1997). Curso de atualização em topografia e GPS (segundo a norma NBR 13.133. Apostila não publicada, Escola de Engenharia de São Carlos, Universidade de São Paulo, 164p. 
SILVA, A. S., GRIPP JUNIOR, J. (1996). Geodésia Geométrica. Apostila não publicada. Universidade Federal de Viçosa, p.131.

SILVA, A. S., FERRAZ, A. S. (1985). Transporte de Coordenadas Geodésicas. Imprensa Universitária da Universidade Federal de Viçosa. Viçosa, MG. Apostila n.220, 76p.

SLATER, A. JAMES. (1993). A new GPS geodetic control network for Paraguay. Surveying and Land Information Systems, v.53, n.2, p.179-186.

SOARES, SÉRGIO M. (1996). Nivelamento de precisão com técnica GPS. Revista A Mira, n.53, p.19-27.

SOLER, T., GARCIA, G.A., NAVARRO, A.H. (1996). GPS high accuracy geodetic networks in Mexico. Journal of Surveying Engineering. p.80 - 94.

SOLER, T., D. LARRY. (1988). Coordinate systems used in geodesy: basic definitions and concepts. Journal of Surveying Engineering, v.114, n.2, p.84-89.

TORGE, W. (1983). Geodesia. Editora Diana, Mexico. Primera Edición, 289p.

VANÍCEK, P., KRAKIWSKY, E.J. (1982). Geodesy: The Concepts. North-Holland Publishing Company Amesterdam Ney York Oxford, 697p.

VANÍCEK, P., STEEVES, R. R. (1996). Transformation of coordinates between two horizontal geodetic datums. Department of Geodesy and Geomatics Engineering, UNB, 7p.

VERONEZ, M. R.; SILVA, A. S. (1997). Determinação dos parâmetros de transformação entre os sistemas WGS-84 e SAD-69 para uma região de Minas Gerais. Revista A MIRA, n.63, p.28-36.

WHITE, L. HASCHAL, et al. (1989). World Geodetic System 1984. A modern and accurate global reference frame. IGSOSP/DMA, p.127-141. 